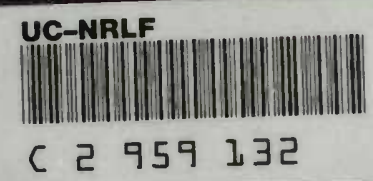



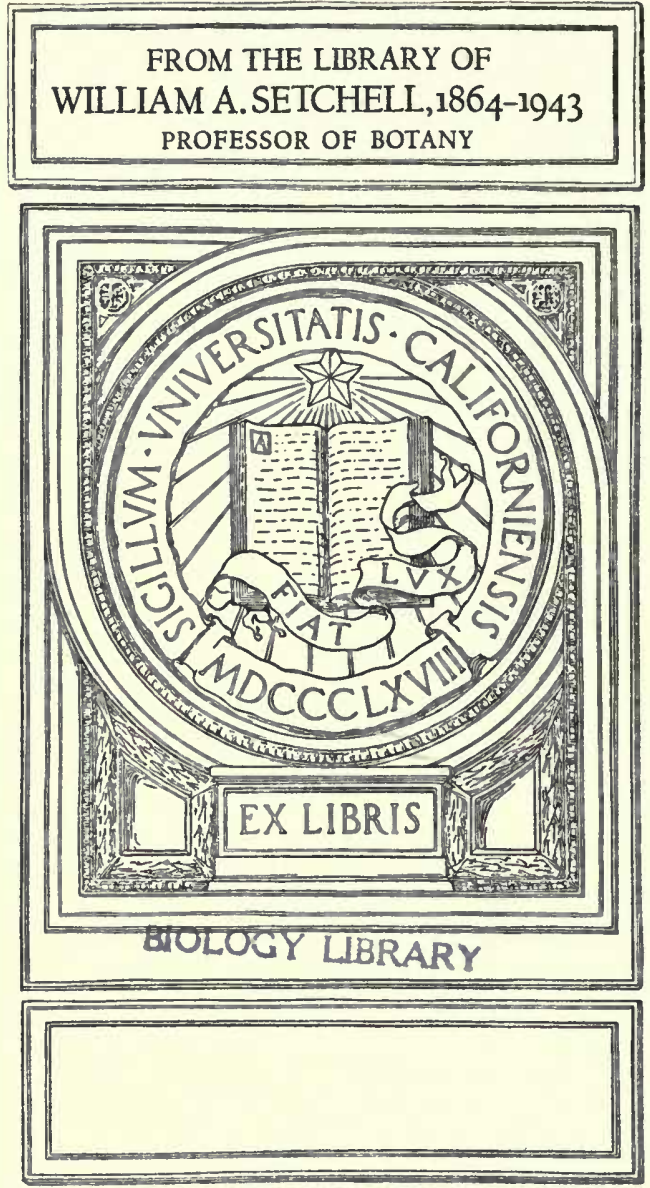



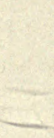






\section{Sexual Reproduction and the Organization of}

the Nucleus in Certain Mildews.

BY
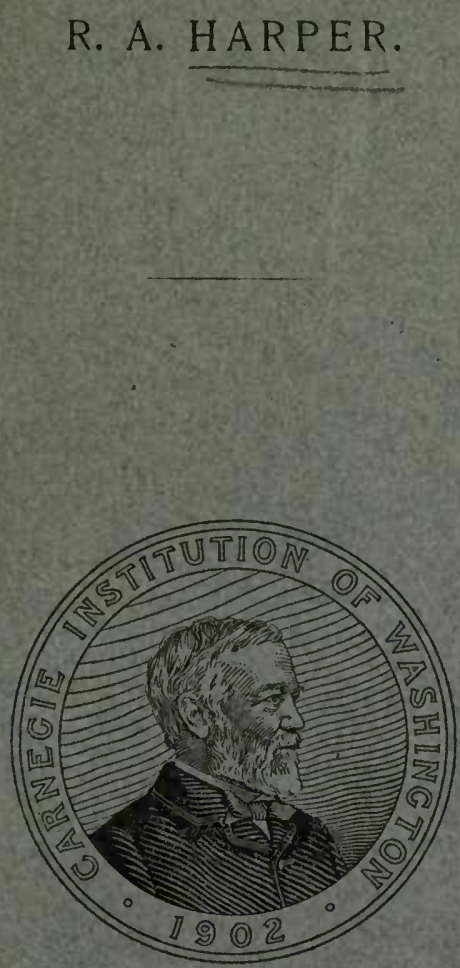

WASHINGTON, D. C.:

Published by the Carnegie Institution of Washington Octobèr, 1905. 
With the compliments of the author 


\section{Sexual Reproduction and the Organization of the Nucleus in Certain Mildews.}

BY

R. A. HA RPER.
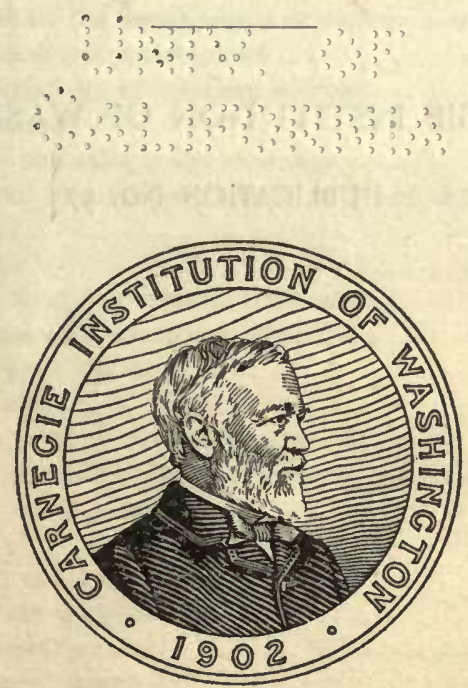

WASHINGTON, D. C. :

Published by the Carnegie Institution of Washington

September, 1905. 


$$
\begin{aligned}
& \text { QK } 827 \\
& \text { H34 } \\
& \text { Biol. } \\
& \text { Lib. }
\end{aligned}
$$

\section{CARNEGIE INSTITUTIOIN OF WASHINGTON}

\section{Publication No. 37}

\section{BIOLOGY LUBRARY}

FROM THE PRESS OF

THE HENRY E. WILKENS PRINTING CO.

WASHINGTON, D. C. 


\section{CONTENTS.}

Page.

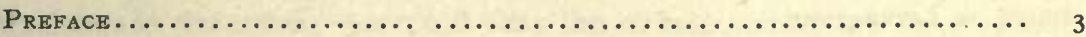

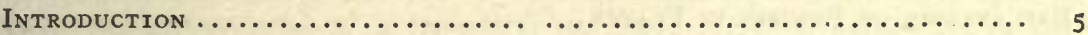

Development of the Perithecium-

The mycelium and the origin of oogonium and antheridium........... 8

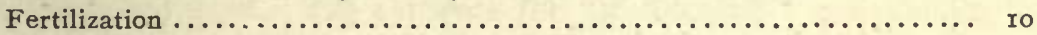

Degeneration of antheridial wall and cytoplasm $\ldots \ldots \ldots \ldots \ldots \ldots \ldots \ldots$ I2

Development of the ascogonium and origin of the asci as binucleated cells... I5

Secondary mycelium, appendages, and penicillate cells.............. $2 \mathrm{r}$

Function of appendages and period of spore formation $\ldots \ldots \ldots \ldots \ldots \ldots .24$

MORPHOLOGY OF THE ASCOCARP-

Review of recent work on the development of various Ascomycetes ....... 29

Dangeard's conception of the gametophore $\ldots \ldots \ldots \ldots \ldots \ldots \ldots \ldots \ldots \ldots . . \ldots \ldots$

Conclusions as to morphology of ascocarp and asci................ 29

Special Nuclear Phenomena-

Relative size of nuclei and cells in the ascocarp.................. 30

Structure of nuclei and relations of central body and chromatin in gametes

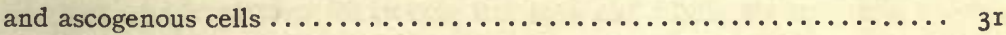

Nuclear fusion in ascus ................................ 36

Synapsis, spirem, number of chromatin filaments................. 39

Spindle formation, equatorial plate, and anaphases $\ldots \ldots \ldots \ldots \ldots \ldots \ldots \ldots, 43$

Formation of the daughter nuclei $\ldots \ldots \ldots \ldots \ldots \ldots \ldots \ldots \ldots \ldots \ldots \ldots,{ }_{4} 6$

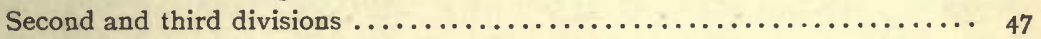

Development of ascospores by free cell-formation................. $4^{8}$

Summary of relation of central body and chromosomes in the development

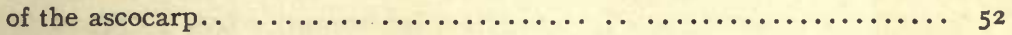

Theoretical Discussion:

The central body in Phyllactinia-

Polar organization of the nucleus $\ldots \ldots \ldots \ldots \ldots \ldots \ldots \ldots \ldots \ldots \ldots \ldots \ldots, 53$

Central body a permanent structure $\ldots \ldots \ldots \ldots \ldots \ldots \ldots \ldots \ldots \ldots \ldots \ldots, \quad 54$

Permanence of THE Chromosomes-

The organization of the chromatin in resting nuclei and segregation of the

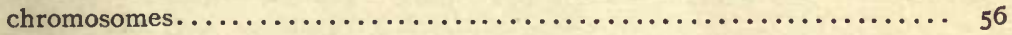

Individuality of chromosomes.......................... 57

Review of data as to connection of chromosomes and centrosome........ 59

THE NUCLEAR FUSION IN THE ASCUS-

Comparison with fusion in oogonium and in æcidium of rusts.......... $6 \mathrm{r}$

Doctrine of the nucleo-cytoplasmic relation........................ $6_{4}$

Relation of assimilation and growth to cell and nuclear division ......... 67

Conclusions as to origin and nature of fusion in ascus. . . . . . . . .

Effects of development of conjugate nuclear division $\ldots \ldots \ldots \ldots \ldots \ldots \ldots, \quad 7^{2}$ 
Relations of Ascomycetes and Basidiomycetes-

Evidence from binucleated cells for relations of rusts and Basidiomycetes...
Resemblances in Ascomycetes and Basidiomycetes due to parallelism in func-

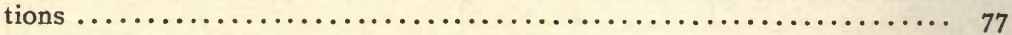

ALTERNATION OF GENERATIONS IN HIGHER FUNGI-

Evidence from reduction phenomena and binucleated cells ........... 79

Correlation of triple division in ascus with two preceding nuclear fusions ... 8 8

Relations of ascus, teleutospore, basidium, and tetrasporange......... 85

Summary as to sexual reproduction and alternation of generations in higher

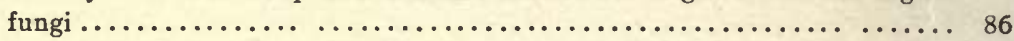

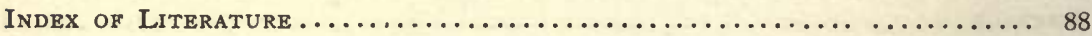

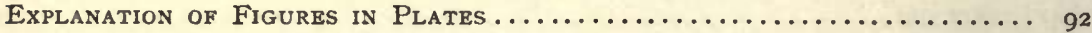




\section{PREFACE.}

The organization of the resting nucleus and its relation to the processes of nuclear fusion and division are the main problems with which I have been concerned in continuing my studies on the mildews. The doctrine is commonly accepted that the chromosomes are in a special sense the physical basis of heredity, but their relation, especially in the resting nucleus, to the mechanism of cell division and to the centrosome is still undetermined. The evidence for the so-called "individuality" of the chromosomes has been developed almost entirely from a study of their appearance in mitosis. In Phyllactinia I have been able to show that the material of each chromosome is in permanent connection with the central body throughout the stages of nuclear fusion and the resting condition, as well as in mitosis, thus affording an explanation of the means by which the permanence of the chromosomes is secured and throwing further light on the mechanics of nuclear division. The nucleus is thus shown to have a permanent polar organization; and the central body is a permanent structure in the cell which determines the point of special connection between the nuclear contents and the cytoplasm in the mildews. The regularly recurring triple nuclear division in the ascus has been the most serious objection to the acceptance of the frequently proposed view that the ascocarp is a sporophyte and the ascus a spore mother cell. But with the facts of the nuclear history in Phyllactinia here brought out, showing that each chromosome is a permanent unit through the processes of nuclear fusion as well as division, and that synapsis and a numerical reduction of the chromosome number occur in the ascus, it becomes plain that the triple division in the ascus is a natural correlative of the occurrence of two nuclear fusions in the development of the ascocarp. The evidence thus becomes very strong that we have a true alternation of generation in the Ascomycetes. In the light of the principle of the "nucleo-cytoplasmic relation" it is also evident that the size, method of development, and functions of the ascus all indicate that the nuclear fusion which occurs in it is a correlative of the general vegetative and growth processes involved in maintaining the nucleo-cytoplasmic equilibrium in a cell of such relatively gigantic size as the ascus.

The presence of typically differentiated and functional sexual cells in Phyllactinia, together with the abundant evidence which has recently 
accumulated, and is here summarized, as to their presence in other types, must be regarded as establishing the fact that the ascocarp originates in a sexual apparatus. Objections which are still urged by the opponents of De Bary's views are rather in the nature of complaints and denials than in the presentation of new facts.

A most fertile source of confusion in the discussion of the relationships of fruit forms in the fungi has been the failure to make all comparisons from the standpoint of a strictly phylogenetic morphology. Whatever excuse there may be for introducing physiological conceptions into the formal classification of tissues in the higher plants, there can be no question that great confusion has arisen in the morpinology of the fungi and algæ from allowing considerations of functional equivalence or difference to mingle with and modify the conceptions of what should be a strictly phylogenetic morphologv. It may be a hopeless task-it certainly is not at present a very important or stimulating one-to attempt to determine with exactness lines of phylogenetic descent among such plastic forms as the algæ and fungi; but no other or lesser aim than this should be allowed to masquerade under the guise of morphology. Physiological data as to the functions and mechanics of cells and organisms are of far greater biological significance than those of phylogenetic morphology, but this is no reason for mixing the two or allowing such attempts as we may make at the arrangement of plant forms in evolutionary series to be vitiated by the introduction of purely functional criteria into the determination of our morphological classifications. The question, for example, whether a given organ is functional in its more primitive or in some modified fashion can have no bearing upon the determination of its morphological nature or relationships.

Comparisons must frequently be made and hypothetical morphological categories established on data which are incomplete and can, perhaps, never be made complete, but a lack of data as to phylogenetic relationship can never be compensated for by evidence of functional equivalence or non-equivalence. The modern fields of causal and experimental morphology, developmental mechanics, etc., belong with the physiological rather than the morphological disciplines, and their results have the same bearing upon the classifications of phylogenetic morphology as have other physiological data. If there can be agreement that the various developmental stages and fruit forms of the fungi and algæ shall be classified and named in accordance with what can be determined as to their phylogeny a number of disputed questions will disappear. 


\title{
SEXUAL REPRODUCTION AND THE ORGanization OF THE NUCLEUS IN CERTAIN MILDEWS.
}

\author{
BY R. A. HARPER.
}

\section{INTRODUCTION.}

It is one of the best-established facts regarding mitosis that from certain late prophase stages until the formation of the diaster a specially evident connection between the chromosomes and the spindle poles is maintained by means of conspicuous fibrillar structures. The existence of these apparent fibrillæ is generally admitted even by those who accept a so-called dynamic theory of the central body as opposed to the conception of contractile spindle and polar fibers. It is evident, also, that this connection influences, if not directly determines, the motions of the chromosomes and their separation into two groups to form the daughter nuclei. This is equally true for the cells of animals and plants and for cases of multipolar as well as bipolar spindles.

Rabl was the first to point out that in the spirem, and even in the earlier resting-stages, some influence is exerted on the nuclear contents which gives a definite polar arrangement to the chromatic clements. This centering of the spirem loops on a polar field has come to be commonly known as Rabl's (78) figure. The same arrangement of the spirem was found by Strasburger (88) in both the dispirem and the prophases of dividing plant-cells, and its regular occurrence has since been described and figured by numerous authors and for widely separated organisms.

The discovery of the so-called attraction sphere and its relation to the karyokinetic figure by Van Beneden $(6,7)$ gave a further impulse to the doctrine of polarity, both in the cell and nucleus, and in a further brief paper (79) Rabl accepted Van Beneden's conception of an attraction sphere and gave a fuller statement of the doctrine that, not only during the process of division as shown by Van Beneden, but in the so-called resting stages, the whole structure of the cell and nucleus is

NotE.-Numbers inclosed in parentheses refer to the numbers in the literature list at the end of this paper. 
centered on the polar body in the polar field of the cytoplasm. He described the nucleus as showing thus a polar and an antipolar region and its whole structure, including both chromatic and achromatic elements, as permanently centered on a definite pole. Rabl further conceives the achromatic fibers of the resting condition as forming the spindle figure in karyokinesis, and thus the basis is given for a mechanical conception of division on the assumption of the contractility of the fibrillar elements of the nucleus and cytoplasm.

Rabl's conception of the polar organization of the nucleus and of the mechanics of nuclear division was adopted by Flemming and is given its fullest expression in his discussion of the mechanics of cell division in the tissue cells of the salamander (25, pp. 715-749).

Boveri (I0), on the ground of his observations on the eggs of Ascaris, opposed the doctrine of a persistent connection between the chromatic elements and the centrosome, and maintained that a new connection between chromosomes and poles is established in the prophases of each succeeding cell division. With the development of the doctrine of the individuality of the chromosomes this question has gained still more fundamental importance, and in this connection I shall discuss, further on, the observations of some later investigators.

My earlier work (38) on the dividing nuclei in the ascus led me to suspect that a permanent connection of chromatin elements and central body exists in the mildews, and I have described and figured such a condition in certain resting stages of the nuclei. In extending my studies to the genus Phyllactinia I have found a more favorable form with somewhat larger nuclei and have been able to trace a continuous connection of centers and chromatin in both resting, fusing, and dividing nuclei.

Since various authors have expressed themselves as still denying or as doubtful as to the existence of differentiated sexual cells in the Ascomycetes and as to the consequent morphological relations of the ascocarp, I shall precede my special description of the nuclear structures and processes with an account of the development of the sexual organs and the perithecium. I am convinced that on these much-vexed questions of the alternation of generations, relations of Ascomycetes, Basidiomycetes, red algæ, etc., we shall only arrive at certainty by the most painstaking study of the nuclear structures and processes and especially the chromosome number at all stages of development, and I have returned to the mildews for a further contribution to this subject because in Phyllactinia I have found the most favorable ascomycete for the study of the nuclei which I have yet encountered. Phyllactinia is 
undoubtedly the most highly specialized of the mildews and represents the culmination of the developmental tendencies found in the group. It is one of our most widely distributed mildews and has been repeatedly the object of investigation from the standpoint of its general structure and habits of life. Recently Salmon (82, p. 224) has investigated very fully the published species of the genus, and has concluded that we have but one polymorphic and cosmopolitan type. He adopts the name Phyllactinia corylea (Pers) Karst.

Salmon (83, pp. 20I-205) has also made very extensive and interesting comparative studies of the form of the peculiar penicillate cells, and concludes that the most extreme types of these cells are connected by a series presenting all possible intermediate variations in form. Palla (76) and Smith (86) discovered the interesting fact that Phyllactinia, unlike other mildews, is not strictly epiphytic, but sends branches through the stomata into the intercellular spaces of the mesophyl, producing haustoria ultimately in the cells at the base of the palisade parenchyma, and especially where nutrition is most abundant. Neger (68) has also corrected the erroneous view that the conidia are borne singly, instead of in chains as in other mildews, and has given very interesting data as to the operation of the spine-like appendages, which, by their hygroscopic motions, loosen and lift up the perithecia from the leaf of the host when they are ripe.

Phyllactinia occurs on a considerable series of host plants. I have sectioned and studied especially material from the white ash (Fraxinus americana), the hazel (Corylus americana), the bittersweet (Celastrus scandens), and the yellow birch (Betula lutea). The material was fixed, immediately upon being gathered in the field, and its subsequent treatment was essentially the same as I have previously described. 


\section{DEVELOPMENT OF THE PERITHECIUM.}

The sexual apparatus in Phyllactinia arises in general as I have earlier described for Sphaerotheca (36) and Erysiphe (37). As a rule the ascocarps are more sparsely scattered than in either of the above genera, and the labor of bringing together a series of developmental stages is proportionally increased. As has been many times noted, the perithecia of Phyllactinia are regularly hypophyllous, a fact which has its explanation in the existence, as above noted, of interior mycelial branches which gain access to the mesophyl through the stomata of the host. This habit brings with it further a relatively slight development of the superficial mycelium, and hence the infected spots are, as compared with those of most mildews, extremely inconspicuous until the young fruit bodies have grown large enough to be visible to the naked eye and have taken on the characteristic yellowish color of young, half-developed mildew perithecia. At stages when fertilization is going on, the infected spot on the ash or bittersweet leaf is faintly visible as a slightly whitened region scarcely noticeable unless the leaf is held so that the light is reflected from its surface at a particular angle. In my experience conidiophores are almost or entirely lacking, even in the earliest stages, on the mycelia which produce the most abundant perithecia. It should be said, however, that I have uniformly obtained my best material of this fungus in the autumn, and in regions where the fungus develops richly earlier in the season a greater abundance and prevalence of the conidiophores may be expected.

It is, of course, well known that not all the perithecia on an infected spot develop simultaneously. In Sphaerotheca, as I have already described $\left(3^{6}\right)$, there is a considerable peripheral growth of the mycelium, and the perithecia may be half-grown in the center of a spot while an abundance of the younger stages is still to be found on the periphery. In Phyllactinia, however, this is at least not so notably the case; the mycelium on an infected area seems to get almost its full development before the perithecia begin to appear, and they are then formed scatteringly, more or less, over the whole spot; the later-formed fruits are thus mingled with the earlier. The most abundant fertilization stages in my experience are to be found on spots in which the earliest-formed perithecia appear as mere white specks under the magnifier and none are yet far enough developed to have begun to turn yellow. 
The sexual apparatus is formed, as in other mildews, where two hyphæ cross or lie close beside each other, and we have thus the oogonia and antheridia arising as lateral branches from separate hyphæ, though it seems fairly clear, from the circular shape of the infected spots in most cases in Phyllactinia, that both these hyphæ belong to a single mycelium, which in all probability is the product of the growth of a single spore.

The oogonium and the antheridial branch seem to arise simultaneously, and they become closely applied to each other and begin to become slightly spirally twisted at once. The oogonium is thicker and heavier from the start and grows in length more rapidly also, so that it bends around the antheridial branch while the latter remains straighter. The oogonium may make one almost complete turn about the antheridial branch, which tends to stand rather vertically to the surface of the leaf (figs. 2, 3, Io). The oogonium is much thickened in the middle and may taper considerably toward both its base and apex (fig. I). It is densely filled with protoplasm and contains regularly a single nucleus (figs. I, 3-7). It is cut off from the hypha, on which it arose as a lateral branch, by a cross-wall which is put in a short distance from its point of origin on the mother hypha. The mycelial cell from which the oogonium arises is generally of average length, and the oogonial branch may arise at either end or in the middle of such a cell (fig. 2).

There is no evidence of any special differentiation in the cell from which an oogonium arises, and the first division of the nucleus of such a cell furnishes one daughter nucleus for the gamete and the other for the cell of the mother hypha. The antheridial branch arises in the same fashion, but is slenderer at the start, and there is apparently no pushing up of the antheridial branch by the side of the already developed oogonium, as I have described for Sphaerotheca. Indeed, it seems as if the two branches were firmly attached at a very early stage and that this condition, combined with the more rapid elongation of the oogonium, leads to the bending of the latter around the antheridial branch. This stretching of the oogonium also bends the tip of the antheridial branch to one side and twists it slightly, so that it comes to lie on the upper side oi the end of the oogonium (figs. $3,4,5,3$, Io), not forning a cap on its apex, as in Sphaerotheca.

It is to be noted that the unequal tendency to spiral twisting in the sexual branches, together with their unequal size, produces a structure whose appearance varies considerably, according to the side and the angle from which it is viewed, as is well seen by comparing figs. I to II, which serve to show the various possible aspects as well as the different 
stages of development of the sexual apparatus. It is not easy to bring out by shading the various bendings of the cells, as they can be followed by focusing up and down through the thickness of the section, and at the same time to show the contents of every part of each cell as it appears in median optical section. For the most part $I$ have contented myself here, as in my earlier figures of Erysiphe, with fulfilling the second and, of course, the more important of the two requirements. Hence the figures, with the partial exception of 2 and 3 , are to be regarded as representing projections of the outlines of the cells as they are followed by focusing up and down through the section, with the content of each cell as shown in median optical section. As a further result, the relative length of the cells in each section and in successive figures is not in every case correctly indicated. In a majority of cases the long axis of the oogonium tends to be parallel to the surface of the leaf or to rise slightly at its outer end, as shown in figs. 2, 3, 4, Io, while, as noted above, the antheridial branch is more nearly vertical to the leaf surface. Many exceptions to these relations are, however, to be found, as shown in the other figures of these stages.

Fig. I shows a stage when the antheridial branch is not yet cut off from the hyphal cell from which it arose, and it contains a single nucleus. This nucleus divides, and a cell-wall is formed between the daughter nuclei, so that one of them becomes the nucleus of the antheridial branch and the other remains in the hyphal cell below (fig. 3 ). This cross-wall is put in quite constantly at the narrowed region where the antheridial branch is partially encircled by the oogonium (figs. 3 , Io). The nucleus of the antheridial branch now divides, and one of the daughter nuclei migrates into the tip of the branch (fig. 4). The tip is cut off by a cross-wall and becomes the antheridial cell (figs. 5, 6, 7).

At this stage no trace of the enveloping perithecial hyphæ can be found. The whole apparatus consists only of the two gametophores and the gametes which have developed almost simultaneously and are thus sharply distinguished in the time of their development from the protective enveloping hyphal branches which come later. In Phyllactinia, as in Sphaerotheca and Erysiphe, the claim that the antheridial branch is to be interpreted as merely the first of the protective hyphæ is negatived by its appearing almost simultaneously with the oogonium, while the protective hyphæ arise much later and not singly, but in series around the base of the sexual branches.

Fertilization occurs, as in Sphaerotheca and Erysiphe, by the breaking down of the walls separating the protoplasts of the oogonium and antheridium and the fusion of the two protoplasts, and ultimately their 
nuclei. Figs. 5, 6, and 7 show successive stages after the gametes have been differentiated and just before fertilization occurs. The oogonium especially grows in size, and both the egg and male nuclei also increase in size. At the time of fertilization the male nucleus is smaller than the egg-nucleus, but hardly, perhaps, to the same degree that the antheridial cell is smaller than the oogonium. The cytoplasm of both gametes is quite free from reserve food granules or other stainable inclusions at this stage. Some small bodies, staining red with the triple stain, and a good many small spherical vacuoles are present in the oogonium, as shown in the figures, but for the most part the cytoplasm is a finemeshed, spongy mass, which appears pale-bluish or gray with the triple stain. The nuclei are very sharply and characteristically differentiated at this stage, and their structure will be described in detail later. The antheridium is closely pressed upon the oogonium a little to one side of and generally above the apex of the latter. Their walls in the region of contact are flattened upon each other and closely united. Every appearance is similar to those found in other cases of non-motile conjugating cells among the algæ and fungi.

A portion of the walls between the antheridium and the oogonium is now dissolved in such a fashion as to form a circular conjugationpore leading from the antheridium to the oogonium. The protoplasts of the antheridial and oogonial cells are thus brought into direct contact and combine to form a continuous protoplasmic mass (figs. 8,9 ). The nucleus of the antheridium migrates through the conjugation-pore into the oogonium and approaches the egg-nucleus. The male nucleus is, at this stage also, somewhat smaller than the egg-nucleus. This inequality in size is, however, by no means so great as is found in the pronuclei of many other plants and animals, in the early stages of the prucess of fertilization. Figs. 8 and 9 show cases in which the conjugationpore is open and the male and female nuclei are side by side in the oogonium. In fig. 9 the male nucleus, as recognized by its smaller size, has moved past and appears on the side of the egg-nucleus farthest from the antheridium.

It is evident that the conjugation-pore can be most easily found and studied in cases in which the plane of contact of the antheridium and oogonium cut the plane of the section at right angles, or nearly so, as is the case in figs. 9, IO, and II. Cases in which the sexual cells present the aspects shown in figs. 6 and 7 , in which the antheridium is more or less behind the tip of the oogonium, are of course much less favorable for the discovery and study of the actual fusion of the cells. Still it is perfectly possible in well-fixed and clearly stained material to 
demonstrate the conjugation-pore from this aspect also. Fig. 8 shows such a case in which the surface of contact of the gametes lies almost exactly in the plane of the section. The conjugation-pore appears here as a clean-cut opening in the floor of the antheridium. It is a perfectly clear, circular area, sharply distinguished from the bluish material of the cell-walls which surround it. This figure, in the region of the antheridium, represents an optical section lying in the plane of contact of the gametes, and the existence of an open pore from the antheridium to the oogonium is unmistakable. It is evident from the description given above that the shape and relations of the gametes are such that, with any possible orientation of the host-leaf to the plane of the sections, the aspects shown in figs. 6,7 , and 8 will be quite as common as those shown in figs. 9, I0, and II. The necessity for finding this latter aspect of the gametes in order to demonstrate the process of fusion with the greatest ease is doubtless the reason why some observers have failed to convince themselves that a union of the gametes actually occurs. Fig.9 shows this latter aspect of the fusing-cells. The plane of contact of the gametes cuts the plane of the section almost exactly at right angles, and the conjugation-pore appears as an absolutely unmistakable open passageway leading from the antheridium to the oogonium; and the cytoplasmic contents of the gametes are seen to have fused to form a continuous protoplasmic mass through which the male nucleus has migrated into the oogonium. The two pronuclei lie side by side in the oogonium and are readily distinguishable by their difference in size. In this particular case a vacuole lies just outside the conjugation-pore in the antheridium, indicating, perhaps, a relative increase in the cell sap of the latter after the departure of the male nucleus.

The entire contents of the antheridial cell does not enter the cogonium. In the old antheridium, after fertilization is complete there is considerable material which degenerates into a dense, structureless mass. In fact, it seems quite likely that here, as in many other cases, only a minimal amount, if any, of the cytoplasm of the male cell is actually taken up into the egg. The male nucleus apparently leaves the most, if not all, of its cytoplasm behind when it enters the egg. The cytoplasm of the antheridium is certainly less dense and is more vacuolar for a time after fertilization has taken place. A few deeply-stained granules are present in the antheridium while the conjugation-pore is still open (fig. 9) and are perhaps the first indication of the degeneration of its protoplasm. After the closing of the conjugation-pore they may become more numerous (fig. I0), but the antheridial cytoplasm keeps its spongy appearance for a time (fig. II). Soon the whole of the cyto- 
plasm becomes a dense, shrunken, highly stainable mass, as will be described in more detail a little later.

It is to be noted that in Phyllactinia there is no lack of granular material in the disintegrating cytoplasm of the antheridium to represent a degenerating nucleus for one who, like Dangeard, has failed to find the real process of fertilization. Apparently the fusion of the pronuclei occurs in about the center of the oogonium. The fusion nucleus is slightly larger than either of the pronuclei (figs. IO, II) and may show an increased density of its chromatin for a time (fig. IO). Details of the fusion-process and the union of the different parts of the pronuclei in the fusion-nucleus, so far as I have been able to observe them, are presented later in connection with my studies of the fusion of the nuclei in the ascus. After fusion the nucleus lies in the middle region of the oogonial cell (figs. IO-I2).

The conjugation-pore leading from the antheridium into the egg cell is closed at once after the passage of the male nucleus (fig. 10) and the antheridial cell now undergoes some very interesting and characteristic degenerative changes which make it a most conspicuous object all through the earlier development of the ascocarp, and which in themselves are conclusive evidence that it is a differentiated gamete-cell differing entirely in its nature from the cells of the perithecial envelopes. These changes consist in a swelling and change in composition of the antheridial wall and the shrinkage of the protoplast. $U_{p}$ to the time when the conjugation-pore is closed the antheridial cell-wall has been of the same thickness as that of its stalk cell and of the oogonium, and has showed no tendency to stain differently than the walls of these cells. With the triple stain the walls in these stages tend to stain pale blue. Very soon after the fusion pore is closed, however, the antheridial cell-wall begins to increase very markedly in thickness by swelling and undergoing what seems probably to be a mucilaginous degeneration (fig. II). This swelling is all toward the interior of the cell. With the swelling of the wall the protoplast apparently shrinks together, still keeping, however, the general outlines of the cell. The surface layer of the cell-wall remains dense and sharply marked, and the antheridial cell as a whole maintains its contour quite unchanged or with a very slight sinking in of the walls, indicating diminished turgidity.

This swelling of the wall continues until its thickness is equal to one-fourth or more of the transverse diameter of the entire antheridial cell (figs. 12-20, 23, 24). The swelling is least in most cases on the cross-wall cutting off the antheridium from its stalk cell and greatest on its outer wall opposite the region in which it is pressed against the 
oogonium. Commonly, especially in the earlier stages, the thickening is markedly less in the region of the closed conjugation-pore (fig. I.3). This swollen wall, in preparations colored with the triple stain, shows a most pronounced affinity for the orange. In preparations given an exposure of only a few seconds to the orange this wall appears deeply and brightly orange-yellow in color, and forms a most conspicuous and sharply contrasted object in sections of all the younger stages of the ascocarp. The remains of the protoplast at first shrink to an irregular oblong body which, with the triple stain, usually appears red and is dense and structureless. Later this mass seems to grow less dense and loses its staining capacity, so that ultimately the cavity of the antheridium appears quite empty, while it is still surrounded by the conspicuous swollen wall.

The degeneration of the remains of the antheridial cytoplasm is an interesting process in itself, and a comparison of its structure during the successive changes which it undergoes, with the structure of the adjacent perithecial cells, is interesting in several points. The most conspicuous change which it seems to undergo is associated with an apparent loss of water. The cytoplasm of the perithecial cells is loose and spongy in texture, with large spaces filled with watery cell-sap, while the non-stainable cell-sap seems to disappear gradually from the antheridial cytoplasm, allowing the denser portions of the meshwork to draw together so as to form ultimately a homogeneous mass. Further, while the normal cytoplasm tends, with the triple stain, to be colored faintly gray-blue, or slightly buffy with longer exposure to the orange, the contracted cytoplasm of the antheridial cell shows a pronounced affinity for the safranin, and when once stained red retains the color with great tenacity, so that the entire content of adjacent cells may be decolorized by washing in alcohol without noticeably affecting the appearance of the degenerating antheridium. The change in the protoplast here is similar in most points to that which I have already described (39) as taking place in the end cell of the promycelium of the anther-smut after the two basal cells have been joined by fusiontubes. The end cell ordinarily dies under these conditions and its protoplast forms a dense red-stained mass like that of the antheridial cell, except that in the promycelial cell the nucleus can be distinguished for a considerable period, while in the degenerating antheridial cytoplasm no nucleus is present. The swollen yellow-stained walls of the antheridial cell makes it a conspicuous object in sections of the perithecium in all its earlier development. The empty wall persists until the perithecium is half-grown, occupying a characteristic position toward the 
base of the perithecium considerably to one side of its stalk and commonly in about the third layer of cells from the surface of the perithecial wall. From the time of the completion of the process of fertilization and the closure of the conjugation-pore it is most conspicuously a dear cell, and its differentiation from all the later-formed perithecial protective cells, both in function, structure, and fate, is one of the most conspicuous facts that appears in any series of sections of the developing ascocarp of Phyllactinia, and is in itself sufficient to suggest the morphological relationships of the ascocarp.

The fertilized oogonium in Phyllactinia begins its further development at once. The egg in this case is the oogonium, and the use of the term oosphere seems quite superfluous. We have no rounding up of the protoplast of the oogonium and separation from its wall to form an oosphere, as in Oedogonium or Vaucheria. Still, there is no question that the female cell in Phyllactinia corresponds entirely to that of Oedogonium; and the fact that it does not round itself up is due to its habit of continued development as a cell of the mycelium which produced it. It is set free from vegetative continuity with the mother plant in no respect. Whether it is to be regarded as the beginning of a new individual life history is a question which must be settled on other grounds than that of its being set free from the mother plant as an independent life unit.

While the process of fertilization is going on, the protective branches which are to form the perithecial envelope push out from the stalk-cell of the oogonium and grow up about the two gametephores, applying themselves closely to their surface and following an irregular path, owing to the slight spiral twisting of the oogonium. In the figures I have put in only such portions of them as lay outside the outlines of the sexual apparatus. In Phyllactinia it is very conspicuous that these enveloping branches may and do arise from the stalk-cell of the antheridium as well as from that of the oogonium (figs. I4, r7). Even before fertilization is complete the antheridial stalk-cell becomes much enlarged and is apparently in a very active vegetative condition (fig. 7), resembling that of the stalk-cell of the oogonium. After fertilization its condition is in striking contrast with that of the antheridial cell which was cut off from it. While the walls of the latter swell and apparently become mucilaginous, and its protoplast degenerates as described above, the stalk-cell continues to enlarge, its nucleus divides, and hyphal buds push out from its surface At the very first one or more hyphal branches push out just below the cross-wall separating the antheridium from the stalk-cell and grow up over the former (fig. I4), inclosing and covering 
it and thus closing the apex of the ascocarp, though, as noted, because of the curved form of the oogonium, this region may not be vertically over the stalk-cell of the oogonium. The further growth of these and other hyphæ from the antheridial stalk-cell plays an important part in the development of the perithecial envelopes, but the branclies from the oogonial stalk and those from the antheridial stalk become so intermingled that it is not easy to distinguish them in later stages.

While the first enveloping branches are pushing up from the stalkcells the oogonium is also beginning its further development. From its function in the mature ascocarp we may call this product of the growth of the oogonium the ascogonium. This growth of the oogonium is essentially, as noted, the germination of a fertilized egg which, instead of being set free from the mother plant, continues in unaltered vegetative connection with it. In its growth the ascogonium elongates and increases in diameter. At first, since the antheridial stalk-cell does not elongate and the end of the ascogonium is firmly attached to the antheridium, the two ends of the ascogonium are held at about the same distance apart as they were at the time of fertilization, and its growth results in a bulging out and increased convexity of its free middle portion. The suggestion given by sections of the growing fruits at this time is that of a mutual rivalry in growth between the ascogonium and the enveloping hyphæ. The ascogonium tends constantly to burst out of the inclosing hyphæ, which latter, by elongation and richly branching, tend to inclose and cover it over its whole surface.

Whether or not the inclosing hyphæ grow more slowly at first and actually exert pressure on the growing ascogonium, it is certain that the ascogonium becomes curved in a very irregular fashion at this stage. The sections (figs. 12-23) are about $5 \mu$ thick, and the ascogonium bends up and down in the thickness of the section in a fashion which would be difficult to represent without special shading, which would interfere with the representation of its protoplasmic content, etc. Hence, I have here, as in the earlier stages, disregarded in the drawings the vertical bending of the ascogonium, and have, by focusing up and down, shown it in median optical section as if projected in the plane of the section. This has resulted, of course, in making it appear somewhat shorter than it really is, and as a further result, in cases of successive sections in which the ascogonium appears, its parts do not seem to fit together as they would if its actual windings were shown in the figures. Since, however, we are concerned only with the facts of its increased size, the multiplication of its nuclei, its division into cells, and 
ultimate branching to form the ascogenous hyphæ, the representation of its exact form may be considered as a matter of secondary importance.

With the first growth of the ascogonium in size the fusion nucleus divides and we have a binucleated stage, which is apparently rather long continued, lasting until the complete inclosure of the ascogonium by the enveloping hyphæ (figs. 13-16). It is an apparently abundant stage and an easy one to study, since the fruits are now large enough to be readily found, and the greater part of the ascogonium and the old antheridial cell can frequently be found in a single section. The nuclei are as a rule symmetrically placed in the axis of the ascogonium. In Phyllactinia, according to my observations, cell division never follows this first division of the egg-nucleus. The ascogonium remains onecelled and its nuclei continue to divide. As to how many nuclear divisions may precede cell division I am not certain, but in the end we have formed a row of from 3 to 5 cells (figs. 17-22). The end cell of the ascogonium regularly contains one nucleus and remains attached to the old antheridial cell for a considerable period, though finally the two are commonly forced apart, apparently by pressure of the surrounding cells of the enveloping hyphæ. Sometimes this separation may occur at quite an early period (fig. I8b). The old antheridial cell commonly remains at a depth of about two or three cell layers from the surface of the perithecium, while the end of the ascogonium may become more deeply buried by growth of the perithecial hyphæ around it. The ascogonium forms at its maturity a single row of cells, the penultimate one of which regularly contains more than one nucleus.

The next step in the development of the ascocarp consists in the formation of the so-called ascogenous hyphæ. These arise as lateral branches from the ascogonium. Whether they all arise from a single cell of the ascogonium, as one might expect from analogy with Ascobolus, or whether two or three of the upper cells may sprout out in branches, is not easy to determine. It is certain that some branches arise from the penultimate cell. The ascogenous hyphæ arise relatively early in the development of the ascocarp in Phyllactinia (figs. 22, 25a) at a time when the ascogonium is inclosed by only about two layers of perithecial cells. It is thus impossible for them to grow out vertically from the ascogonium for any great distance, and the result is that they lie flat on the cells of the ascogonium, crowding back the perithecial cells and overlapping and intertwining with each other so as to cover the whole upper part of the ascogonium. This makes it very difficult to trace a particular branch to its point of origin, especially since the walls of the cells are thin and their form distorted by the crowding of 
the perithecial cells and the young ascogenous hyphæ. The questions here involved are of interest as bearing on the relationship of the mildews with such forms as Ascobolus and Pyronema, but have no direct bearing on our interpretation of the ascogonium or the entire ascocarp.

In view of Blackman's and Christman's remarkable discoveries in the rusts, noted further below, I have devoted special attention to the question as to whether in Phyllactinia, either in the ascogonium or the ascogenous hyphæ, binucleated cells may not be present. My results have been entirely negative. While occasionally a binucleated cell is found (fig. $2 \mathrm{I} a$ ) in the ascogonium, it is even here uncertain whether a subsequent cell division may not separate these nuclei. The great majority of the cells are uninucleated. As just noted, the ascogenous hyphæ in Phyllactinia, in whole or in large part, arise from the penultimate cell of the ascogonium, and this cell regularly contains several nuclei (figs. 19, 20, 21, 25a). The cells that are to become asci contain two nuclei (figs. 28, 29). The remaining cells of both the ascogonium and the ascogenous hyphæ after cell division is complete are almost without exception uninucleated (fig. 19-29). This comes out very strikingly in the case of the old cells of the ascogonium and ascogenous hyphæ, which are largely filled with a watery cell-sap (figs. $25 b, 29$ ).

The enveloping hyphæ of the perithecium continue to grow, and thus the protective envelope is enlarged. The ascogonium reaches its full development rather early in forming the row of cells above described, and then ceases to enlarge and remains lying in the basal portion of the growing perithecium (fig. 27). With the enlargement of the perithecium the ascogenous hyphæ push up vertically and away from the ascogonium. It is quite plain from fig. 27 , as also from a study of the earlier stages, that the ascogenous hyphæ develop considerably before they become septate. Later, after cell division is complete, the asci are formed, either as lateral outgrowths from intercalary cells or from the terminal cell of an ascogenous hypha. In fig. $29 b$ we find the terminal cell developing as an ascus and also evidence of the repeated pushing out of the subterminal cells, though it is possible that this appearance is due to the formation of the entire branch before cell division occurred. In this figure the second cell appears empty of contents, but this is due to the fact that only a small portion of its base appeared in the section drawn, the remaining portion extending into the next section. In this case the two cells which are to produce asci are each binucleated, while the stalk-cells below are uninucleated. Quite possibly the cell division does not occur in the ascogenous hyphæ until the stage when the young asci are differentiated, and this gives full 
possibility for special arrangements of the nuclei as to their distribution in asci and stalk-cells. Fig. 29a shows an ascogenous hypha in which the end cell is enlarged and is apparently destined to form an ascus, but contains only a single nucleus. I am inclined to think this is due to the fact that the cell in question is cut in two and that a portion of it should appear in the next section. In this particular case, however, I have been unable to find the second nucleus, and it is possible that we have here a case of a young ascus just cut off and containing only one nucleus. If this is the fact it is certainly to be regarded as a rare exception to the rule that the young ascus contains two nuclei when first formed. The cell below this in the same hypha contains two nuclei and is pushing out laterally and upward to form an ascus in the normal fashion. The third cell is plainly, from its lack of content, to remain sterile and contains a single, much smaller nucleus. It is evident that there is in Phyllactinia, as also in Erysiphe, no such regular process of forming an ascus from the penultimate cell of a curved lateral branch of an ascogenous hypha as one finds in Ascobolus, Pustularia, Pyronema, and some other Discomycetes.

The young ascus regularly contains two nuclei, and since, as noted, the ascogenous hyphæ are multinucleated before they are cut up into cells and their cells, which are to form asci, regularly contain two nuclei from the time they are formed, there is no reason for supposing that the pairs of nuclei are daughter nuclei of the same mother nucleus; but there is no such apparent method of preventing the inclusion of two sister nuclei in the same ascus as one finds in the Discomycetes mentioned above. Certain cells of the ascogenous hyphæ which remain sterile contain only one nucleus, and this may be the reason for their failure to develop further. Still other cells of the ascogenous hyphæ containing two nuclei are apparently prevented from developing by overcrowding, so that one can not conclude positively that the number of nuclei which it contains determines necessarily the fate of the cell of an ascogenous hypha. On the analogy with the Discomycetes it seems fair to assume, in the absence of any evidence to the contrary, that the two nuclei in the young ascus are not sister nuclei, though there is again no reason for assuming in Phyllactinia that their relationship is a very distant one. The asci now elongate rapidly in a vertical direction, while the sterile cells of the ascogenous hyphæ with which they are connected below undergo no further development. As a result these sterile cells and the old ascogonium come to lie further from the center of the perithecium and are more noticeably left behind, as it were, in the basal portion. The asci, on the contrary, continue to occupy a 
central position. Their shape at this time is well shown in fig. $4 \mathrm{I}$. It is noticeable that they are thicker in their upper portion and taper considerably below. A comparison of figs. 53-56 with fig. 4I suggests that the vertical elongation of the asci has been mainly in this lower tapering region, which has been extended as a stalk-like prolongation connecting the upper thickened portion, in which-it is to be noted-lie the nuclei, with the sterile cells of the ascogenous hyphæ below. This tapering stalk portion is never cut off by further cross-walls to form a true stalkcell. A considerable portion of it thickens up later and the nucleus comes to lie much further down than in the present stage. There is always, however, in the mature asci an abruptly narrowed basal portion (see figs. 55, 56) where the ascus connects with the next adjacent cell of the ascogenous hypha. A basal stalk-cell is, however, never cut off from the lower end of the ascus. It remains always the entire cell of the ascogenous hypha, as it was formed when the hyphæ became septate.

The young asci are very closely inclosed from the start by the vegetative hyphæ of the perithecium. At a time when the asci are scarcely differentiated and the division of the ascogenous hyphæ into binucleated cells is scarcely complete the perithecium has the general structure shown in fig. 27. No differentiation of the perithecium into separate layers can be made out at this stage. There is no evidence of a radial growth of hyphal branches inward from the perithecial wall. The hyphæ of the perithecial wall extend between the branches of the ascogenous hyphæ so that the latter hardly come in contact with each other, but are separated and partly inclosed by hyphal branches which, from their subsequent development and differentiation, we may suppose-even at this early stage-are nurse cells which give up food stuffs to the ascogenous cells among which they lie and which are destined to perform the spore-bearing function.

Median sections show the cells of the perithecium for the most part as oblong in section and apparently uninucleated. Tangential sections show, however, that at this stage they are in reality flattened polygonal plates and contain generally three, four, or even more nuclei. The original stalk-cell of the oogonium is shown in figs. 22 and 27 forming the center of support and attachment for the entire perithecium. The lower cells of the ascogonium extend upward from this stalk-cell and curve to one side in the base of the ascocarp. These cells are large and swollen in appearance. The ascogonium as a whole is never found lying in a single plane so as to appear entire in a single section. Generally its path is so irregular and it has become so distorted by the pressure of the perithecial cells that its successive cells bend back and forth 
in a fashion very difficult to show in even a large drawing. Drawing the successive cells as they appear in one plane, as I have done, results, for example, in causing the second cell of the ascogonium in fig. 27 to appear very short as compared with the first and third. As a matter of fact, however, the second cell is as large as the first, but bulges out on the lower side, as the section lies, so as to appear for the most part in the next section.

From the outer cells of the perithecium in its basal region hyphæ have begun to sprout, which form a sort of secondary mycelium comparable to the secondary mycelium of many Discomycetes (fig. 27). These hyphæ grow out for a considerable distance and become interwoven with the mycelial hyphæ over the stomata. Whether they give rise to internal hyphal branches with haustoria I have been unable to determine with certainty, as they are in no way differentiated from ordinary mycelial hyphæ in appearance and their course is not easy to trace. There are good reasons, however, for doubting whether they ever pass through the stomata. The latter are crowded full, with all the entering branches which apparently can find room, long before the perithecia are sufficiently developed to give rise to these secondary hyphæ. It seems likely that the latter serve merely for the better attachment and support of the developing perithecium. The single stalk-cells of the oogonium and antheridium together certainly seem hardly adequate, from a mechanical point of view, for giving a firm and safe support for the relatively immense fruit body developed on them. In a section such as that shown in fig. 30 the asci seem already to lie at approximately the same level in the ascocarp, and to be-for the most part, at least-in a horizontal layer slightly above the middle of the perithecium. Close examination and comparison of successive sections show, however, that in reality the individual asci extend to quite unequal levels both toward the base and toward the apex of the perithecium, as would be expected from the irregular course of the ascogenous hyphæ from which they arise. At this stage the two nuclei of the young ascus have fused to form the primary ascus-nucleus of De Bary and Strasburger. The process of fusion is described fully below.

In this stage of the development of the perithecium the old ascogonium and the sterile cells of the ascogenous hyphæ are scarcely recognizable. The asci have grown to be swollen, oblong sacks and are pressed together and flattened upon each other in their middle regions, while the perithecial cells still press in between their ends. The nucleus of each ascus lies in its lower end and below this the ascus is narrowed sharply into a stalk. This stalk-like portion frequently does not lie in 
the same plane as the body of the ascus, and hence does not appear in the section in which the body of the ascus is best shown. In fig. 30 the second and third asci, counting from the right, show the narrowed basal portion, and, as suggested, these figures do not show the body of the ascus so fully as those lying further to the left.

At this stage the wall of the perithecium in Phyllactinia can be roughly differentiated into three layers. The outermost consists of a single layer of peripheral cells. From these cells in the basal region the secondary mycelial hyphæ sprout as noted above. From this same layer in the equatorial region of the perithecium the spine-like appendages with enlarged bulbous bases arise. These have not yet begun to develop at the stage shown in fig. 30. From the same peripheral layer, in a zone about the apical region of the perithecium, are developed the peculiar penicillate cells which have been so frequently the objects of study in recent years. The first beginnings of these outgrowths are shown in the swollen and protuberant form of certain of the peripheral cells in the upper portion of fig. 30, to the left. The outer layer of perithecial cells in Phyllactinia is especially active in growth. They remain thin-walled and show no tendency to become hardened and to dry out until the perithecium is nearly ripe.

Beneath the peripheral layer is a zone several cells in thickness, which functions as a protective, mechanical, strengthening layer from a relatively early stage in the development of the perithecium. Its protoplasts contain large vacuoles and its cell-walls undergo a change apparently analogous to lignification. The cells appear as poor in content and with specially strengthened walls. Inside this zone and next to the developing asci are several layers of cells richly filled with protoplasm and with thin, apparently unmodified walls. These cells constitute a close packing about the developing asci and, as has been suggested, are very probably concerned with their nutrition, though it is difficult to bring positive evidence on this point.

The later development of the perithecial walls consists simply in further differentiation of the parts already indicated. The penicillate cells already referred to are very easily studied in all stages of their development. They arise, as noted, as blunt outgrowths of the peripheral cells in a zone about the apex of the perithecium. They are either not developed at all, or are relatively small in the apical region itself. The cells which give rise to them push up vertically to the surface of the host-leaf, rather than radially to the surface of the perithecium. They are at first blunt and unbranched projections from the peripheral cells (fig. 50), but after they have reached a height equal to about twice 
or three times their diameter they suddenly break up into a number of very fine, thread-like branches, which bud out from their upper ends and grow on up to a height about equal to that of the unbranched basal portion of the cell. This is the simplest type of these cells in the forms of Phyllactinia I have studied. Much more abundant are other types which, before breaking up into the ultimate thread-like branches, divide first into two or three main branches, which may be very unequal or approximately equal in size (fig. $5 \mathrm{I}$ ). As a rule this latter type of cells lies farther away from the apex of the perithecium, and hence, owing to its curved surface, must grow higher in order to bring the ends of the filamentous branches to a level with those of the more centrally placed brush cells. The penicillate cells begin their development some time after the fusion of the nuclei in the ascus is complete, and have completed their growth, as a rule, before the nucleus of the ascus begins to divide preparatory to spore formation. The penicillate cell is never divided, but remains throughout simply an enlarged and branched peripheral cell of the perithecium. It contains two or three nuclei, as a rule, before its special growth begins, and when fully developed may contain as many as eight or ten nuclei. These are always situated in the enlarged basal portion of the cell and never penetrate into the filamentous branches. They form generally an irregular, scattered group in the upper part of the basal portion of the cell (fig. 5I).

As soon as, or even before, the penicillate cell reaches its full size the walls of the filamentous branches begin to swell and become gelatinous. As a result they become fused together laterally to form the slimy mass crowning the perithecium which has been described by many authors. The wall and contents of the basal portion of the cells remain unchanged for some time (fig. $5 \mathrm{I}$ ), but gradually it, too, is more or less involved in the degenerative processes, and almost the entire walls and contents of the penicillate cells are ultimately converted into a sticky, gelatinous mass.

When the walls of the filamentous branches swell, their cell content is reduced to a mere granular thread except at the very apex, though earlier a well-marked prolongation of the protoplast with normal protoplasmic appearance extended to the end of each branch. With the swelling of the wall this structure gradually deteriorates, though a granular thread persists till a late stage to mark the original lumen of the branch. At the very apex the wall does not swell so strongly and the protoplast also persists as a small oval vesicle tapering below into the granular thread just mentioned (fig. 5I). As a result the upper ends of the filaments are slightly enlarged and the surface of the slime mass 
is covered by a layer of these oval vesicles. It is possible that the vesicles burst and exude a slime more liquid than that of the deliquescent walls at the time when the perithecium is overturned, and thus aid in making more certain that it shall stick fast to any object which touches it. In this gelatinous cap, when the perithecia are ripe, the hyphæ of molds may frequently be found growing. The functions and adaptations of this slime-cap have been fully discussed by Neger (68), and I need not go into the matter further here.

The appendages arise in a zone about the equatorial region of the perithecium as swollen cells of the peripheral layer. As has been many times described, in their mature condition they consist of a slender, straight spine with a very much enlarged bulbous base. They grow horizontally outward in a bristling phalanx about the middle of the fruit body. As it ripens they bend downward and, pressing on the leaf surface, lift the fruit up, tearing it loose from its stalk and the secondary mycelial filaments described above. It is thus set free to fall or be blown by the wind until it strikes and adheres to some object by the mucilaginous cap described above. As a matter of fact, what seems frequently to happen is that the perithecium simply rolls over and remains sticking wrong side up on the same leaf on which it grew.

The walls of the appendages very early become hardened and brittle, so that they break up in cutting, and it is not common to find good entire longitudinal sections of them in microtome preparations. Still, their structure is very clearly shown. They contain an apparently living protoplast until late in the ripening of the perithecium. As a rule they have only one or two nuclei. It is quite common to find the single nucleus lying, not in the bulbous base, but somewhere in the basal region of the spine. The cytoplasm consists of a thin lining layer just inside the wall and large vacuolar cavities filling the greater part of the bulb and extending into the spine. The thickening of the wall is characteristic and especially adapted for producing the motions of the appendage, as noted above. The spine is thick-walled throughout, its apex being without a lumen for some little distance. The bulb is thickwalled over its upper surface, but on the under side there is an oval region whose wall has remained thin. This thin area extends up on the sides of the bulb also. The functioning of the structure so formed is very simple. As the perithecium loses water-dries out in beginning to ripen-the appendage loses water also by evaporation. This results in a pushing in by atmospheric pressure of the thin area on the bottom of the bulb and a consequent pulling down of the end of the spine as a result of the shortening of the under surface of the bulb. If the 
appendage is allowed to absorb moisture again it will straighten out, and by drying again the bending may be repeated. Neger (68) describes the repetition of the process a number of times as a result of alternately moistening and drying the perithecia. The protoplast is apparently living in the appendages of Phyllactinia till late in the ripening, at least till after they have performed their function in breaking the perithecia loose. Neger's (69) experiments on old, dead perithecia, in which he found the appendages still capable of executing their hygroscopic motions, would seem to show that the living protoplast is not essential for their proper functioning. The small number of nuclei in the spinous appendage as compared with that in the actually much snialler penicillate cell is notable and may perhaps be connected with the difference in function of the two types of outgrowths. The work of the penicillate cells is largely chemical in the formation of the mucilaginous cap; that of the spinous appendages is largely mechanical in the bending motions they execute in tearing the perithecium loose from its attachments.

With the full maturity of the perithecium the development of the spores in the asci begins. As a matter of fact, in sectioned material one almost never finds spore formation beginning until after the perithecia have broken loose from their original position and are lying wrong side up and attached by the mucilaginous cap described above. It is possible, of course, that many perithecia may be overturned prematurely in the processes of fixing, etc. Still only those in which the brush cells have formed their mucilage will become fixed to the leaf and so appear in the sections. The number of asci in a perithecium varies from 12 to 25. Median sections through the perithecium show sections of from 3 to 5 or 6 asci. The bursting of the perithecia and asci and the germination of the ascopores have not been observed for Phyllactinia, so far as I am aware. 


\section{MORPHOLOGY OF THE ASCOCARP.}

Considerable further evidence that the ascocarp originates in a functional sexual apparatus has accumulated in recent years. Miss Dale (I8) has shown conclusively that a fusion of gametes occurs at the origin of the ascocarps of Gymnoascus Reesii and Gymnoascus candi$d u s$, and concludes that the normal method of origin of the fruit bodies of the Gymnoascaceae and their related forms is by the union of two cells of more or less widely separated origin. Monascus is a very interesting object of investigation and its affinities have been quite variously interpreted. Barker's (3) complete and consistent account and the more recent briefer one by Olive (72) agree in describing the origin of the asci from ascogenous hyphæ and an ascogonium, so that we may probably conclude that it belongs among the Ascomycetes. Barker, Ikeno, and Olive maintain the existence of a sexual cell-fusion, while Kuyper $(55,56)$ and Dangeard $(20)$ deny that any such process occurs.

Ikeno's account of two successive free-cell formations in the ascogonium seems highly improbable, though Kuyper agrees with him on this point. Neither Ikeno's nor Kuyper's figures are, however, convincing, and to establish the existence of a process of forming asci or spore mother cells, as well as ascospores, by free cell-formation certainly demands the presentation of a detailed account with good figures of the stages involved. If the asci or "spore mother cells" of Monascus are formed by free cell-formation, it is certainly evidence against its close relationship with the Ascomycetes. Kuyper believes it should be made the representative of a new family, the Endascineae, connecting the Ascomycetes to the Oomycetes. Ikeno probably calls these bodies "spore mother cells" on an assumed analogy between them and the cells formed by free cell-formation in Taphridium, to which Juel (5I) has given this name. It is to be remembered, however, that these "spore mother cells" of Taphridium form spores not by free cell-formation, but by ordinary division. It is hard to see how Ikeno's account of spore formation gives any basis for his conclusion that his Monascus has relations with the other so-called Hemiasci. Kuyper indulges in some very sharp criticism of the lack of homogeneity of this group, which is doubtless justified, though we are more in need of new facts about the forms in question than of a priori criticism. Still later papers by Barker (4) reaffirm the correctness of his account of the reproduction of Monascus and add a preliminary account of sexual cell fusion in the development of the ascocarp of Rhyparobius. In this form we find a fusion of gametes with several nuclei. The ascogonium develops 
as a several-celled structure from which the ascogenous hyphæ arise. We have thus a fusion of gamete cells in another typical discomycete.

Baur (5) has added a further valuable contribution to his studies on the development of the apothecia of the lichens, in which he establishes the existence of carpogonia and trichogynes in a further series of forms. Especially interesting is the demonstration of carpogonia and trichogynes on the margins of the podetia of Cladonia, which corrects the mistaken, though generally accepted, conclusion of Krabbe that the entire podetium is homologous with an apothecium. Baur also shows that Wahlberg's recent conclusion that in Anaptychia the paraphyses arise from the ascogenous hyphæ is incorrect. The hyphæ which sprout from the carpogonium never form paraphyses. Baur also adds another form, Solorina, to the list of lichens which seem plainly apogamous. The lichens bid fair soon to become, if they are not already, the bestknown group of the higher fungi as to the actual facts in the development of their fruiting organs.

Claussen (I6) has also made a most interesting and important contribution to our knowledge of the ascocarp as a result of very carefully conducted studies on a new species of Boudiera. By growing the fungus in appropriate cultures he was able to follow the development of the sexual apparatus and the fusion of the gametes in living material. The apothecium of Boudiera takes its origin, like that of Pyronema, from several pairs of gametes. The antheridium and oogonium are spirally coiled together, and a trichogyne cell is cut off from the apex of the latter. As in Pyronema, the fusion-pore between the antheridium and trichogyne is more permanent, while the disappearance of the wall between the trichogyne and oogonium is transient and much more difficult of observation. Claussen did not find this opening in sections, but was able to determine the transitory disappearance of the wall between the trichogyne and oogonium in living material. The ascogenous hyphr arising from the ascogonium seem each to produce but one ascus which is typical in all respects in its development. We have thus a further case of an ascocarp which arises from a compounded sexual apparatus. As Claussen points out, such discoveries as these will furnish data for a much more satisfactory arrangement of the groups of the Ascomycetes than is yet possible.

Juel ( 52 ) has given a most interesting account of the nuclear phenomena in the fertilization of Dipodascus. The gametes are multinucleated, but only a single pair of nuclei fuse. By division of the fusionnucleus the spore-nuclei are formed. In view of Dangeard's attempt to homologize each ascus of the higher Ascomycetes with a supposedly 
apogamous fructification of Dipodascus, it is interesting to note that Juel insists that the spore-sac of Dipodascus corresponds to the entire cell complex which arises from a fertilized carpogonium. The nuclear fusion in Dipodascus corresponds to the sexual fusions in the carpogonium and not to those in the asci. This is the view adopted by Wager (97), and in his more recent discussions Dangeard (2I) has given up his earlier position, since plainly the individual asci in his fig. 5 , p. 55, do not correspond to the fructifications shown in fig. 4, p. 154. With this the contention that the ascus is an egg becomes still more inconsistent. In adopting this latest conception that the ascogonium and ascogenous hyphæ constitute a gametophore derived by growth and branching from a gametangium which has ceased to produce motile gametes in adaptation to a terrestrial habit, Dangeard admits De Bary's contention that the ascocarp is a unit morphologically comparable in its initial stages to one or more pairs of oogonia and antheridia. He thus, in reality, rejects his earlier conception that each ascus is an egg and morphologically the equivalent of a hypothetical parthenogenetic fruitbody of the lower fungi or algx. Dangeard now inclines to the view that the ancestry of the Ascomycetes is to be sought in the Oomycetes; and the real conclusion from his argument, admitting his premises, is that the ascogonium and ascogenous hyphæ are vegetative outgrowths from a parthenogenetic egg and that the ascus is a new structure in which this vegetative development ends.

Dangeard (2I) maintains that he can not find the stage when fusion takes place in Pyronema, but negative evidence on a point of this kind, when unaccompanied by positive results as to further details of cell and nuclear structure and behavior, are of little value. Meanwhile, we may be sure that morphologically, in its relation to the fruiting bodies in other groups of fungi or algæ, the ascocarp is to be interpreted as originating from a sexual apparatus. This fact will not be altered by the discovery of forms in which, by apogamy or parthenogenesis, the sexual cells have either been modified in form or become functionless.

I am unable to find anything in the discussions of Dangeard to invalidate the conclusions which I reached in a former paper (40) as to the morphology of the ascocarp. Further, the positive results briefly summarized above-obtained, as they are, by different workers and on widely separated forms-certainly favor the conclusion that the sexual organs of the Ascomycetes are regularly functional; and when we consider the difficulties involved in actually working out every stage in the development of an ascocarp from its earliest inception, it is not surprising that our knowledge has not advanced more rapidly. 
Dangeard persists in professing himself quite indifferent to the existence of antheridia and oogonia as the initial cells of the ascocarp, if only they be not functional at the present time; but one can hardly believe him so lacking in penetration as not to realize that so long as the Ascomycetes are regarded as a monophyletic group the establishment of the existence of antheridia and oogonia as the initial cells of the ascocarp settles at once, and finally, the old question of the sexuality of the group in favor of the views of De Bary and his school and against those of Brefeld-and this, too, without any regard to the question as to whether these sex cells are functional or not. Interesting evidence on this point is shown in the attitude of the present adherents of the views of Brefeld (57), who are solely interested in the question whether archicarps, pollinodia, etc., are really sexual cells, and appear relatively indifferent as to the existence of the fusions in the asci. No one can reasonably doubt that the antheridia of the Saprolegniaceae are sexual germ-cells, regardless of the question as to whether they are functional at the present time. The proof brought by Trow (95) that a fusion of cells and nuclei occurs at the present time is confirmatory evidence of their sexual nature, but it is in no way necessary for their correct morphological characterization as compared with corresponding structures in other groups of algæ and fungi. It was the supposed similarity of De Bary's antheridial branch in the mildews to the laterdeveloped perithecial branches which was a justification for doubt as to its morphological nature and made it necessary to show that it was a functional male branch in order to establish its morphological character. Could De Bary have brought such evidence of the special differentiation of its walls and its fate in the developing perithecium as can be found by modern methods in Phyllactinia, in addition to the facts as to its origin, position, etc., we can hardly imagine that its sexual nature would ever have been doubted, regardless of whether it was shown to be functional at the present time. The ascus is in its origin a new structure, the outgrowth of ascogenous hyphæ and ascogonium, and the fusion of nuclei which occurs in it, whatever may be its physiological nature, is not homologous with the fertilization of the egg out of which the ascogonium develops. It is thus fairly established and admitted that the "macrocysts and paracysts" of Pyronema and the "archicarp and pollinodium" of the Erysipheae and other Ascomycetes are to be compared morphologically to the gametangia and oogonia and antheridia of other fungi and algæ, and that the ascogonium, ascogenous hyphæ, and asci are new structures gradually developed in the evolution of reproductive processes, just as are the gonimoblasts and carpospores of the red algæ. 


\section{SPECIAL NUCLEAR PHENOMENA.}

Phyllactinia is especially favorable for the examination of the structure of the nuclei and their fusion and division in the ascogenous hyphæ and asci. The large number of asci formed in each ascocarp makes it possible to readily obtain large numbers of the nuclei in all stages of their development. The young perithecia of Phyllactinia also, in most of their stages, seem especially favorable for fixation, so that the nuclear figures in the sexual cells, the ascogenous hyphæ, and young asci are differentiated with exceptional distinctness and clearness of detail. As a result, certain structures which could be made out only at particular stages and without full details in Erysiphe can be found at every stage of nuclear development in Phyllactinia. I have described (38) for Erysiphe a peculiar and characteristic attachment of the chromatin of the nucleus to the central body, giving the nucleus a characteristic polar rather than a radial structure. This condition is very conspicuous in the young daughter nuclei in the ascus of Erysiphe. In Phyllactinia the nuclei throughout the entire plant, in both the mycelium and ascocarps, show this characteristic relationship of the chromatin and the central body; and in the ascogenous hyphæ and young asci a very definite type of orientation of the chromatin threads as a cone or partial aster extending from the central body into the cavity of the nucleus is conspicuous. This persists through the fusion stages in the ascus as well as through division and the resting-stages, and the central body is thus shown to be a permanent structure through the whole life history of the mildews.

I shall continue, as in former papers, to call this structure a central body rather than to use the term centrosphere or centrosome. I do this not to indicate that I consider this body in the mildew as different from apparently similar structures found in the karyokinetic figures of other plants, but merely because I prefer the more general descriptive term rather than a more technical one, since the bodies in question are still so variously described by the different authors who have worked on them.

It is a conspicuous and important fact that the nuclei and cells of the mildews undergo extreme variation in size in the course of the development of the fungus, and in general it is plain that the nuclei are larger in the larger cells. Before proceeding with the description of the organization of the nucleus I shall briefly summarize the facts as to this variation, since, as we shall see later, these facts may have an important bearing on the interpretation of the nuclear fusion in the ascus. The nucleus of the oogonium is considerably larger (fig. 7) than the 
ordinary hyphal nuclei. The nuclei of the stalk cells of both oogonium and antheridium, from which the protective hyphæ are to sprout, are frequently larger (figs. 7, I0), at least at the stages when the formation of the perithecium is about to begin, than those of the ordinary hyphal cells, though not as large as the nucleus of the oogonium. As in many other cases, the male nucleus is regularly smaller than that of the egg, just as the antheridium is smaller than the oogonium (figs. 5, 6, 7, 8, 9).

After fertilization, with the growth of the ascogonium its nuclei become still larger, and in the young ascus the pair of nuclei which fuse are conspicuously larger than any that have preceded them (figs. $31-33$ ), and the product of their union, the primary nucleus of the ascus, is one of the largest nuclei to be found among the fungi (figs. 48, 49). It is much larger than the nuclei of the cells of the leaf on which the mildew grows. Its diameter is about $10 \mu$ as compared with a diameter of $2 \mu$ in the hyphal nuclei. This large size of the primary nucleus of the ascus may well be regarded as correlated with the large size of the ascus itself. Roughly, the volume of the nucleus of the ascus seems to stand in a similar proportion to the volume of the entire ascus as the volume of a hyphal nucleus does to the cell which contains it. The cells of the full-grown perithecium contain several nuclei which are rather smaller than those of the mycelial cells, which are regularly uninucleated. When the primary nucleus of the ascus divides, the daughter nuclei are certainly not more than half as large (fig. 62) as the parent nucleus. The size of the nuclei produced in the second and third divisions is also proportionally reduced, and finally the nuclei of the ascospores are of about the size of the ordinary nuclei of the young perithecium (fig. 79). There can be no doubt that we have here a definite correlation between nuclear and cytoplasmic masses, such that the larger cells contain proportionally larger nuclei, and we have thus an illustration of the principle of the nucleo-cytoplasmic relation developed by R. Hertwig, Gerassimoff, and Boveri.

The nucleus of the oogonium is, as noted, considerably larger than those of the vegetative hyphæ. The oogonial cytoplasm is quite dense and shows a fine, close, spongy structure (figs. I-7). The central body of the oogonial nucleus is a conspicuous, well-differentiated, disk-shaped granule (figs. $4,5,7$ ) lying close on the surface of the nuclear membrane and generally occupying a slight depression in it. The arrangement of the chromatin content of the nucleus can not be so clearly made out at this stage as at later stages in the larger nuclei of the ascogenous hyphæ and the asci; still it is perfectly plain, in every case in which the plane of the section permits a profile view of the structure, that the 
chromatin is in intimate connection with the central body (figs. I, 3, 4, 5,7 ), and in specially favorable preparations (figs. 4,7 ) it is clear that there are strands in the chromatin reticulum which radiate back from the central body into the cavity of the nucleus, forming an intranuclear system almost like an aster whose rays appear quite straight and definite in many cases, though they are connected by transverse fibrillæ and lose themselves in a more indefinite granular reticulum in the region opposite the central body. The nucleus has plainly, at this stage, a unipolar structure, and the chromatin is definitely oriented with reference to the central body. Following Rabl's terminology, I shall speak of that part of the nucleus which is antipodal to the central body as the antipolar region and the region about the central body as the polar region.

The nucleus of the oogonium has regularly a single oval or spherical dense homogeneous nucleole (figs. I-7), which commonly lies somewhere in the antipolar region, but may frequently lie close to the central body, crowding aside the chromatin elements.

The nucleus of the antheridial cell is still smaller prior to fusion than that of the oogonium; still its central body is sharply differentiated and the chromatin is plainly connected with it (figs. 5,6 ). It has also regularly a single nucleolc. The structure of the nucleus of the antheridial stalk-cell and of the other vegetative nuclei agrees with that of the sexual cells (figs. 4, 5, 7). Frequently the hyphal nuclei are oval or more elongated, and may be drawn out to a point on which the central body sometimes lies. (Compare figs. 24 and 14). After its migration into the oogonium the antheridial nucleus enlarges and the two pronuclei are each plainly seen to be provided with central bodies at a stage just before they fuse (fig. 9). The fertilized egg-nucleus also shows a single conspicuous center (figs. IO, II, I2), and it seems probable that it has been formed by the combination of the centers of the pronuclei. It is also probable that this central body of the fertilized eggnucleus is actually double as compared with those of the pronuclei, since, as we shall see later, we have strong evidence of the permanence of the chromosomes as cell structures, and a nuclear fusion should hence produce a nucleus with a double number of chromosomes, each of which would have an independent attachment to the central body. But I have not been able to obtain a sufficient series of preparations at this stage to be able to trace the process of the combination of the chromatin and centers in this fusion, nor to determine the number of chromosomes in the next succeeding division. The fertilized egg-nucleus regularly contains a single, rather large nucleole (figs. IO, I2), which, it seems probable, is also formed by the fusion of the nucleoles of the pronuclei. 
With the growth of the ascogonium the egg-nucleus divides and the daughter nuclei become successively larger with the increasing size of the cells in which they lie. This growth continues till the ascogonium and ascogenous hyphæ reach their full development, as described above.

The nuclei appear at this stage in pairs in all the cells of the ascogenous hyphæ which are destined to produce asci (figs. 28, 29, 31-33). The question as to the probable relationship of these nuclei has been discussed above. There is no such arrangement for preventing the inclusion of sister nuclei in the ascus as I have described for Pyronema (40). On the other hand, the ascogenous hyphæ are multinucleated before cell division occurs, and there is no direct evidence that the nuclear pairs are formed by the division of a single nucleus.

The structure of these larger nuclei (figs. $3^{\mathrm{I}-33}$ ) appears to be the same as that of the sexual nuclei just described, but owing to their greater size the details can be made out with greater definiteness. The relations of the central body and nuclear content come out much more sharply, and it is possible to count with some certainty the number of chromatin strands which extend into the nuclear cavity from the central body. The nucleole stains bright red with safranin and is frequently flattened somewhat against the nuclear membrane, even tending, at least in fixed material, to break through it (figs. 31,33 ). The flattened disk-like form of the central body, as it lies pressed against the nuclear membrane, can be clearly made out. Its appearance and staining reactions are the same as I have already described $\left(3^{8}\right)$ for the central bodies of other mildews and Discomycetes. With the triple stain the chromatin shows a bright-blue color and the central body is reddish or violet.

The strands of chromatin are regularly attached to the central body, and from this point they extend into the central cavity of the nucleus, forming a sheaf of diverging rays. The series of threads as a whole produces distinctly the effect of a cone or bundle of rays extending from the central body into the cavity of the nucleus (figs. $3^{1-34}$ ). The bundle is broader or narrower, according as the threads diverge more or less rapidly from their point of attachment. In some cases the outer rays may follow more or less closely for some distance the inner surface of the nuclear membrane, and the whole system of threads may thus be distributed quite evenly through the nuclear cavity. In this case the appearance of a cone or bundle of threads diverging from the central body is partially lost, but the orientation and attachment of the threads on the center is distinct and definite. In the majority of cases, however, in this stage the threads form, for some distance inward from the center, quite a definite diverging bundle (figs. 33,34 ). If we 
endeavor to follow the paths of the individual threads we find them either straight or wavy in outline, and not infrequently threads are found which bend sharply this way and that, following no definite direction. Such threads are, however, relatively few and never abundant enough to interfere with the general appearance of a radiating system centered on the central body. Fig. 34 shows a section cut from one side of a nucleus, so as to include only three chromatin strands with fragments and cross-sections of others. In composition the threads appear lumpy or finely granular, and hence of quite irregular thickness and density, since the nodules are by no means of equal size. They probably consist of chromatin granules embedded in and connected by a less stainable linin, though the distinction of chromatin and linin can scarcely be made out at this stage. The main threads do not apparently anastomose, though they are occasionally found crossing each other. They are, however, connected by lateral fibrillar or granular extensions which are extremely delicate and quite numerous, so that in sections showing the entire nucleus (fig. 32 ) the more prominent threads appear almost as if embedded in a very faintly blue-stained ground substance. In fig. 34 the antipolar ends of the strands seem very definite, but this is probably due to the fact that they are cut off in sectioning. In figures showing the entire nucleus (figs. 32-34), and especially in the smaller nuclei of a slightly earlier stage (fig. $3 \mathrm{I}$ ), it is plain that the farther one follows the threads from the central body across the diameter of the nucleus the more difficult it is to distinguish them. In the nuclei prior to their fusion it is impossible to trace the threads across the entire diameter of the nucleus. They seem to fade out and lose their identity in a less strongly differentiated granular and thready mass, whose structure and relation to the main chromatin strands is not easy to make out clearly. The whole system of threads seems to pass over very soon (in fig. 3I) into a less differentiated granular reticulum composed of deeply stained chromatin granules connected with abundant, more faintly stained fibrillæ, which seem almost to form a ground substance. The fibrillæ resemble closely the faintly stained fibrous material which connects the threads nearer the center. This condition in the antipolar portion of the nucleus doubtless represents more nearly a resting condition of the nuclear material in which the chromatin is more irregularly scattered in the nuclear cavity, but is still connected definitely with the central body.

The appearance of the chromatin in the resting nuclei in the mycelial hyphæ and the cells of the perithecium (figs. 23, 24) is very similar to that which we find in the antipolar region of these nuclei of the 
young ascus. I have elsewhere described (37) such mycelial nuclei as finely granular, and the description applies to the vegetative nuclei of Phyllactinia. It is clear that these granules are the chromatin elements in a finely divided and distributed condition, such as has been commonly associated with the resting condition of the nucleus. In all the vegetative resting nuclei of Phyllactinia, however, the central body is in intimate connection by delicate fibrillæ with this granular content of the nucleus, and, since the antipolar region of the larger nuclei of the young asci shows a similar granular appearance with the linin fibrillæ connecting the granules into a reticulum, it is probable that this represents the structure of the resting nuclei generally in this mildew. In the resting nucleus the chromatin threads are so loosely distributed and are connected so frequently by linin fibers as not to be clearly distinguishable, the appearance being that of a reticulum; but the attachment of the chromatin threads to the central body is continuous and becomes conspicuous in the process of aggregation by which the apparently scattered granules of the nuclear reticulum of the resting stage are transformed into the spirem thread.

Tracing the course of any particular chromatin thread, then, at this stage, we may say that it is attached at one end on the central body, passes back through the nucleus in a path which may be rigidly straight or more or less wavy or bent, and either ends freely or seems to fade out in the apparently less differentiated granular reticulum of the antipolar region. The whole series of threads forms a broader or narrower cone or pencil of coarse rays extending from the central body into the nucleus and filling more or less completely the nuclear cavity. The outline of the more dense portions of the nucleus is determined by the outline of the chromatin system. The nuclear membrane may lie on the surface of this chromatin mass or it may be separated from it by a zone of clear non-stainable nuclear sap (fig. 3I). Frequently this zone of nuclear sap extends around the whole surface of the chromatin system, except where the threads are fastened to the central body. The relations of the threads to the centers is much emphasized in such cases, in that the center is the only point in which the chromatin is in contact with the nuclear membrane, and thus with the cytoplasm of the cell. Such figures indicate, as I have suggested in an earlier paper (38), that the central body represents a special region of connection between the interior of the nucleus and the cytoplasm.

The connection of the nuclear threads with the central body implies, of course, that the nuclear membrane is not continuous at this point, or at least that it permits in some way the connection of the threads with 
the pole. In the prophases of the division of the nuclei in the asci of E. communis the connection frequently appears partially ruptured (38, Taf. II, figs. 4, II). This may be due to the fixation. Occasionally the undifferentiated portion of the chromatin reticulum rests also on the nuclear membrane over the whole antipolar region, and this may possibly be regarded as the more normal condition. The nuclear membrane is spherical in such cases, and the only region of clear nuclear sap is that left by the drawing together into a cone of the chromatin threads which are converging on the central body.

In some cases the zone of clear nuclear sap extending around the entire chromatin system, except at the pole, is so wide as to suggest that the nuclear membrane has swelled away from the nuclear contents in fixation. Such figures, assuming that they indicate swelling of the nuclear membrane, give evidence of the firmness of the attachment of the chromatin threads to the central body and of the latter to the cytoplasm, since in well-fixed material the chromatin is never separated from the center nor the latter from the cytoplasm, no matter how wide the clear zone may be about the remainder of the chromatin system.

Sometimes also a clear zone is formed about the nucleus outside the nuclear membrane, such as has been described for the nuclei of Chara; but in this case the central body is neither separated from the nuclear membrane nor the cytoplasm, indicating again its connection with both of those structures. Not infrequently the chromatin threads at this stage show parallel bends and curves, and I find many figures in which the whole system tends to be slightly spirally twisted. There is also some evidence that the threads are arranged in pairs.

When the young ascus has reached the stage shown in fig. 33 , the pair of nuclei fuse to form the primary nucleus of the ascus. The process of fusion can be followed in all its details with relatively great readiness in Phyllactinia, owing to the large number of asci in each perithecium. At the time of fusion the ascus-cell consists of an upper enlarged portion, in which the nuclei lie, and a lower stalk-like portion, which is much narrower and extremely irregular in its shape, twisting about among the wall-cells of the base of the perithecium and connecting with the original system of the ascogenous hyphæ from which it developed. A section of the upper portion of the ascus rarely shows this elongated narrower portion in its entire length, since the two rarely lie in the same vertical plane. Later, with the growth of the perithecium, this stalk-like portion of the ascus swells and becomes a part of the oblong ascus-sac, except at its lowest portion, which still remains as a narrowed foot or stalk. 
The cytoplasm of the ascus is homogeneous and spongy, with no large vacuoles or inclusions at this stage. The nuclei lie rather close together, separated by a less distance than their own diameter throughout the early development of the ascus (figs. 31,32 ). They fuse at a stage just before the penicillate cells begin to sprout out on the upper surface of the perithecium. As they approach each other to fuse, the central bodies may be very variously placed with reference to each othes and to the plane of contact of the nuclei. I have been unable to find any evidence that the position of the centers influences in any way the approach of the nuclei or determines the point of their first contact. The centers are frequently placed facing each other (fig. 3I). In other cases they are separated by 90 or more degrees on the surface of the nuclei (fig. 33). Occasionally, just prior to fusion, one nucleus may be pulled out into a pear-shaped body, with the center at its narrowed end, and this narrowed end may be extended beside the second nucleus. In this case, however, the centers may still be separated by half a circumference from each other.

The nuclear membrane disappears at the point of contact, and the chromatin and nucleoles of the two nuclei thus come to lie in a common cavity. In fig. 35 one chromatin system is drawn out into a long cone, the central body apparently having pushed ahead into the second nucleus, dragging the chromatin after it. The chromatin threads maintain for some time their independent orientation about their separate central bodies (figs. 35-37). The outline of the double nucleus may for a time show a constriction in the plane of fusion; later it may round out on one side before it does on the other (fig. 38). The centers are still variously placed with reference to each other. In rare cases they may even be for a time exactly opposite each other on the surface of the nucleus, with their respective chromatic systems extending toward each other, suggesting the formation of a spindle. Frequently, however, the fusion occurs in such a way that the centers are brought close together at once.

Wherever the centers may be, the masses of chromatin show no tendency at this stage to combine; they may be in contact with each other, but are simply crowded together and show no tendency to unite. Later, in all cases the centers are found lying side by side in preparation for fusing, but the chromatin-thread systems are still quite independent (fig. 38). At this stage, as at the stage just before fusion, it is possible to count approximately the number of threads extending back from each center. There are, as a rule, at least four or five threads lying in about the same focal plane near the median optical section of the system. By focusing up and down at least four more threads can be made out which 
pass up or down from the center so as not to lie in the median plane of the nucleus as a whole. There are then, approximately at least, eight or nine threads in each system just before fusion occurs. The exact number, of course, is difficult to determine in every case, since in such minute objects it is difficult to be sure in focusing up and down that different threads are not confounded with each other in certain portions of their extent, or that some threads do not escape notice altogether by being hidden behind others lying in nearly the same vertical plane.

The two centers can be found closer and closer together, and finally they combine side by side, forming at first a double center, from which the distinct sets of fibers can be still made out (fig. 38). A little later the two sets of fibers are no longer distinguishable (fig. 39). The centers at the time of fusion maintain their ordinary disk-like shape, and it is plain that the fusion figures will have a different appearance according as the centers lie side by side or one above the other. The former are, of course, much more favorable for study.

The nucleoles also fuse at some time during the process of the fusion of the nuclei. They are extremely conspicuous, bright-red globules, dense and homogeneous, and most sharply distinguishable by their red color in the triple stain from the blue-stained chromatin. Each nucleus contains without exception a single nucleole, and when the nuclear membranes disappear in the process of fusion the two may be very variously placed, as shown in the figures. Later they approach or are brought together in the movements of the other parts of the nucleus, and when once in contact they remain together and gradually fuse into a single nucleole whose diameter is conspicuously greater than that of either of the two which fuse. (Compare figs. 31-33 with 36,37 , 39,42 .) If they had a perfectly spherical shape it would, of course, be easy to determine the exact relation of the volumes of the two which fuse with that of the resulting nucleoles. They are, however, frequently somewhat oblong or flattened on one side, and since it is not easy to determine their vertical diameters in any given case, exact measurements of their volume can not be obtained. As is seen from figs. $36-42$, the fusion of the nucleoles may be completed either before or after the fusion of the centers. The nucleoles at this stage always lie outside the chromatin systems and their fusion seems to be an entirely distinct process.

The process of nuclear fusion may be summed up as a union of the two resting nuclei into a single spherical nucleus whose volume is much greater than that of either of the single nuclei, whether or not it is exactly equal to their sum. The nuclear sap of the two makes a single homogeneous non-stainable liquid. The centers fuse into a single larger 
disk-shaped center and the chromatin systems have become intimately intermingled, though there is still evidence for some time of the presence of a greater number of threads in the combined chromatin masses than were present in either of the fusing masses. The nucleoles combine into a single homogeneous nucleole of approximately twice the volume of either of those which combined. The process of union so far has gone on rather rapidly; at least there is no evidence of increased size in the entire perithecium between the stages when the fusion begins and the time when it is completed. The nucleus thus formed is the so-called primary nucleus of the ascus.

The ascus has reached about half its mature dimensions at this stage, but the whole perithecium is rather more than half grown. As noted, the penicillate cells have begun to develop, but the characteristic bulbous-based, spine-like appendages are not yet present. A relatively long period now ensues, leading up to the spirem stage in the prophases of the first division. The nucleus during this period grows with the growth of the ascus and also undergoes characteristic changes, part of which constitute essential stages of the fusion process.

In the nuclei at the time of fusion, and immediately thereafter, the chromatin substance extends through a large part of the nuclear cavity (fig. 39), as was described above for the stage preceding fusion. The chromatin threads are still abundantly connected by fibrillæ, and these seem to become more numerous and delicate, so that their outlines can scarcely be made out and the chromatin strands appear as if they were embedded in a more faintly stained ground substance. As a result the threads become progressively more difficult to follow, and it is less easy to count them. The whole chromatin mass now begins to contract and becomes more dense (fig. 43). This contraction is always away from the antipolar region and toward the center, as if a contraction of the threads had taken place by which they are drawn up to their points of attachment in the center. The antipolar region is thus left almost free of stainable materials except for the large red-stained nucleole. With the completion of this stage of contraction the threads may become more plainly visible (fig. 44), but they are much shorter. Frequently the free ends of the threads stick out from the denser mass and are plainly shown, at this stage at least, not to be connected as loops at their antipolar extremities (fig. 44). Occasionally a thread may extend from the mass as far as the nucleole.

There is evidence in some cases also of the presence of a considerable amount of faintly stained thready material which may appear in section, extending from the surface of the denser mass as a sort of 
fringe. It is plainly identical with the fibrillar material of the earlier stages. This contracted stage lasts for some time if estimated in terms of the growth of the ascocarp.

While the chromatin is thus drawn up to the centers the outlines of the latter are difficult to make out in preparations stained so as to give the chromatin a deep-blue color. The whole chromatin mass in deeply stained specimens may appear as a roughly oval body pressed against the nuclear membrane in the region of the central body. If, however, the staining be modified by increasing the time of exposure to the orange $G$ of the triple stain, until the blue is removed from the chromatin, leaving it a pale-gray, the center appears with its customary disk-like shape and showing a dense violet color. With this treatment the red nucleole and the violet center are the only deeply stained portions of the entire ascus. The chromatin is pale gray and the cytoplasm faintly gray or orange. The appearance of such a preparation is shown in fig. 45. A similar sharp differential staining of the center can be achieved by the use of iron hæmatoxylin, the washing out with the iron solution being prolonged till the chromatin is colorless. Both nucleole and center appear bluish or black with this treatment. Preparations made in this way show the persistence of the center during the contracted condition of the chromatin and demonstrate very clearly the possibility of differential staining of the center by appropriate methods.

It is clear that this contracted stage of the chromatin elements is identical with the synapsis stage in the spore mother cells of the higher plants. Here, as there, it is probably associated with an interaction and combination of the chromosomes prior to reduction, and the evidence from the attachment of the chromatin threads to the center is practically conclusive that the combination occurs by the union of the chromatin threads in pairs side by side. We shall find that the succeeding spirem stage shows chromatin strands of unusual thickness and density.

The contracted condition of the chromatin is followed by a loosening up of the mass and a transition to a very strongly marked spirem stage in the preparation for the first division. As the chromatin mass spreads out again into the antipolar region, and loosens up, it frequently appears for a time as if reticulated (fig. 46). Very soon, however, the threads become more distinct, their apparent anastomoses largely disappear, and they form an irregular cone, with its apex in the central body (fig. 47), such as we found prior to the nuclear fusion. The threads at this stage are, however, much more distinct and sharply outlined than in the earlier stages. There also seem to be fewer of the faintly stained interfilar fibrillæ. It should be noted that all the nuclei in the phase of 
contraction (figs. 43-47) are magnified only by 1,000 , while the figures of the earlier stages, Nos. 31-34, are magnified by 1,500 .

The spirem figure becomes still more definite with the further growth of the nucleus and the ascus till, at a stage when the penicillate cells are well started in their development and the perithecium is nearly full-sized, the ascus nucleus reaches its full size and we get such spirem stages as those shown in figs. 48 and 49. The nuclear structures at this stage are very sharply defined. In these figures I have brought all the threads into the plane of the median optical section of the nucleus, representing those that lie above as darker and those below as lighter and fainter. This makes the figures appear much more crowded and confused than they really are in the preparations. The center is a disk lying on the outer surface of the nuclear membrane, frequently in a slight depression, and from it very sharply differentiated threads pass back and can be traced with the greatest ease into the antipolar region. There is practically no stainable interfilar substance; the threads lie in an unstained nuclear cavity, with nothing to interfere with the sharpness of their outlines. As in earlier stages, two extremes as to the distribution of the threads in the nuclear cavity can be distinguished. In the one case some of the threads follow rather closely the inner surface of the nuclear membrane and others pass more directly to the antipolar region through the midst of the nuclear cavity. This results in a fairly even distribution of the chromatin material in the nucleus (fig. 49). In the other case all or most of the strands pass from the central body through the middle of the nuclear cavity, forming a spreading bundle or irregular cone (fig. 48), and then spread out in the antipolar region. Frequently at this stage, as at earlier stages, the whole bundle may be spirally twisted.

The antipolar ends of the threads are frequently seen to be free. In other cases they are in contact with each other, giving the appearance of being fused or continuous. Not infrequently they are in contact with the nucleole. The end region of a thread may lie on the surface of the nucleole for a short distance, but there is never any indication of a fusion of the substance of the chromatin thread with that of the nucleole. The nucleole is a sharply defined oval body, and the ends of the threads appear to be merely in contact with it.

Superficially, perhaps, the nucleus at this stage bears little resemblance to the spirems figured by Rabl and Flemming for the salamander, or by Strasburger for the endosperm nuclei of Fritillaria and the pollen mother cells of the lily, but there can be no question that this is a spirem stage corresponding to spirems in the cases mentioned and that in the 
conspicuous attachment of the chromatin threads to the central body we have a satisfactory explanation of the unipolar structure of the spirem nucleus. Flemming's schematic figures of the spirem of the salamander are, in the relation shown between the center and the chromatin loops, strikingly similar to the figures shown in the ascus; but no such conspicuous connection between the center and the chromatin strands as is seen in the ascus could be demonstrated by Flemming in the cells of the salamander.

The number of strands of chromatin at this stage can be determined with great certainty. In practically every figure which was studied careful focusing shows that there are just eight threads passing back from the center into the antipolar region. Near the center, of course, they may in some cases overlie and obscure each other, but by tracing them back a short distance toward the antipolar region the number can be made out with unfailing regularity. The number of these strands coincides, as we shall see, with the number of chromosomes in the equatorial plate, and the conclusion seems entirely certain that each of the strands corresponds to a single chromosome, and that thus each chromosome has a permanent attachment to the central body.

A further, rather long, period intervenes between the stage of the fully developed spirem and the equatorial plate of the first division. The perithecium and the asci continue to grow slowly in size, but more marked than the growth in size at this period is the differentiation which occurs in the perithecial cells. The penicillate cells proceed to their fullest size and differentiation as described above. The appendages are developed and the differentiation of the outer, middle, and inner zones of the perithecial envelopes becomes more apparent.

The nucleus remains for some time at the base of the ascus, where the latter narrows to form the short stalk; but as it passes on in its development toward the formation of the chromosomes and the spindle, it generally migrates to a region higher up and nearer the middle of the enlarged portion of the ascus. The further differentiation of the chromosomes now continues. The process seems to be as follows: A more densely staining portion of each thread becomes differentiated at some point in its length, forming an elongated and bent rod-shaped body, which is to become the chromosome. The process of differentiation seems to consist in the drawing together and the aggregation at some point of the more densely staining constitutents of the strand. At the same time a contraction or shortening of the whole thread occurs. The segregation of the more stainable portions of the thread into the chromosomes leaves an achromatic filament or bundle of fibrillæ connecting 
the chromosome to the pole. The process is analogous to the shortening of the chromatin thread, which is common in the higher plant and animal cells in the prophases, but differs from it in the fact that the chromosomes are throughout the process so conspicuously attached to the pole. It is generally agreed that the chromatin thread in the higher plants consists of two substances; but the conspicuous separation of these two constituents during the shortening of the chromatin thread seems to be peculiar to the mildew. Still it is to be remembered also that there is in many cases-for example, in the pollen mother cells of the larch-at about this stage a large increase of linin fibrils in the nuclear cavity, and it is at least possible that these fibrils arise from the spirem thread in the process of the differentiation of the chromosomes. The chromosomes appear now as oblong or irregular bodies connected to the central body by fine pale-blue stained or grayish fibers. They are distributed irregularly in the nuclear cavity, and in a polar view of the nucleus may appear as if supported in an anastomosing reticulum. They may be pressed closely against the nuclear membrane in some cases, and in others they may lie in the central region of the nuclear cavity or may be closely pressed against the nucleole.

The spindle is formed in Phyllactinia essentially as I have described for Erysiphe (38). The central body divides and the daughter centers migrate away from each other on the surface of the nuclear membrane. In Erysiphe and many Discomycetes the nuclear membrane remains intact till the diaster stage. In Phyllactinia, at least in some cases, it may disappear much earlier. The separation of the daughter centers divides the achromatic filaments which connect the chromosomes to the central body into two cones or bundles. This process seems also to bring the chromosomes farther and farther into the antipolar region of the nucleus, where they form a rather dense group connected by broad bundles of fibers with the daughter centers (fig. 52). The bundles or cones of fibers are distinct until near their antipolar ends, where they cross and interlace in connecting with the chromosomes.

This figure resembles that of Hermann (43, Taf. 3 r, figs. 8-9), in which the mantle fibers extend from the spindle poles toward the chromosomes. There is, however, this essential difference, that according to Hermann the mantle fibers are at this stage for the first time extending toward and becoming connected with the chromosomes, while (as we have seen in the ascus) the chromosomes have been continuously attached to the centers through all the preceding stages of nuclear development. Whether there is longitudinal splitting of the individual fibers, or whether they are merely separated into two groups, I have been 
unable to determine. In the case of reduction divisions it would seem probable that the fibers merely separate in two groups. There is no trace of a direct connection between the centers as they separate. There is no evidence of the existence of a differentiated central spindle at this stage. As I have suggested ( 38 ) for Erysiphe, it is possible that, for a time at least, the presence of the nuclear membrane makes a central spindle unnecessary. As to the permanence of the nuclear membrane and the absence of a central spindle in the early stages of the separation of the centers, the conditions in the ascus are similar to those in the spindle formation in the cleavage of the egg of the trout, whitefish, and many invertebrate animals in which the centers migrate to opposite poles of the nuclei before the nuclear membranes disappear. It has, however, been rather generally assumed by students of karyokinesis in these eggs that the connection of the centers to the chromosomes is established by the growth of spindle fibers into the nuclear cavity after the centers have reached their position at the poles. It is interesting to note in this connection, however, that Janssens (49) claims, on the basis of an investigation of the spindle formation in Triton, that even here no central spindle is formed between the separating centers as described by Hermann (43) for the salamander.

The centers continue to separate until they have passed through an entire half-circle and come to lie opposite each other, forming the poles of the spindle. The fibers attached to the chromosomes have shortened at the same time and have drawn the chromosomes up into the middle region between the poles (figs. 53, 54). The nuclear membrane may be still intact in some cases (fig. $67 b$ ) at this stage in Phyllactinia, as it regularly is in Erysiphe. In other cases it seems to have entirely disappeared (figs. 53,54,67a). A remnant of the nucleole may still be present at the equatorial plate stage (fig. 53).

The chromosomes are oblong or oval bodies in the equatorial plate stage and stand frequently in a radial position on the spindle-that is, attached to the spindle fibers at one end and with their long axes at right angles to the long axes of the spindle. They are small as compared with the size of the spindle and generally lie entirely free from each other, so that they can be very readily counted (fig. 53). The number is quite regular and corresponds with the number of strands attached to the central body in the spirem stage. These figures agree with those I have already published for other Ascomycetes in showing the incorrectness of Maire's (6I) and Dangeard's (2I) claim that the Ascomycetes have regularly four chromosomes. The spindle fibers 
now stain more deeply than in the prophase stages and appear blue or violet in the triple stain.

In describing and figuring the three successive divisions of the nucleus of the ascus $I$ have had a great abundance of figures at my disposal and have chosen to select those stages in each division which mutually supplement each other rather than to give a full series of stages in any one division. In this way the evidence that the number of chromosomes is the same throughout and that the central bodies are present at each stage is brought out more clearly.

If we compare the chromosomes in the equatorial plate with the spirem strands in the prophases we get evidence of a great reduction in volume. This may, of course, be partially due to condensation of their substance, although in reality the spirem strands (figs. 48, 49) appear quite as dense as do the chromosomes in the equatorial plate. However, as we have seen, the formation of the chromosome from a strand of the spirem consists in the segregation of two substances present in the spirem. The densely staining chromatin aggregates in the chromosomes, leaving the achromatic portion as a series of threads connecting the chromosomes to the central body, and these threads later form the spindle.

Following the equatorial plate stage, the chromosomes are drawn back to the spindle poles, and during this process again their number may be easily determined. Fig. 54 shows an early metaphase in which the daughter chromosomes are beginning to separate. In fig. 55 it is perfectly plain that sixteen daughter chromosomes are being drawn back to the poles, eight on each half of the spindle. These figures are abundant in the mildews and are very easily fixed and stained. Maire has evidently seen more than four chromosomes in many cases in the prophases, but maintains his contention by calling these more numerous bodies "prochromosomes" and asserting that they later fuse into four true chromosomes. He will hardly maintain, however, that the bodies shown on the spindle in fig. 55 are prochromosomes, and there can be no question that there are at least eight of them on each half of the spindle. With poor fixation it is possible to find the chromosomes of the mildew fused together into irregular masses, as may happen also in the pollen mother cells of the larch or lily, and it is doubtless such cases of poor fixation which have misled Maire and Dangeard. The polar asters at these stages are very strongly developed, and it is apparent that some of the astral rays extend to the plasma membrane of the ascus.

The central spindle fibers left after the chromosomes have reached the poles seem to disintegrate and pass over into the general cytoplasmic 
substance (figs. 56,57 ). Frequently they may be much elongated by further separation of the young daughter nuclei, but this is not necessary to their disappearance.

The chromosomes are next found loosely aggregated at the poles and still plainly connected to the central body by the fibers which drew them back from the equatorial plate region (fig. 56). This results in a sort of diaster stage (fig. 57), though the significance of the name does not appear in any conspicuous arrangement of the chromosomes.

A nuclear membrane is next formed, close in to the surface of the chromosomes at first, but soon expanding so that more or less clear space appears around the mass. The chromosomes themselves seem to be the cause of this enlargement. They grow in length backward from the center, at the same time swelling and becoming somewhat irregular and knotted (fig. 58). As a result we get at once a rough duplicate (fig. 59) of the spirem stage of the prophases. From the central body coarse, irregular threads are seen extending back into the enlarging nuclear cavity.

I have studied these stages carefully, and it seems very clear that we have here, in reverse, the same process by which the chromosomes were segregated out of the spirem-strands of the prophases. The substance of the chromosome is being redistributed in the rapidly growing achromatic linin substance. The general resemblance between the conditions in figs. $5^{8-59}$ and $47-48$ is certainly noteworthy and shows clearly that the chromosomes in passing over into the so-called resting-stage in the reconstitution of the daughter nuclei do not lose their connection with the central body.

As the reconstitution of the daughter nuclei progresses, the nucleoles reappear and the distribution of the chromatin becomes progressively more irregular. The strands become longer and apparently may become more or less connected by anastomosing fibrillæ. The connection with the central body is, however, still perfectly definite and conspicuous (figs. 60, 6r). The irregularity of the strands may be interpreted as due to a diminished tension in their connection with the central body as compared with the prophase stages. Ultimately the chromatin may become quite evenly distributed through the nuclear cavity, and from the polar view appears much like an ordinary reticulum. But the constant conspicuous attachment of the strands with the central body is maintained even though, as is quite commonly the case, the nucleus projects on that side in a short cone or papilla (figs. 59-6I).

As in the nuclei of the ascogenous hyphæ, the attachment of this apparent reticulum to the center becomes especially conspicuous if the 
reticulum is for any reason drawn together and away from the nuclear membrane. In such cases the chromatin threads are always attached to the center, though they may be drawn away from the membrane everywhere else. This condition is also conspicuous in the figures of Erysiphe which I have already published. The polar asters through these stages are very sharply differentiated, the fibers extending in some cases almost, if not entirely, to the plasma membrane of the ascus (figs. 55-6r).

The daughter nuclei formed by the division of the primary nucleus of the ascus, as just described, never grow to the size of the mother nucleus. Their volume is apparently not more than one-half that of the primary nucleus. As a rule they divide again immediately, though in some cases apparently a considerable period may intervene.

Fig. 62 shows an early stage of the spirem of the nucleus in the binucleated stage of the ascus; and fig. $63 a, b$ shows a stage in the separation of the daughter centers and the formation of the spindle. The chromosomes appear as oblong, densely stained, bent or irregular bodies in a fairly dense group in the antipolar region. The group was cut in two in sectioning and is reproduced in the two figures $(63 a, b)$. The halves of the spindle appear as broad series of fine achromatic fibers and the centers have their characteristic flat, disk-shaped form. The stage is a little earlier than that shown in fig. 52 for the first division. It differs in that the nuclear membrane is in this case still partially present, though breaking down in certain portions. Fig. 64 shows a somewhat later stage, in which the centers are farther apart and the halves of the spindle diverge at a correspondingly greater angle. In this case the polar asters appear as well-developed systems of fibers radiating from the central bodies into the cytoplasm.

Fig. 65 shows the two nuclei of the ascus in the equatorial plate stage. The upper spindle lies in the plane of the section and the lower is cut through obliquely, so that only one pole and one half of the spindle appear in the section. As is to be seen, eight chromosomes are present at this stage also. In Phyllactinia, as in all the Ascomycetes I have studied, the number of chromosomes remains the same through all three divisions of the primary nucleus of the ascus. Fig. 66 shows a further stage in the division of the two nuclei. One spindle lies in the long axis of the ascus and the other almost transversely and in the upper end of the ascus. As a rule only two spores are formed in the ascus of Phyllactinia; and a study of the further stages shows that both the daughter nuclei produced from this transverse spindle will remain in the upper end of the ascus and fail to become centers for spore forma- 
tion. In this upper spindle the chromosomes are a little nearer the poles than in the lower one, but in both either seven or eight chromosomes can be made out in each group.

Figs. $67 a, b$ show three nuclei from an ascus in the four-nucleated stage. They are all in the stage of division when the daughter chromosomes are just separating out of the equatorial plate. Fig. $67 a$ shows one profile and one polar view of the spindles which lie at the upper end of the ascus and are destined to form supernumerary nuclei. Fig. $67 b$ shows a somewhat larger spindle figure which lies near the center of the ascus. It is probable that both nuclei formed from it will become centers for spore formation. In this division also the chromosomes can be counted with perfect certainty as they are drawn back to the poles. Fig. 68 shows two nuclei at this stage, and in each of the four daughter groups seven or eight chromosomes can be counted.

In both the second and third divisions it is plain that the central body continues in the same relation to the chromatin as in the first division and the fusions which preceded it. The figures in the two and four nucleated stages are not so favorable for counting the number of strands in the spirem stage of the prophases by reason of their greatly diminished size, but as to the main fact, that the central body maintains a continuous connection with the chromatin, just as in the first division, the evidence is perfectly conclusive.

As noted above, only two spores are formed as a rule in the asci of Phyllactinia. This leaves six supernumerary nuclei which disintegrate in the epiplasm. Generally these supernumerary nuclei at the time of spore formation are all in the peripheral end of the ascus, while the two nuclei which are to become the centers of the two spores are rather above the middle of the ascus. The supernumerary nuclei frequently are pressed against the wall of the ascus, with their central bodies on the side next the wall. Later several of these supernumerary nuclei are frequently found lying in a bunch free in the cytoplasm.

The process of spore formation is especially well shown in the asci of Erysiphe cichoracearum, and I have included for these stages some figures from this species with those from Phyllactinia. Figs. 80 and 81 are from $E$. communis. The polar aster from the third division persists in all the eight nuclei for some time, but is most conspicuous in the case of the nuclei which are to be inclosed in spores (fig. 69). A beak is next pushed or pulled out from the nucleus, which is generally already pear-shaped, as in the corresponding stages in the earlier divisions (figs. 70, 71, 72). 
The metamorphosis of the polar aster in Phyllactinia and Erysiphe cichoracearum is entirely similar to that in Erysiphe communis. In view of the above-described facts as to the connection between chromatin and central body at other stages, it is interesting to note that in the protrusion of the nuclear beak the same condition comes most strikingly to view. The beak is not merely an extension of the nuclear membrane, but the chromatin is also pulled out as slender strands in the beak and maintains its connection with the central body through the whole process of the delimitation of the spore. This is very clearly shown in both Erysiphe and Phyllactinia (figs. 70-78).

The central body on the apex of the beak is very broad and flat in Phyllactinia (fig. 72). Its diameter is apparently greater than that of the outer portion of the beak. I have occasionally found cases in which the central body had divided at the end of the beak and the fibers were also separated into two systems (fig. 80). Whether this condition would be followed by normal spore formation I have not determined. It shows the capacity of the centers to divide and seems to indicate that such division separates the fibers into two groups without splitting each fiber.

The process by which the beak is formed on the nucleus is not easy to understand. I have elsewhere discussed (38) the possible methods by which such a beak-like elongation may be pulled or pushed out from the surface of the nucleus. My observations on Phyllactinia and E. cichoraccarum incline me more strongly to the view that it is formed by the activity of the aster rather than by any spontaneous change of form in the relatively inert nuclear mass.

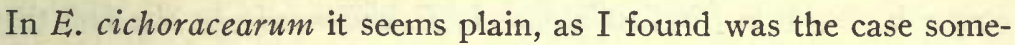
times in Lachnea and Pyronema, that in some cases, at the time of the formation of the beak, the center and aster may be in close contact with the plasma membrane of the ascus (figs. $69,73,74$ ), just as is quite regularly the case with the supernumerary nuclei (figs. 70, 73, 8I). The folding over of the rays may begin while the centers are in this position and may seem to be a result of the flattening of the aster against the membrane of the ascus (figs. 73, 74).

In Phyllactinia the beaked nucleus and aster seem much more commonly to lie free in the cytoplasm from the start (figs. 70, 71, 72). Occasionally, even when the center is quite distant from the plasma membrane, a broad depression is found in the latter just opposite the center, as if the astral rays were attached to it and by contraction had pulled it away from the cell-wall (fig. $7 \mathrm{r}$ ). In the later stages in all cases the whole system is found lying free in the cytoplasm and generally at some distance from the wall of the ascus. It is quite possible that 
while in contact with the plasma membrane of the ascus some of the material of the latter may pass over into the rays and thus aid in forming the membrane of the spore. There is, however, no break in the plasma membrane of the ascus as a result of any such possible participation in the formation of the new spore membrane. The membrane of the ascus remains as a continuous envelope of its cytoplasm, and there is no apparent loss of turgidity in the latter. In Phyllactinia also it is quite common to find the cytoplasm very loose and showing large vacuoles in the neighborhood of the beaked nuclei (figs. 7o, 72). These spaces may represent the remains of the nuclear cavity of the preceding mother nucleus. This looser cytoplasm is sharply bounded by the inner rays of the aster (figs. 70,72 ).

The stages in the process of the folding over of the rays and their union to form the plasma membrane of the spore are very well shown in E. cichoracearum. The rays become elongated during the process by growth which apparently proceeds from the central body outward, and at the same time they fold over and combine side by side to form a continuous broad, umbrella-shaped membrane (figs. 74, 8I). Sometimes the rays on one side seem to be in advance of those on the other in the process of inclosing the spore-mass (fig. 73). If, in folding over and elongating, the rays of one center come in contact with those of another, they tend to fuse, at least temporarily (fig. 74). Later, however, they must separate again, since one almost never finds spores with two nuclei, while such conditions as those shown in fig. 74 are not uncommon.

That the rays actually combine to form a membrane in these early stages is shown in Phyllactinia, as in E. communis, by the fact that the polar region of the spore may draw away from the adjacent cytoplasm as a result of fixation before the spore is entirely delimited. The broad, umbrella-shaped membrane shown in figs. 74 and 81 gradually closes in to form, by further marginal growth, the ellipsoidal plasma membrane of the spore (fig. 75). The whole spore body is cut out of the previously undifferentiated cytoplasm of the ascus by the formation of a new plasma membrane derived from the fibers of the polar aster and without the deposition of a cellulose wall. In this case, as in animals and the higher plants, the process of cell division consists in the formation of new plasma membranes which, in the latter at least, originate as a socalled cell plate from the fibers of a portion of the karyokinetic figure.

Such a process of migration of the astral fibers demands the assumption that they are contractile elements comparable to cilia, even though we have not as yet sufficient data on which to carry out such a comparison in every detail. The abundant evidence which has accu- 
mulated in recent years, in both animals and plants, that the ciliary apparatus of the male cell arises from a more or less modified central body, is strong ground for the acceptance of this view. Further, the process of transformation of the polar aster into an ellipsoidal membrane is to be compared with other cases of intra-cytoplasmic migrations, such as those of the central spindle fibers in building the cell plate and the migrations of the asters of the sperm cell in the animal egg in the processes of fertilization. Though the resemblances in all these processes are not yet clear, we certainly have sufficient ground for assuming that the fibrous material concerned in them all constitutes a specially differentiated material of the cell-the kinoplasm.

That the spore as at first formed has no cellulose wall is well shown in cases in which it is plasmolyzed in fixation. In such cases the separation of the spore-plasm from the epiplasm is complete and there is no trace of a cell-wall in the cleft so formed. The surface of the plasmolyzed spore shows the same continuity as we find in the surface of the protoplast of the ascus, and there can be no doubt that the spore boundary formed by the fibers of the polar aster, even at this early stage, is essentially similar in its nature to the layer bounding the entire ascus or other cells of the mycelium.

Whether the material of the fibers has undergone a chemical change in forming this continuous membranous layer is difficult to determine. That their staining reactions change somewhat seems fairly evident in most cases. As fibers of the polar aster they take the blue color in the triple stain. On the surface of the completely delimited spore it is difficult, if not impossible, to distinguish a layer differently stained from the spore-plasm which it surrounds. Still occasionally, in the triple stain, this layer does show a bluish-gray tint somewhat clearly differentiated from the gray or faint orange of the inner spore-plasm. If, as Overton $(73,74)$ concludes, the outer layer of the protoplast is a cholesterin-like substance or is impregnated with such a substance, it must probably be assumed that the kinoplasmic fibers undergo a decomposition in forming the limiting layer of the spore. On the other hand, the fact that these fibers maintain their identity and do not mingle with or dissolve in the cytoplasm about them while they form the polar aster is sufficient evidence that their substance is capable, without chemical change, of forming an osmotic layer sufficiently differentiated to separate the spore-plasm from the remaining cytoplasm, at least to an extent which would permit the plasmolyzing of the spore mass.

In the case of these preparations with shrunken spores we can make out, by careful observation, in some cases, an interesting difference 
between the surface of the spore and that of the epiplasm from which it is drawn back. The surface of the spore is plainly smooth and continuous, while that of the epiplasm is slightly ragged and irregular, indicating that the spongy cytoplasmic reticulum has been cut through without closing the interstices of the epiplasm, either by the rounding out of reentrant cavities by surface tension or by the deposit of a surface layer of material to close such openings. The spore-plasm is evidently inclosed and smoothly enveloped by the material of the polar fibers, while no such substance has been deposited on the corresponding surface of the epiplasm.

After the spore is completely inclosed the remnant of the fibers disappears from the region about the central body (fig. 76). The latter then breaks away from the plasma membrane and the nucleus gradually regains its spherical or oval shape by drawing in the beak-like prolongation. The stages in this process are very well shown in Phyllactinia (figs. 77, 78). The central body comes thus to occupy its old position on the surface of the spherical nucleus. The chromatin is apparently at this stage an irregular reticulum, but is always attached to the central body. It is frequently drawn back from the nuclear menibrane into an irregular mass on all sides, except where it is attached to the central body (fig. 79). Later a wall is built around the spore and a resting condition ensues which lasts till the bursting of the perithecia in the following spring. The connection of chromatin and center can be observed in favorable preparations in the fully matured spores, but these stages, owing to the presence of the spore wall, are less easily fixed than the earlier ones. In the fully ripened condition a considerable amount of reserve material is deposited in the spore-plasm, which thus becomes quite different in its composition from the surrounding epiplasm.

The germination of the ascospores into a vegetative mycelium completes the life cycle of the mildew. The nuclei of the mycelial hyphr, as already described, show the same polar structure, with the chromatin directly connected with the central body, which we have traced through the stages in the development of the ascocarp. We thus have a fairly continuous account of the existence of the central body and the maintenance of its connection with the material of the chromosomes through two nuclear fusions in the oogonium and in the young ascus, through a series of divisions in the ascogenous hyphae, and the triple division in the ascus, and finally through the formation of the ascospores by free cell formation. This constitutes the longest and most varied series of stages through which the central body of a plant has yet been traced. 
THEORETICAL DISCUSSION.

THE CENTRAL, BODY IN PHYLLACTINIA.

We find in the above-described series of nuclear fusions and divisions not alone the persistency of a central body as such, but a center that remains throughout in intimate and organized connection with the chromatin content of the nucleus. The center is not a naked granule or centrosphere which can be distinguished only with difficulty from other stainable granules in the neighborhood of the nucleus. It constitutes throughout a point of attachment for the elements of the nucleus, and in all the various modifications which it and they undergo in the processes of division and fusion this relation is maintained in the most definite fashion. The central body by its position determines in an important sense a definite polar organization on the part of the chromatin, and thus of the nucleus as a whole. At no stage in its development is the nucleus of Phyllactinia an isotropic or radially organized body. In every stage the chromatin is definitely attached to either one or two central bodies on the periphery of the nucleus. The nucleus is hence strictly unipolar throughout its so-called resting stages, becoming bipolar by division of the center for the formation of the two daughter nuclei. We can thus distinguish throughout its history both polar and antipolar regions in the nucleus. The position of the central body on the nuclear membrane is characteristic of the fungi, and the greater readiness with which a permanent connection between the nuclear elements and the center can be demonstrated in them is no doubt associated with this fact.

Further, it is plain that the chromatin elements are throughout definite in number and each one is attached independently to the center. In the so-called spirem stage each chromatin element consists of a relatively thick thread or strand, which is attached at one of its ends to the center, from which it extends back to the antipolar region of the nucleus, where it ends freely, or may be loosely joined to the other strands, or lie in contact with the nucleole.

In the reconstitution of the daughter nuclei, from the diaster stage on, the chromosomes elongate and pass back into their more diffuse condition without losing their connection with the center; and even when the daughter nucleus passes into the complete resting condition and the chromatin strands apparently anastomose by fibrillar outgrowths 
to form what may appear to be a chromatic reticulum, its attachment to the central body is still conspicuous and indicates that each strand maintains its separate and individual connection with the nuclear pole. In favorable preparations close analysis of the resting stages show considerable evidence that the eight chromosomes are still to be differentiated as constituting the main strands of the reticulum, though they may be quite irregular in their outline and connected by anastomosing fibrillæ. The central bodies are thus seen to be permanent structures of the cell during both the dividing and resting stages of muclear development.

In the processes of nuclear fusion in Phyllactinia the permanence of the central body is also evident. In the vegetative nuclear fusions in the young ascus each nucleus has a conspicuous polar structure and central body at the time when the nuclear membranes break down and the nuclear cavities combine. The fusion nucleus thus formed has for a time two centers and two independent systems of strands of chromatin. These, however, gradually approach and combine into a single centered system with one central body. The centers fuse and the chromatin strands combine, so that the fusion nucleus has one central body and the same apparent number of strands of chromatin as each of the nuclei which combine to form it. In the sexual fusion at the initiation of the ascocarp we find both antheridial and egg nuclei provided with conspicuous centers. When the pronuclei are lying side by side in the egg their centers are also still present. The small size of the nuclei and of the whole sexual apparatus at this stage makes it difficult to trace the stages in the combination of the pronuclei, but the fertilized egg-nucleus shows conspicuously a single center, and it seems probable that here, as in the fusion of the ascus, this center takes its origin in the union of the centers of the fusing nuclei. The permanence of the centers throughout the remaining stages in the life history of the fungus, and especially their definite connection with the chromatin content of the nucleus, makes it highly improbable that either one of them should disappear and be replaced by the other during the process of fertilization.

In the process of spore formation by free cell division the center is also constantly and conspicuously present, and we are justified in concluding that in Phyllactinia the central body is a permanent cell structure maintaining its identity through the whole life history of the plant, involving the varied processes of nuclear division, nuclear fusion, and free cell formation. This, of course, does not necesarily imply the individuality of the center in the sense that it is to be considered an elementary organism or even an organ with complex internal structure, such as we seem bound to conceive is present in the chromosome. The 
facts seem adequately accounted for by the conception that the central body is a more permanent cell element composed of the same kinoplasmic material which is found in the polar rays and spindle fibers.

I am of the opinion that the various activities shown in spindle formation and the movement of the chromosomes, as well as in free cell formation, are to be regarded as functions of the individual contractile kinoplasmic fibrillæ of the spindle and asters rather than of the centers in which these fibers meet and are combined. The determination of a constant fibrous connection between the central body and the chromosomes is a strong point against the so-called dynamic theories of the centrosome. In such a system we have no need for the assumption of any radially working force which goes out from the sphere as a dynamic center. The motions of all the bodies connected with the center are much more adequately provided for by the assumption of contractility in the kinoplasmic fibers which connect them to the center. This contractility is to be compared to that of the cilia and the elements of the muscle cell. The comparison of the kinoplasmic fibers to cilia or muscle elements suggests further that the fibers need not necessarily be arranged in centered systems, and indeed we have abundant evidence in the higher plants that the kinoplasmic fibers may perform their characteristic functions in nuclear and cell division without the presence of a central body. Under this conception of the central body, the types of spindle formation in the vascular plants on the one hand and in the fungi and alga and the animals on the other can be brought together.

The conception of a unipolar structure of the resting nucleus plainly can not apply to the nuclei of the higher plants, whose spindles are formed from a perinuclear weft of fibers. Still, it is by no means impossible that a permanent connection between the chromatin elements and the surrounding material of the cytoplasm by kinoplasmic fibrillæ exists also in these cases. There is considerable evidence in the prophases of division in the pollen mother cells of the larch, as shown by Allen (I), that the fibers of the cytoplasm which later form the spindle are connected through the nuclear membrane with the chromosomes. The difficulty in understanding how the daughter chromosomes in turn become attached to fibers from one pole only of the spindle, unless the chromosomes occupy definite regions in the nucleus and are permanently attached to the kinoplasmic fibers, is just as great here as in the case of the formation of the spindle in animal cells. Still, Strasburger (89) holds that in the vegetative divisions in various root tips the nuclear membrane disappears at the poles and the spindle fibers grow 
in and attach themselves to the chromosomes or meet and form the central spindle fibers extending from pole to pole.

The figures of Swingle (92a) seem decidedly to favor the view that in Stypocaulon the spindle fibers form new connections with the chromosomes by growing in from the poles at each mitosis. The same is true of the spindle formation in the first division of the tetraspore mother cell of Dictyota, as described by Mottier ( 67$)$. On the other hand, the same author's figures of spindle formation in the second division seem to agree closely with the corresponding stages in the ascus.

PERMANENCE OF THE CHROMOSOMES.

It is evident that the resting reticulum of the nucleus of the mildew contains at least two elements, and that the chromosomes of the equatorial-plate stage are formed from the chromatin of the resting and spirem stages by the segregation of a less stainable naterial-the lininand a denser, more stainable material. The latter becomes condensed into the oblong chromosomes connected to the central body by bundles of achromatic threads. The formation of the spirem is a process in which the principal strands of the reticulum come more prominently into view as a result of their contraction while attached at one end to the central body. In this process they lose the fibrilla by which they were connected to form the resting reticulum and become sharply defined, highly stainable threads lying in an entirely achromatic nuclear sap.

The material of each chromosome is still distributed at the spirem stage through the whole length of the strand out of which it is later segregated. The withdrawal of this chromatic material into the compact body of the chromosome leaves the spirem strand as a thin achromatic fiber or bundle of fibers connecting the chromosomes to the pole. Whether in the division of the central body and separation of the daughter centers to form the poles of the spindle the achromatic fibers are split longitudinally or are merely separated into two bundles is not clear from my preparations. It is, however, plain that each chromosome is from the start connected with both poles, and that provision is thus made for the separation of the daughter chromosomes and their withdrawal to the poles of the spindle to form the daughter nuclei.

During the separation of the daughter centers no so-called central spindle is present, but in the anaphases central spindle fibers running through from pole to pole are conspicuous; and they persist until the daughter nuclei have begun their independent development, being then apparently gradually disintegrated. How these central spindle fibers arise as distinct from the fibers which draw the chromosomes to the poles is not clear. 
In the fusion of the nuclei of the young ascus the generally parallel position of the strands of the two chromatin systems at the time the centers unite leads naturally to the assumption that the individual strands are combined side by side, so that the number of the chromosomes is not, apparently, doubled in the fusion nucleus. The fusion of the male and female pronuclei probably proceeds in the same fashion, so that here again the chromosome number in the fertilized egg will not appear to be doubled, though the individual chromosomes must be regarded as bivalent structures. The details of this fusion I have not as yet been able to make out, but, since the chromatin of the pronuclei is plainly attached to the centers, just as in the fusion in the ascus, it is probable that the method of combination is the same in both.

The evidence given above, that the chromosomes are in continuous connection with the central body in the resting-stages, as well as when dividing and fusing, is fairly conclusive that in Phyllactinia, and presumably in other mildews, the chromosomes are permanent cell structures. The facts which favor the doctrine that the chromosomes are everywhere permanent cell organs have accumulated very rapidly and from many sources in recent years. This evidence, both from older and more recent authors, as to permanency of size, number, form, position in the nucleus of the whole series of chromosomes, and the further remarkable facts of chromosome differentiation in size, form, etc., as described by Henking (42), Montgomery (66), and others for the accessory chromosome, and by Sutton (92) for the whole series of chromosomes in Brachystola, has all been fully summarized and its significance critically estimated by Boveri (13). Still more recently Rosenberg $(8 \mathrm{I} a)$ has described the existence of chromosomes of unequal size in Listera. The vegetative cells here show regularly Io large and 22 smaller chromosomes.

We have in these newer facts not only proof of specific differences between chromosomes, but indisputable evidence that individual chromosomes are perpetuated as such from one cell generation to another. It is a question, however, whether Boveri is justified in combining with the conception of the permanency of the chromosomes as cell structures the further doctrine that they are individual and elementary organisms leading a relatively independent existence in the cell, and thus in a sense comparable in their individuality to the cell itself. It is doubtful whether the facts of permanence in number, form, position in the nucleus, etc., even suggest any such conclusion.

The conception of the cell as made up in whole or part of more elementary independent organisms is not a necessary conclusion from, 
nor to be confused with, the conception that the cell mechanism contains definite and permanent parts with specific functions. It may even be a question whether it is advisable to call such parts of the cell organs, since they are not to be compared morphologically to the organs of multicellular plants or animals.

The most specific evidence which Boveri advances for his conception is the fact that the chromosomes grow and can thus be said to have a youthful and an adult condition and that they reproduce by division. These are interesting analogies with the cell itself; but the cytoplasm as a mass also grows from the size it has in the daughter cell to its size in the adult cell, and it is reproduced by division; still, it adds nothing to our understanding of the cytoplasm to call it an individual organism in the sense in which we so characterize the cell. Reproduction by division and growth are necessary characteristics of any even relatively permanent portions of cells which assimilate, grow, and divide. It is to be remembered, further, that the permanency of the chromosome means only the continuity of a structure which is undergoing continually its own series of cyclic changes in resting-stage, mitosis, fusion, etc. It is doubtless susceptible to minor alterations due to its changing environment, and is an active seat of metabolic changes. And further, as to the significance of such external features as permanence in number, size, form, and position in the nucleus for the functions of the chromosomes in determining, through heredity, the structure and functions of cells and cell colonies, we have as yet little positive evidence. It is not impossible that the organization of the chromatin is a matter of molecular rather than a grosser structure. The doctrine of permanence of the chromosomes as structures of the cell does not necessarily carry with it the assumption that the chromosomes are themselves composed of such differentiated structures, as is the cell.

The evidence summarized by Boveri, while it is entirely convincing as to the permanence of the chromosomes in the resting condition, is almost wholly inferential and based on their appearance in constant number, form, size, etc., in the division stages. Rosenberg (8I) has recently brought very interesting direct evidence that the chromosomes are present as definitely differentiated structures in many nuclei in the resting condition. He finds that in the resting nuclei of Capsella, Zostera, Calendula, and other plants the resting nuclei show a series of sharply differentiated masses of the same number as the chromosome number for the species-32 for Capsella, I2 for Zostera, 32 for Calendula-and represent a form in which the chromosomes persist from one 
nuclear division to another. Rosenberg says nothing as to how the chromosomes become connected with the spindle fibers.

All the earlier evidence that the chromosomes are permanent structures in the cells of the higher plants and animals, except that of Rabl and Flemming, has been developed from a study of the form, number, appearance, etc., of the chromosomes themselves as they recur in each dividing stage, and does not rest on any proof of the structural relations in the nucleus by means of which, in all the manifold changes of fusion and division, such permanence is assured.

The nature of the mechanism by which the scattered chromatin elements of the so-called resting condition are brought back into the definite form and positions which the chromosomes occupy in the karyokinetic figures has been left undetermined. Boveri (IO, II) puts the question as to the possible nature of these structures clearly, but is compelled to resort to numerous accessory hypotheses in order to account for the regularity with which the chromosomes reappear in the same positions and number after their apparent total disintegration in the resting reticulum and the certainty with which each daughter chromosome is found attached to one, and only one, of the poles of the spindle. He assumes a peculiar affinity on the part of each daughter element by which it is predetermined that the fibers from a particular pole will become attached to it, and, further, that there is an especial handle ( Henkel) on each daughter chromosome, by which alone the fibers may become attached to it; if a fiber from one pole has once gotten hold of the handle on one daughter chromosome, those from the other pole are excluded from it; and, further, other fibers from the same pole are unable to get hold of the handle on the other daughter chromosome of the same pair, etc. It is hardly necessary to remark that the complexity of the mechanism by which such a series of affinities and capacities could be brought into effective action is well-nigh inconceivable. Boveri, in I888 (IO), and again in I897 (II), decided against the possibility of a permanent connection between centers and chromosomes in favor of the above hypotheses, and reaffirms his old position in his most recent contribution on this subject.

It is further interesting to note that the theory of the polarity of the cell which has perhaps been most discussed in recent years-that of Heidenhain (4I)-leaves entirely untouched the question of the organization of the nucleus, and further assumes not only that there is no permanent connection of the central body with the nucleus, but that the organization of the cytoplasm is entirely independent of that of the 
nucleus in the resting condition. The nucleus lies in the cytoplasm as a ball pushed between the organic rays, none of which are connected with it. Heidenhain (4I, p. 504-505) avowedly leaves untouched the question as to how the spindle fibers become attached to the chromosomes, but is positive that there is no fixed relation of position or connection between the nucleus and center in the resting condition. $\mathrm{He}$ plainly feels the weakness of his position on this point, and resorts to a doubtful analogy in pointing out that the discontinuity of nucleus and center in the resting condition, which passes over into a continuity in mitosis, is no more difficult to understand than that independent cells, i. e., muscle and nerve, may become connected in ontogeny.

Heidenhain's mechanical theory thus breaks down at a critical point. The system of organic rays is strictly a cytoplasmic system, and yet the most important process in mitosis is the division of the chromosomes. Rabl had both these factors of cell organization in mind, but his own observations were directed most successfully to the establishment of the polarity of the nucleus. In view of these facts it is hard to see the basis for Heidenhain's low estimate of Rabl's work (4I, pp. 698-702).

Against the sweeping contentions of Boveri and Heidenhain there is, none the less, an abundance of evidence to be found in the work of some of the best students of the animal cell. Meves (63, p. 47) holds that the connections between centrosomes and chromosomes by the so-called mantle fibers in the spermatocytes of the salamander are visible much earlier in the prophases than Hermann (43) admits, and accepts the conception that the mantle fibers arise directly from the linin network. Kostanecki $(53,54)$, developing still further the conception of a system of organic rays advanced by Heidenhain, holds that all the fibrous elements of the karyokinetic figure are reproduced by longitudinal division during mitosis, and regards each ray and spindle fiber as a permanent cell structure.

Conklin, who has studied the mutual relations of the cell structures more fully than any other investigator and has shown the relative positions of nucleus, centrosome, sphere substance, etc., through the restingstages as well as in karyokinesis, holds (17, p. I06) that it is evident that some kind of connection exists at all stages of the cell cycle between the centrosome and the nucleus. He further states that "whether this connection during the rest is in the form of fibers (possibly a persistence of those which previously connected centrosome and chromosomes) or is the expression of some other mechanical action or of chemotropic attraction, does not appear from my studies." Conklin 
maintains ( 17, p. I08), also, that in the rotations which occur in the telophases the centrosome and sphere and the nucleus present their same sides to each other throughout.

Of the more prominent workers on the subject of the mechanism of karyokinesis who have obtained positive evidence of a permanent connection of the nuclear content with the centrosome may be mentioned Rabl, Flemming, Meves, Kostanecki, and Conklin. Those who believe that the contractile fibers each time form a new connection with the chromosome include Van Beneden, Boveri, Hermann, Drüner, and many other recent students of nuclear division in animal cells.

Montgomery (65) and Paulmier (75) hold that the connection of the spindle fibers with the chromosomes persists between the first and second maturation divisions. Boveri (13) also accepts this view and believes that thus the chromosome reduction is effected in the second division, regarding this case as an exception to the general rule. Paulmier holds that in the first division the spindle fibers arise by a special orientation of the linin of the nucleus.

Jenkinson (50), who has approached the question with quite different preconceptions as to cell structures, and whose results are certainly unreliable on many points, finds that in the origin of the cleavage spindle of the axolotl the membrane of the sperm nucleus appears weakened or wanting on the side where the centrosome first appears, and that the centrosome is here so close to the nucleus as to appear as if emerging from it.

\section{THE NUCLEAR FUSION IN THE ASCUS.}

The evidence from the series of figures showing the nuclei of the ascogenous hyphæ in their later stages of development, as given above, indicates that the fusion of the nuclei in the young ascus does not result in doubling the number of chromosomes as they appear in the succeeding divisions, and in this respect this nuclear union differs fundamentally from any sexual fusion of nuclei in the higher plants or animals in connection with which the chromosome number has been yet established. There is no visible doubling of the number of chromosomes in the ascus, and while we must assume that the combining chromosomes maintain their identity, the centers unite so intimately that at least nothing of a double organization is visible. On the other hand, the fusion of the ascus is followed at once by a synapsis stage and a triple instead of the ordinary double division of the spore mother cell. We have thus an immediate apparent reduction of the number of the chromosomes by one-half, the 16 chromatin strands of the fusing nuclei appearing as 8 strands in the spirem stage of the fusion nucleus and 
as 8 chromosomes in the equatorial plate a little later. Doubtless in the lower algæ and fungi cases of sexual fusion, followed by immediate reduction, may exist, but not in connection with any such elaborate differentiation of fruit-forms as we find in the conidia and ascocarps of the Ascomycetes.

In the oogonium of the mildew, on the other hand, the fusion of sexual nuclei from separate gametes is not followed by any evidence of reduction processes, but results in a vegetative growth plainly comparable to the development of a sporophyte generation, as has so many times been suggested by the older authors. I have not been able so far to count the chromosomes in the fertilized egg-nucleus, but in the growth of the ascogonium and ascogenous hyphæ before the ascus is formed there is no evidence of the existence of any synapsis stage or special double division, such as is now universally recognized as associated with the process of chromosome reduction. We shall see also that there is evidence for believing that the chromosomes of the nuclei which fuse in the ascus are already bivalent structures as a result of the previous nuclear fusion in the oogonium.

We must note, as bearing on this point, that while the process of fertilization, in all cases -where it has been thoroughly investigated, is the formation of a cell with the double number of chromosomes, the combination of these chromosomes in the single nucleus may be either immediate or a more gradual process, as is conspicuous in the embryos of Cyclops; and Blackman's (8) and Christman's (I5) interesting discoveries in the rcidium of the rust show that the final combination of the nuclei may be delayed through an indefinite number of cell generations. The ultimate fusion in this case seems to be associated with the process of chromosome reduction and the development of spores.

Blackman's discovery of his so-called vegetative fertilization in the acidium of the rusts, bearing as it does on the whole question of the homologies and relationships of the higher fungi, as well as on the general question of fertilization and alternation of generations, is certainly of the highest importance. With his account and that of Christman we may believe that the historic question as to the sexuality of the æcidium is finally settled. Blackman finds that the basal cell of each row of xcidiospores in Phragmidium violaceum is fertilized by the migration through its wall of a nucleus from a neighboring cell. The pronuclei do not fuse, but divide by conjugate division, and thus the cycle of binucleated cells which terminates with the nuclear fusion in the teleutospore is begun. There is no wide communicating pore between the gametes, as found by Blackman. The nucleus passes through the 
wall without leaving a trace to indicate its path. The fertilization is accomplished by the nucleus alone.

Christman's (15) further discoveries in the same line and on a related species form a most valuable extension of Blackman's results. In Phragmidium speciosum Fr. Christman finds an actual and typical cell fusion at the base of each row of æcidiospores. The fusion is between vertical hyphal cells whose bases diverge below, indicating that they arise from quite widely separated hyphal branches. The fusing cells are equal in size, and it is as an outgrowth of their combined apices that the row of æcidiospores takes its origin. Here, again, the nuclei of the gametes do not fuse, but divide simultaneously to form the pairs of nuclei found in the æcidiospores.

I shall have occasion to return to Blackman's and Christman's results in other connections. Here we are chiefly concerned with the fact that the time and degree of the visible combination of the sexual prochromosomes is a variable matter. If the prochromosomes can remain either in one nucleus with double chromosome number or in two distinct nuclei through part or all of the sporophyte generation, it is also possible that they may combine in one nucleus into bivalent chromosomes and maintain their identity in this condition through the sporophyte generation till a true reduction occurs in spore formation. It is certain that with the nuclear organization described above the individual chromosomes must be permanent structures, and that for every chromosome unit which enters a given nucleus a corresponding chromosome unit must reappear in the division of that nucleus.

I have already (37, pp. 677-678) advanced the view that the formation of the primary nucleus of the ascus and the succeeding divisions may correspond morphologically to the process of spore formation at the end of the sporophyte generation in the ordinary cases of alternation of generations. With the evidence presented above, that a reduction of the number of chromosomes occurs in the formation of the primary nucleus of the ascus, the evidence that the ascus, like the spore mother cell of the moss or fern, represents the close of a sporophyte generation is apparently strengthened; still, it is plain that, since the nuclei that fuse in the ascus are themselves products of a nuclear fusion in the oogonium which must double the chromosome number, we must look further for a complete explanation of the processes here involved.

I shall present further evidence on this point later; but whether we accept or reject the evidence for the existence of an alternation of generations in the Ascomycetes and their probable congeners, the Floridex, the problem as to the nature of nuclear fusion in the ascus still remains. 
The problem is not more difficult, perhaps, in the case of the fusion in the ascus than in that of the fusion of the polar nuclei and the second sperm nucleus in the embryo-sac, or the second nuclear fusion described by Chmielewski ( I4) as taking place in the formation of the zygospore in Spirogyra, or the fusion vegatative nuclei in endosperm cells (87), or the experimentally induced nuclear fusions observed by Nemec (70) in root cells. It must be admitted that there has been so far no general agreement as to either the morphological or physiological significance of any of these processes, and doubtless we need more facts as to the relation of the nucleus to other processes in the cell besides fertilization before a final solution can be reached. It is a question, further, how much any two of the individual cases mentioned have in common. Each may well be, to a considerable extent, the reaction of the nuclei to different conditions and with quite different results for the cell. With the exception of the second fusion in the zygospore of Spirogyra they have, however, one very striking point in common. They all occur in cells whose dimensions are, or become, greater than those of the ordinary cells with which they are associated. This is strikingly true of the ascus, which, as I have pointed out above, is gigantic in size compared with any other cells of the mildew. Into it are poured, for the formation and nutrition of the spores, all the surplus food materials accumulated in the vegetative cycle of the fungus. The injection of this immense amount of food material into the cytoplasm and its consequent rapid growth leads naturally to the expectation that a correspondingly large nucleus must be formed; and, as I have pointed out above, the nucleus of these ascus cells is actually as much greater than the ordinary vegetative nuclei as the ascus is larger than the vegetative cells.

My studies of the nuclear processes in the ascus have from the first led me to the conclusion that the nuclear fusion in the young ascus was correlated in some way with the vegetative development of the relatively gigantic size of the ascus as compared with other cells of the fungus; and in these facts of relative size I am convinced we have a basis for correlating these cases of nuclear fusions with the broader facts as to the relation of nuclear dimensions to cell dimensions which have been frequently noted and recently have been given striking experimental demonstration by Gerassimoff, R. Hertwig, and Boveri. The fact that large cells in general have large or numerous nuclei and that small cells have small or few nuclei is well known, but that this relation is fundamental and necessary was first shown by the experimenters just named.

We may note, first, Gerassimoff's (26-29) results. As is well known, by ingenious experimental methods-cooling while cell division 
is going on, etc.-Gerassimoff has been able to check the normal course of cell division in filaments of Spirogyra and to produce binucleated cells or to cause the fusion of the two daughter nuclei into a single proportionately larger nucleus. In either case the result is the same. The cells with the larger nuclear mass increase in size beyond the norm for the species to which they belong. These enlarged cells divide, and thus filaments are formed whose cells are all above the normal in size. In the binucleated cells with two fully developed nuclei the latter tend ordinarily to repel each other $(29, \mathrm{p} .73)$ to the extent necessary to maintain their mutually symmetrical position in the central region of the cell. Still, if the cells are weakened or starving, the nuclei may approach each other and apparently tend to combine. Gerassimoff concludes (29, p. 77) that the cells of Spirogyra possess the ability to compensate for any disturbance of the quantitative equilibrium between the mass of the nucleus and that of the remaining components of the protoplast by varying their rate of cell division. Increase of nuclear material leads to a delay of cell division and a relative diminution of nuclear material in the daughter cells. On the other hand, lack of nuclear material is followed by increased frequency in cell division. It should be remembered that other methods might lead to the same result, and if the maintenance of an equilibrium between nuclear and cytoplasmic masses is a fundamental necessity for the cell, it may be expected that in different cases different means adapted to the special conditions of the individual cells or organisms will be found in operation.

R. Hertwig $(44,45)$ has reached results similar to those of Gerassimoff in his experiments with cultures of certain Protozoans (Actinosphaerium, Dileptas). He finds that lack of food leads to a reduction of the volume of the cytoplasm; the nuclei shrink and a certain proportion of them actually disintegrate. The nuclei of Actinosphaerium may thus be reduced from several hundreds to one or two. In overfed individuals the reverse is true. It is thus shown that the regulative function is a reversible one. Experimentally achieved increase of the nuclear mass in Spirogyra leads to the enlargement of the cytoplasmic mass. Reduction of the cytoplasmic mass by starvation in Actinosphaerium leads to a reduction of the nuclear mass. Boveri (12) has also shown by experiments, in which he fertilized both nucleated and non-nucleated fragments of the eggs of sea-urchins, that those with the abnormally reduced amount of nuclear material produce larvæ with smaller but more numerous cells. By shaking the sea-urchin eggs just after fertilization he was able also to achieve the same result as did Gerassimoff for Spirogyra. The daughter chromosomes after their 
formation reunite to form a single nucleus with a doubled number of chromosomes -72 instead of 36 . The result is identical with that in Spirogyra. The larva produced from an egg so treated has abnormally large cells. Boveri further observed that in all these variations the superficial area of the nucleus and not its cubic content is proportional to the number of chromosomes in it.

On the ground of a general consideration of the relations of nuclear and cytoplasmic masses, as well as his own, Gerassimoff's, and Boveri's experimental results, Hertwig (45) extends these conclusions to all cells as a general law of cell organization, which he calls the principle of the nucleo-cytoplasmic relation. Nuclear masses and cytoplasmic masses strive always to maintain a definite proportionality in which they are in equilibrium. Any increase in the mass of either tends toward producing a corresponding increase in the other; a reduction in one necessitates a reduction in the other, in order that the nucleo-cytoplasmic equilibrium may be maintained. Hertwig considers this relation as one chiefly of mass, but it is plain that other factors are also involved. A mere equilibrium of mass could be attained in the starving Actinosphaeria by an equal and proportional reduction of each nucleus, but instead of this the object is gained by the total destruction of certain nuclei and the survival of others. In Spirogyra, also, the equilibrium in the binucleated cells at least might be established by the later completion of the cell division which was artificially interrupted. It is plain, then, that factors are present in the process which tend not only to establish a definite nucleo-cytoplasmic relation of mass, but which also determine the method by which this condition of equilibrium is brought about. Equilibrium in the nucleo-cytoplasmic relation in the case of enlarged cells may be brought about either by the presence of two or more small nuclei or by the formation of a single nucleus of proportionally greater size.

If we now compare the cell-reactions experimentally discovered by Hertwig and Gerassimoff with those prevailing in the normal development of the ascus, we shall find a striking similarity in all characteristic features. We may consider first the ascus of the mildew.

The ascus is to be developed as a relatively large cell to serve as a storehouse, with an abundant supply of material for the formation of ascospores; and in order that the nucleo-cytoplasmic equilibrium may be maintained, it must be provided with an excess of nuclear material as compared with the other cells of the ascogenous hyphæ and the ascogonium. There are several stages in this differentiation of the ascus as to its nuclear content. It is binucleated from the first, while the 
other cells mentioned are uninucleated; and, further, its two nuclei fuse with the union of all their corresponding parts to form a single larger nucleus, which in turn grows with the further growth of the ascus.

The binucleated condition of the young ascus, we may conceive, is due to an inhibition of cell division, due in turn, perhaps, to a culmination in the process of extra feeding of the ascogenous cells, which the whole structure and development of the ascocarp is calculated to bring about. Cell division and nuclear division are quite independent processes in the development of the ascogonium and ascogenous hyphæ, as we have seen above. For a time the ascogonium and the ascogenous hyphæ, in their rapid growth, are multi-nucleated, but in the end cell division overtakes nuclear division and the whole system comes to consist of uninucleated cells, except the cells which are to become asci. The binucleated condition remains in them simply because cell division is inhibited at just this stage of development. It seems probable that these ascogenous cells are differentiated as such simply on the basis of their more favorable position for nutrition, and that this excessive nutrition is the stimulus which inhibits cell division.

It is a frequently expressed conception that the stimulus to cell division is given in a certain maximal size of the cell, which, when it is attained by the growth of the daughter cells, results in certain tensions which set in operation the mechanism of karyokinesis. Shaper $(85)$ has pointed out that increased volume results in a relative diminution of the surface area as compared with the mass of the cell, and since all nutrition comes through the surface, a stage will be reached when assimilation and dissimilation will balance each other and growth will cease. Cell division now occurs, and by the formation of two smaller daughter cells a relation of volume and surface area favorable for growth will again be established. Considering the growth of the animal egg, Lubosch (58) points out that the special provisions for its nutrition, nurse cells, etc., may have the effect of inhibiting cell division by furnishing such a rich food supply that the relative diminution of absorbing surface will be more than counterbalanced and the cell may continue to grow without dividing as long as the excessive food supply is available. The case of the ascus is similar, and it seems entirely reasonable to assume that the excessive food supply prevents the separation of the two nuclei in the young ascus by the formation of a cell wall. The relative excess of nuclear material thus accumulated favors the further growth of the cytoplasm independently of the rate of food supply, and thus we get further rapid increase in size of the ascus cell. We have thus, in the formation of the ascus, a definite change in the habit of growth of the 
ascogenous cell. While in the growth of the vegetative hyphæ, the formation of sexual cells and the development of the ascogonium and ascogenous hyphæ nuclear division are followed by cell division, so that uninucleated cells are formed, we have here a stage in which cell division does not occur between the two nuclei of certain cells, and the two nuclei remaining in the same cell mass fuse into one. Gerassimoff (26) induced the interruption of cell division by suitably regulated inhibitive stimuli (chilling, anesthetizing). The inhibition is self-induced in the mildew by the operation of factors which are directed to the production of a large cell with abundance of material for the formation of spores.

But whatever the factor or factors may be which inhibit cell division and thus leave the young ascus with two nuclei, this condition results exactly as in Gerassimoff's binucleated Spirogyra cells and Boveri's sea-urchin eggs with the double number of chromosomes. The relative excess of nuclear material facilitates the rapid growth of the ascus in size. The cells of Spirogyra do not complete the interrupted division and thus reestablish the nucleo-cytoplasmic equilibrium, but grow larger, not by pathological hypertrophy leading to death, but in a normal fashion which permits of their indefinite further division and growth. The ascus shows exactly the same physiological reaction to its increased nuclear content. It immediately grows to a far greater mass than that of any of the other cells of the ascocarp or mycelium. The evidence is thus very strong that the doubling of the nuclear mass in the young ascus is merely a preliminary to that growth of the ascus which is necessary for its functioning as a spore-sac. The whole process is thus placed in the category of nucleo-cytoplasmic regulations which are concerned with maintaining an equilibrium between the factors of assimilation and division in the cell.

It is doubtless true that nucleo-cytoplasmic equilibrium is achieved many times by an increased number of nuclei in the cell without their fusion, especially in the algæ and fungi. This is plainly the case in the multinucleated perithecial cells of the mildews themselves and in the multinucleated hyphæ and reproductive cells of Pyronema and Ascobolus. In both of these latter cases increased size as well as increased number of the nuclei especially characterize the large oogonia and the ascogonia. In the multinucleated endosperm cells and in Nemec's (70) binucleated root cells fusion may occur at once or the nuclei may remain independent and divide again, whereupon nuclear fusion may occur. In Gerassimoff's (29) experiments fusion of the nuclei might or might not occur. Hence it seems to be a matter of relative indifference, which 
may be determined by minor factors in each case, whether the nucleocytoplasmic equilibrium be established with or without nuclear fusion.

Nemec (70) has pointed out that the fusion of nuclei, far from always having a sexual significance, may well be considered in many cases merely as a consequence of the inclusion of two nuclei in the same cytoplasmic system, and that the maintenance of many nuclei in the large vegetative cells of the algæ and fungi may be for the purpose of distributing the nuclear material through the cell, so that its relation to growth and metabolism may be more perfectly and readily maintained-a view which appears to be generally accepted by the students of cœnocytic cells. On the basis of his own experiments he further contends that the cell fusion and not the nuclear fusion is the essential feature in sexual reproduction, and that the fusion of the pronuclei also may be regarded as in the nature- of a necessary sequence of the cell fusion without thereby detracting in any degree from the important physiological significance of the former. Blackman's (8) and Christman's (I5) discoveries in the æcidium, discussed above, support this view unequivocally. In the light of these results we are bound to conclude that in the rusts the process of nuclear fusion is associated with the process of chromosome reduction rather than with fertilization.

Nemec has further observed ( 70 ) that these non-sexual fusions in the root cells result in doubling the chromosome number, which, however, is later apparently reduced again to the normal number for the sporophyte. This reduction, he concludes, is an autoregulative function. In the ascus the nuclear fusion, as I have described above, results in an immediate apparent reduction of the chromosome number. That the reduction is immediate in the ascus and occurs somewhat less promptly in the root cells may well be due to the fact that the whole process in the latter demands new adjustments, while in the ascus it is normally recurrent at a definite point in the life cycle and may well have been perfected in its operation by selection.

The nucleus of the ascus under normal conditions, since, as we shall see further on, it presumptively must contain quadrivalent chromosomes without thereby having its own apparent number increased, must be considered to be in a sense hypertrophied as to its chromatin content when compared with the ordinary nuclei of the mildew. As noted also, the whole fungus pours its excess of nutriment into the ascus, and both nucleus and cytoplasm increase greatly in size. The condition is possibly parallel to that of the nuclei in Hertwig's (44) cultures of Actinosphaerium, which he kept for long periods under conditions of overfeeding. In such cases he was able to observe that the hypertrophied 
nuclei underwent changes which resulted in part of their content being thrown out into the cytoplasm as brown pigment granules. It is interesting to note in this connection that the abundant highly stainable granules which I have described as present in the ascus of Ascobolus and Peziza (35, p. 7I), both around the nuclei and scattered in the cytoplasm, originate, according to the recent interesting investigations of Guilliermond (34), in the neighborhood of the nucleus. Guilliermond does not believe that the granules arise directly from the nucleus, but thinks it may play an indirect rôle in their secretion. It is not impossible that the formation of these granules in the ascus may be closely related to the formation of pigment granules described by Hertwig. Ikeno (47) has described a throwing out of chromatin material in the case of the nucleus of the ascus of Taphrina, which may be of a similar nature.

In the further development of the ascus we are confronted with the peculiar fact that nuclear growth continues and nuclear division is inhibited from a period prior to nuclear fusion in the young ascus till the latter is mature and ready for the formation of spores. This condition is in sharp contrast with the fact that in all the vegetative development of the mildew and the development of the ascocarp, up to the formation of the young ascus, nuclear division has always recurred at intervals such as would prevent the growth of any single nucleus beyond the normal size for either vegetative or reproductive cells. We have concluded above that the rich nutrition of the ascogenous hyph inhibits cell division and leads to the formation of the young asci with two nuclei. This condition makes possible a considerable growth of the ascus before the condition of nucleo-cytoplasmic equilibrium is reached. Soon, however, the nuclei continue their growth in size, and this process continues, as noted, through the process of fusion and after it till the ascus has reached practically its mature size. The nucleo-cytoplasmic relation is thus maintained by the development of a single large nucleus rather than by the formation of many smaller ones, as is elsewhere so commonly the case in the fungi.

If we seek, now, the cause of this relatively long inhibition of nuclear division, we may note the interesting fact that the inhibition lasts only until the ascus has reached its maximum size, when we may conclude that the rich supply of food which has been poured into it from the mycelium begins to diminish. With this check in assimilative processes, reproductive activity is at once reinaugurated and the ascusnucleus divides three times in rapid succession, cell division follows, and the ascospores are formed. It seems justifiable to conclude that 
the excessive assimilative activity in the ascus has inhibited nuclear division just as in its earlier stages excess of nutrition inhibited cell division to the extent of leaving the young asci with two nuclei.

In the process of spore formation we have again a most striking example of the controlling influence of the so-called nucleo-cytoplasmic relation. The nucleus of the ascus divides to form two daughter nuclei, and these in turn divide successively to form eight nuclei; but in thus passing from the uninucleated to the multinucleated condition the nucleo-cytoplasmic equilibrium is maintained. The two daughter nuclei are proportionally smaller than the mother nucleus, and the four and eight nuclei in the end bear approximately the same relation to their cytoplasmic masses as did the primary nucleus of the ascus to the cytoplasm of the entire ascus. The two nuclei which become the centers for the formation of spores grow to a somewhat larger size than the remaining six, and accordingly the mass of cytoplasm included in the two spores is more than one-fourth of that in the entire ascus.

A careful study of the processes involved in the development of the ascus leads thus to the conclusion that it is in its nature as a sporeproducing organ that we find the explanation of the various nuclear and growth phenomena which characterize it. By inhibition of cell division at a certain stage in the development of the ascogenous hyphæ the ascus is formed as a binucleated cell, and the excess of its nuclear content makes possible a proportionate development of its cytoplasm. Its nuclei grow and fuse and nuclear division is further inhibited, and thus the relatively enormous size of the uninucleated ascus cell is atained. With the diminution of food supply nuclear and cell division are resumed and the uninucleated ascospores are formed, in which, again, the nucleocytoplasmic relation is also maintained.

A comparison of the processes thus described and analyzed with those associated with fertilization elsewhere makes it still clearer that the development of the ascus can not in any sense be compared with that of the egg. Much attention has been devoted to the problem of the conditions which lead to the formation of the immense yolk masses of some animal eggs and the relation of yolk formation to the size of the germinal vesicle. There is no question that we have here an illustration of the principle of the nucleo-cytoplasmic relation, but in every case the growth of the yolk mass is a purely vegetative process and is the preparation for fertilization. In the ascus nuclear fusion is followed by inordinate growth in the mass of the cell. (Compare figs. 37 to 39 , which are magnified 2250, with figs. 53 and 54, which are magnified I 500.) With the possible exception of a few of the algx, in which 
the nuclear phenomena are yet to be determined with certainty, the union of the male and the female pronuclei is nowhere followed by such a growth. Fertilization is the signal for rapid nuclear division, followed at once or later by cell division, except in cases where the fertilized egg is to serve as a resting stage. Dangeard's own theory of sexuality, based on the character of the gametes in the lower green algæ, is entirely opposed to the assumption that the fusion in the developing ascus is equivalent to an ordinary union of sexual pronuclei. On the other hand, the growth phenomena of the ascus are just what would be expected in a highly specialized spore mother cell.

It is possible that the nuclear fusion in the ascus, arising wholly as I have described above in connection with the maintenance of the nucleo-cytoplasmic equilibrium in the large ascus cell, may still functionally satisfy in some minor degree the requirements of a sexual fusion in case, in the course of development, it should be brought about that the nuclei which so combine arise from a widely separated nuclear ancestry. I have discussed this possibility in connection with both the Basidiomycetes and the rusts in former papers ( $40 a$ and 46 ), and have pointed out that it is possible, though not at all proven, that the fusions in the basidia and teleutospores may in some degree have functionally replaced a true sexual union of nuclei, though occurring at the close of a sporophyte generation. This, of course, does not mean that in any sense whatever basidia or teleutospores can be considered as morphologically equivalent to oogonia, nor that the series of cells from which they arise are morphologically a gametophore, as Dangeard maintains. Blackman's and Christman's discoveries show beyond all question that the morphological equivalents of the oogonia and antheridia of other related fungi and algæ are not the teleutospores formed at the end of a long series of binucleated cells. In the conjugating cells at the base of the rows of æcidiospores we find the real equivalents of the sexual cells elsewhere. Blackman's fertile cell is doubtless a modified egg cell. The other cell of the pair we must conclude is a new structure which has taken on a sexual function, since the spermatia, which are doubtless the equivalents of the male cells of other groups, are still in existence in the rusts. This carries with it the further conclusion that the processes in the teleutospore and basidium form a parallel to those found in the spore mother cells of higher plants.

Blackman on this basis denies all sexual significance to the fusion in the teleutospore and considers the binucleated cells of the uredo and teleuto mycelia as entirely equivalent physiologically, as well as morphologically, to the uninucleated cells of the sporophyte of the higher 
plants, since both contain the double number of chromosomes. While this is possible, I doubt if the evidence proves quite so much. The tendency certainly exists among the most recent students of reducing phenomena, accepting the suggestions of De Vries (96) and still earlier evidence from the side of the zoologists $(65,66)$, to assume that the entire interchange of hereditary units or of hereditary influences between male and female chromosomes takes place in synapsis or the associated stages. With this view it is a matter of indifference, as Blackman maintains, whether the nuclei of the gametes combine into one early or late in the life of the sporophyte. One nucleus with the double number of chromosomes is exactly the equivalent of two distinct nuclei which divide by conjugate division. Still, it is to be questioned whether this is actually the case physiologically. It may very well be that the male and female chromosomes in the nuclei of the sporophyte of the higher plants, though maintaining their individuality as permanent structures, can still exert chemical or other influences upon each other in some degree as a result of their close association in the same nuclear cavity, whether or not an actual interchange of substance occurs between them. The facts of bud variation, adaptation to environment, and other modifications occurring during the life of the individual suggest that this may be the case. If such interchange takes place in a fusion-nucleus and does not occur in a binucleated cell arising from conjugate division, then the fusion in the teleutospore may mean more than the reduction process found in the spore mother cells. A result which is achieved immediately in the union of the nuclei of the sperm and egg, or later during the association of the male and female chromosomes in the sporophyte, may here be accomplished at the stage of chromosome reduction. It may be that the nuclear fusion everywhere means more than a mere preliminary adjustment making ready for reduction. I am inclined to think that this is the case and that the fusion in the teleutospore may involve in some degree the changes resulting from sexual union beyond those which arise from such a cytoplasmic fusion as results in the binucleated cell, as described by Blackman and Christman.

The question further arises, granting that this difference between reduction phenomena in spore mother cells and the processes in the teleutospore exists, whether it is of such a nature as to replace in any degree, when the nuclei which fuse come from a separated ancestry, the ordinary sexual conjugation of cells and nuclei as they are found elsewhere in algæ and fungi. There seems no doubt, in view of Miss Nichols's (7I) results, that in certain Basidiomycetes the origin of the binucleated cells is not found in any such definite structures or at any 
such fixed point in the life cycle as in the rusts, and that in this respect the Basidiomycetes represent a further stage in development following the condition described in the rusts by Blackman and Christman. There are two possibilities as to the causes that have led to this further stage in development. Either sexual reproduction by the union of differentiated gamete cells is gradually disappearing under the influence of the particular habits of life of the, fungi, the conditions in the higher Basidiomycetes representing a further stage in this process, or the new processes of conjugate division, followed by nuclear fusion, in connection with chromosome reduction at the close of a sporophyte generation, has tended to replace the earlier sexual fusion. Blackman is of the opinion that such fertilizations by vegetative cells, as he finds in Phragmidium, will also be found in the higher Basidiomycetes, but Miss Nichols has made it plain that, for certain forms at least, no such assumption is at all probable, and it is further possible that there are reduced forms among the rusts in which the same condition prevails.

On either of the above hypotheses such forms are possible, and if the second hypothesis is accepted we have the key to the explanation of the phenomena involved in the two nuclear fusions found in the mildews, Pyronema, and presumably other Ascomycetes. I have presented above the evidence that nuclear fusion in the ascus arises in connection with the processes involved in the maintenance of the nucleocytoplasmic relation during the development of the relatively enormous size of the ascus cell, and have pointed out that in its origin in this fashion it has nothing to do with sexual reproduction in any respect. If, however, we may assume that, with the development of a separate ancestry for the fusing nuclei by simultaneous nuclear division, as found in the bent-end cells of the ascogenous hyphæ in Pyronema and, according to Maire, in a series of binucleated ascogenous cells in Galactinia and Acetabula (see also $3 \mathrm{I}$ ), the process has gained in some degree a functional equivalence for sexual fusions, we can further assume that this condition, perhaps working together with other influences such as have led to parthenogensis in other fungi, has made possible the occurrence of parthenogenesis or even apogamy in such Ascomycetes, for example, as Pleospora and Teichospora. Such conjugate nuclear division would originate, not as it apparently does at present in the rusts through the failure of the pronuclei to combine in one, but in connection with the development of the spore mother cell, as in Pyro11ema. From this point we might expect the process to work back in the ascogenous hyphæ, as it appears to be doing in Galactinia and Acetabula. Ultimately it might reach the egg-cells and result in the 
condition found now in the rusts. Briefly, the hypothesis involves that the development of conjugate nuclear division and the maintenance of separate lines of nuclear descent in the ascogenous hyphæ might tend to give to the nuclear fusions in the ascus a sexual value in addition to their original and more fundamental significance in maintaining the nucleo-cytoplasmic relation in the enlarged ascus cell, and that thus, in turn, parthenogenesis, and later even apogamy, may have resulted in forms in which conjugate nuclear division in the ascogenous hyphæ had become established. Such an hypothesis as to the possible disappearance of the fusion of sexual gametes and its replacement by the independent fusion in the ascus of nuclei of separated ancestry carries with it no implication that the ascus has become the morphological equivalent of an oogonium. The fusion in the ascus would be only analogous to and not homologous with a true sexual fusion, nor would this hypothesis affect in any way our conception of the morphology of the ascocarp. The ascus is a new structure which originated as an outgrowth of an ascogonium, which in turn was produced by the germination of a fertilized egg. The two fusions must be expected to coexist for a time in the same life cycle, as is actually the case in all Ascomycetes whose nuclear history is fully known.

As I have pointed out before, it still remains to determine how many such cases there are among the Ascomycetes and whether the genera mentioned are really apogamous or parthenogenetic or, as Blackman's discovery suggests, whether they may not possess a fertilization by the migration of vegetative nuclei in their initial cells. It is certainly most highly desirable that we should have a full account of the development of the ascogenous hyphæ and the behavior of the nuclei in some such type. In the case of the forms referred to above also, in which Maire $(59,60)$ has reported that the asci arise from a series of binucleated cells, this series in one case taking its origin in a recurved hyphal tip such as usually gives rise directly to an ascus, it is of the highest importance to know how the ascocarps originate. Until this is settled it is difficult to judge with any certainty of the significance of Maire's observations. It is to be hoped that in the near future we may have a full account of the nuclear phenomena in the development of the ascocarp of some parthenogenetic or apogamous form. Unfortunately, the forms which have so far been reported as developing their ascocarps in some other way than from a sexual apparatus have not shown themselves favorable for the investigation of nuclear phenomena. 


\section{RELATIONS OF ASCOMYCETES AND BASIDIOMYCETES.}

Maire's (62) discovery of regularly binucleated cells in the carpophore of the Basidiomycetes, confirmed by myself $(40 a)$ and others, has firmly established the conception of a phylogenetic relationship between this group and the rusts. The inferences drawn by older authorities from the resemblance of the promycelium of the rusts to the basidium of Auricularia are thus confirmed. Maire accepts the conception of an alternation of generations in the Basidiomycetes and holds that the union of nuclei in the basidium involves the reduction process found in the spore-mother-cell stage of the higher plants, thus rejecting specifically Dangeard's conception of the basidium as an oogonium.

There can be no question, in view of the general agreement of other authors ( $15,8,46,40 a)$, that Maire, like Sappin, Trouffy, and Dangeard, has been misled as to the number of chromosomes in the rusts, the Ascomycetes, and the Basidiomycetes by faulty methods of fixation which have caused the chromosomes to stick together in clumps. Guilliermond $(3 \mathrm{I}, 33)$ finds the number of chromosomes in the divisions in the ascus to be 8 in Aleuria cerea, 12 in Peziza cortinus, I6 in Peziza rutilans, and 8 in Peziza vesiculosa. I have found 8 chromosomes in the asci of Ascobolus furfuraceus and Pcziza stevensoniana (35), 8 in the asci of Erysiphe communis (40), Io in Pyronema confluens (40), and 8 in Phyllactinia. In the face of these facts it is difficult to see how Maire and Dangeard can maintain that there are probably 4 chromosomes in all Ascomycetes. Dangeard originally concluded there were 8 chromosomes in the conidia of Sphaerotheca castagnei, but has now changed his estimate to 4 , in harmony with Maire. It is plain that no such simple conditions exist as Maire imagines when he contends for the universal occurrence of 2 chromosomes in the rusts, 4 in the Basidiomycetes, and 4 in the Ascomycetes. Maire has apparently seen more or less vaguely the true chromosomes in the prophases, but here he was not able to make out any constancy in the number.

Maire (62) holds that the stage corresponding to a true fertilization is that at which the binucleated condition arises in the hyphal cells. He was not, however, able to determine with certainty the method of origin of the binucleated condition, nor to demonstrate the existence of simultaneous or conjugate nuclear division, so that he leaves the initial point of the sporophyte generation-the formation of a fertilized eggstill uncertain for the Basidiomycetes. Miss Nichols's (7I) researches show that the binucleated condition is present in the mycelium of several forms and apparently does not originate at any constant stage nor in any specially differentiated structures in the life cycle of the fungus. 
It is especially of interest that Miss Nichols finds binucleated cells regularly present in the rhizomorphs of a large number of widely separated genera.

The observations of Miss Nichols and those of Blackman and Christman do not make it any easier to assume a phylogenetic relationship between Ascomycetes and Basidiomycetes. It is highly probable that such resemblances as exist between the ascocarp and the carpophore are due to the duplication of unrelated forms under similar developmental conditions, which occurs at many other points in the plant kingdom. While a conjugation of gametes is present in the æcidium, it is still plain, from the existence of the now functionless spermatia, that the present sexual fusions are highly modified processes which have returned in the character of the gamete to something like a zygosporic type from what originally was doubtless a true carposporic method of reproduction. There is no evidence of any such modification in the sexual apparatus of the Ascomycetes, and in them also there is at most only the beginning of the long series of regularly binucleated cells which characterize the rusts and Basidiomycetes. Still, the fusion in the basidium may have had an origin similar to that suggested above for the fusion in the ascus, and, combined with conjugate division, may gradually have led to the apogamous condition which, it seems probable, is found in the Basidiomycetes. The rusts on this hypothesis represent a condition when conjugate division has worked back, in the life history of the sporophyte, to the stage of fusion of the gametes, thus replacing the nuclear fusion in the egg which must probably be assumed to have occurred in some more primitive type from which the rusts have developed. If this more primitive type was, as Blackman believes, one of the red algæ, we must probably consider that two diverging series of fungi, the Ascomycetes and the Basidiomycetes, had their origins in this group.

As has been many times noted, one of the commonest grounds for the assumption of a relationship between Ascomycetes and Basidiomycetes and the relationship of these groups to the Florideæ lies in the generally suggested physiological parallelism between ascocarps, carpophores, and cystocarps with each other and with the sporogonium of the liverwort and moss. A functional resemblance between the structures in question is apparent, and Wolf (99) has described a reduction of the number of chromosomes in connection with the formation of the carpospores in Nemalion. The evidence, however, on which he bases his conclusion is not very convincing. Such comparisons also still leave the nature of the tetraspores and the occurrence of specialized 
tetrasporic as distinct from sexual plants unexplained, and their validity is to be settled by the determination of the chromosome number in each case. Mottier's (67) discovery that the number of chromosomes in the first division in the tetrasporange of Dictyota is 16 , which is about half that found in the vegetative cells of the plant which bears the tetrasporanges, and the evidence brought by Williams (98) that the tetraspores of Dictyota develop into sexual plants, while the eggs develop into tetrasporic plants, lead us to the conception of quite a different set of possible homologies, as will be further noted below.

Better evidence for a relationship between the red algæ and Ascomycetes is found in the method of fertilization by a trichogyne as found in the lichens, Laboulbeniacex and Pyronema, and in the fact that in both groups the fertilized egg through its further development remains in organic continuity with the plant which bore it, instead of being set free to begin an independent existence. It was on this ground that De Bary proposed the conception of the carpogonium to include the female cell of both the Ascomycetes and the red algæ.

Davis (22), in a critical review of the relationships of the higher fungi and algæ, while admitting the force of the evidence in favor of a derivation of the Ascomycetes from the red algæ through the Laboulbeniacex, is inclined to the assumption of a relationship between the lower Ascomycetes and the Phycomycetes and to the belief that the Ascomycetes may be a polyphyletic group. Blackman is of the opinion that such a vegetative fertilization as he finds may also be present in the higher Basidiomycetes and presumably also in those rusts which seem to lack an æcidium. Further studies in the rusts in the light of Blackman's and Christman's discoveries may be expected to clear up many difficult points as to relationships among the higher fungi and algæ. It is interesting to note that Sappin-Trouffy concluded (84) that in some cases the binucleated condition appears first in the teleutospore sorus.

Blackman does not believe that Coleosporium sonchi-arvensis, as described by Holden and Harper (46) really lacks a true æcidial stage. The form is a very common and familiar one which I have collected for many years without being able to find any suggestion of an association with an æcidial stage on a conifer, where one would naturally expect it to occur. It is my opinion that this is a form with reduced life cycle, but I do not hold that this opinion is of any final value in the absence of proper culture experiments on our American forms. Still, it is hardly to be doubted that such types do exist, and it would make no difference with the conclusions suggested whether the binucleated 
condition arises in the sporidium or later in the growth of the mycelium. Still, no claim for completeness was made, since we did not germinate the sporidia nor determine the nature of the early stages of the mycelium which arises from them. As to the question of a name for the fungus, in the absence of definite evidence it is, in my opinion, poor policy to reject this commonly used name (24) until by culture experiments positive proof of its identity and relationships has been attained. The main conclusions reached in the paper in question were that much more differentiated and normal division figures were present in the rusts than had up to that time been described, and especially that the then current conceptions as to the number of chromosomes in the nuclei of the rusts were entirely wrong. In both of these points Blackman's results confirm our own.

If, further, as Blackman believes, the rusts may have arisen from the Floridex, it is probable that, at a time when the spermatia were the functional male cells, there was a fusion of nuclei immediately in the fertilized cell. If, at this stage in the development of the group, a sporophyte generation leading to the formation of such spore mother cells as the basidium were in existence, it is not improbable that two nuclear fusions may have been included in such a life cycle. On the other hand, from this standpoint alone the opposite conception that the various spore forms of the rust arose gradually in connection with a progressive deferring of the fusion of the nuclei of the gametes seems also plausible. There are, however, other facts to be taken into consideration.

\section{ALTERNATION OF GENERATIONS IN THE HIGHER FUNGI.}

It seems entirely clear, from our knowledge of the significance of the chromosome number in nuclear division, in sexual reproduction, and in the alternation of generations in the higher plants, that the determination of the number of the chromosomes at the important stages in the life cycles of the higher fungi will indicate definitely the true nature of the difficult phenomena we are considering, and there is no doubt that the problem is soluble along these lines. We have abundant evidence that in the asci the chromosomes are very sharply differentiated structures, which can be counted with certainty. It is certain that, as shown above, the nuclear fusion in the ascus does not alter the apparent number of the chromosomes found in the fusion nucleus and its offspring as compared with the individual nuclei which combined. The fusion of the nuclei involves the union of the chromosomes presumably in pairs, and thus, through synapsis and the triple division which follows, 
a reduction of the number of chromosomes is effected. The discoveries of Blackman, and even more convincingly those of Christman, by proving that the binucleated cells of the rusts originate in an unquestionable fertilization, have put the existence of an alternation of generations in these forms beyond question. It is to be noted also what positive support the conditions in the rust give to the doctrine of the independent persistence of the prochromosomes throughout the sporophyte generation, which was beginning to be inferred from the phenomena in the higher animals and plants. When the nuclei of the gametes persist as independent structures up to the time of chromosome reduction in the spore mother cell, there can be no question of the independent persistence of the individual chromosomes from the two gametes. This condition also enables us to establish beyond reasonable doubt the existence of a stage in the life cycle with cells containing the double chromosome number without an actual counting of the chromosomes. It is, of course, highly desirable that the number of chromosomes in the division in the teleutospore and elsewhere be established by actual counting, but there can be no question, even without this further evidence, that the main conclusions of these authors are fully justified. The binucleated cells of the rust represent a stage with double chromosome number arising in a process of fertilization and closing with a reduction of the chromosome number. A parallel with the alternation of generations in the higher plants is thus fully established.

If it could be further shown that while the antheridia and oogonia unite and the male nucleus comes to lie in the egg beside the female nucleus they still do not fuse, but maintain their independent existence through the development of the ascogonium and ascogenous hyphæ, finally combining in the ascus, we should have in the mildews and Pyronema an apparent parallel to the nuclear phenomena in the rust. Since, however, the cells of the ascogonium in the mildews are uninucleated and there is no evidence of any provision for maintaining separate and parallel series of nuclei, such as are present in the rusts, it is plain that even if we did not have a fusion of nuclei in the oogonium we could assume no close parallelism between the mildews and rusts on this basis. If we should assume also that in Pyronema the male and female nuclei only become mingled but do not fuse in the oogonium, there would seem to be equally little chance for maintaining any distinct lines of nuclear descent in the multinucleated cells of the ascogenous hyphæ until at the very close of their development, when simultaneous nuclear division occurs and provision is thus made that the nuclei of the ascus shall at least not be sister nuclei. This single simultaneous 
division of nuclei can, however, at the most be regarded as no more than a mere beginning as compared with the indefinite series of conjugate divisions occurring in the rusts.

As compared with the rusts, then, we have in the mildews and Pyronema no series of binucleated cells formed by conjugate division, and we do find positive evidence that the sexual nuclei fuse in the oogonium. Still, I am convinced that in the Ascomycetes as well as in the rusts we have a true alternation of generations. The explanation of these differences, combined with so much of general similarity between Ascomycetes and Basidiomycetes, is given in a further point of difference between the two groups.

In the teleutospore of the rusts and in the basidium, as Blackman believes, we have a synapsis stage followed by a double division of the nucleus leading to the formation of four spores. The parallelism between the teleutospore and spore mother cells of the higher plants is thus complete, and it is justifiable to assume that the first and second divisions in the promycelia and basidia are respectively heterotypic and homœotypic divisions. On the other hand, in the ascus following the very conspicuous synapsis described above, we have a triple division of the primary nucleus of the ascus leading to the formation of eight ascospore nuclei and typically to the formation of eight spores. The synapsis stage suggests that chromosome reduction occurs in the ascus; but in view of the absolutely universal occurrence of only two divisions associated with chromosome reduction elsewhere in both plant and animal kingdoms, this triple division in the ascus must be regarded as a most aberrant occurrence, and has led to very great hesitancy on my part in my earlier investigations in assuming the possibility of an alternation of generations in the Ascomycetes comparable to that in the higher plants. With the discovery in Phyllactinia that the chromosomes are not only permanent structures of the cell, but that they each have permanent and distinct connection with the central body through the resting condition of the nuclei as well as through the processes of both nuclear fusion and division, combined with the evidence which has been accumulating so rapidly from all sources that, even when apparently not connected with the centers, the chromosomes still maintain their identity in all nuclei, both of animals and plants, it becomes evident that the triple division, in connection with chromosome reduction in the ascus, as compared with a double division everywhere else among plants and animals, becomes a fact of still more fundamental importance. There is general agreement at present that the chromosomes of the spore mother cells are bivalent structures and that both heterotypic and 
homœotypic divisions are necessary to reduce them to the condition found in ordinary somatic cells. The three divisions of the nucleus of the ascus following each other in rapid succession, just as do the heterotypic and homøotypic divisions, suggest at once that the organization of the chromosomes in this case must differ from that in the ordinary spore mother cell. The most natural assumption would seem to be that the chromosomes are quadrivalent in the nucleus of the ascus rather than bivalent, as in ordinary spore mother cells, and that in two of the divisions in the ascus chromosomes are separated instead of in one division, as in the ordinary case. Direct evidence as to whether the reductions occur in the first and second or in the second and third divisions is very difficult to obtain. I have not as yet been able to recognize in the figures in the ascus the ordinary distinctions between heterotypic and homœotypic divisions.

In any case, however, the triple division certainly suggests that two reductions may be necessary to bring the chromosomes of each nucleus back to the ordinary number, and this implies that each of the eight chromosomes, as they emerge from synapsis, represents four somatic chromosomes.

If from this standpoint we seek an explanation of such a peculiarity in the chromosomes of the primary nucleus of the ascus, we are led at once to the suggestion that they must have arisen by a double nuclear fusion, such as actually occurs in the oogonium and in the ascus, as I have described. We see thus that the assumption that the ascus, with its triple division, is a spore mother cell, representing the stage at which chromosome reduction occurs at the close of a sporophytic generation, leads naturally to the expectation of two nuclear fusions in the development of the ascocarp. The universality with which the triple division occurs in all asci so far studied is sufficient proof of its fundamental and primitive nature and that it occurs in a spore mother cell following an apparent numerical reduction of the chromosomes, and a synapsis stage is in perfect harmony with the assumption that it is necessary for the true reduction of the chromosome number.

The triple division of the primary nucleus of the ascus is a universally present characteristic of all the higher Ascomycetes. It occurs, none the less, whether eight or a smaller number of ascospores are to be formed, and that it is a process of fundamental importance is thus most strikingly shown, since it necessitates, as we have seen, the destruction by disintegration of six of the eight nuclei formed in such cases as Phyllactinia, in which but two spores are produced in each ascus. It is evident in such cases that the three divisions form together a single 
process, and that they all are necessary for its accomplishment. If, for example, the two first divisions alone were necessary to accomplish the reduction of the chromosomes, we must suppose that the third division would readily disappear when only four or fewer spores were to be formed. The fact that all three divisions persist shows their necessity for the process of reduction.

We are confronted here with cases parallel to those in the higher plants, where fewer than four macrospores are to grow and become functional. In such cases we find a strong tendency to the persistence of double division as such, the supernumerary macrospores becoming abortive and being absorbed. The persistence of the triple division in the ascus thus suggests in itself that the primary nucleus of the ascus contains proportionally more chromosomes than the ordinary spore mother cell in other sporophytes, and we are thus led to expect, what we actually find, the two nuclear fusions in the development of the ascocarp.

Further, on analogy with the spore mother cells in the higher plants, we must conclude that the apparent number of chromosomes appearing in the divisions immediately succeeding synapsis represents the normal somatic number, which in the case of Phyllactinia would thus be eight. I have above pointed out the difficulties involved in counting the number of chromosomes in the ordinary vegetative divisions in the mildews. The best one can say at present is that the appearances are not against the assumption that there are eight chromosomes on each half of the spindle in such a figure as is shown in fig. 23.

It is quite certain that there are eight or more chromatin strands representing chromosomes in the nuclei which fuse in the ascus. The process of nuclear fusion in the case of nuclei whose chromosomes are permanently attached to the centers, as I have found them in the mildews, leads naturally to their approximation side by side in pairs, and it seems probable that the fusion of the male and female nuclei in the oogonium, in which the same attachment between centers and chromosomes exists, would have the same result. The male and female chromosomes would thus be brought together in pairs. If, as in the case of other sexual fusions, the chromosomes brought together in fertilization still maintain their identity till the stage of reduction at the close of the sporophyte generation, we must conclude that the eight chromatin strands found in the nuclei of the ascus just before their fusion are really double, and that in the fusion in the ascus these double chromosomes, becoming approximated in pairs and passing through synapsis, become quadrivalent chromosomes in the primary nucleus of the 
ascus. These would then be in turn distributed in the triple division which follows. The apparent number of chromosomes in each nucleus throughout the life of the mildew would then be 8 . The real number in the nuclei in the ascogonium and ascogenous hyphæ would be 16 , and in the primary nucleus of the ascus 32 , as the size of these nuclei indicates.

It is a matter of great importance to determine, in the nuclear divisions immediately following fertilization, whether, as would be expected by analogy with the higher plants, the 16 chromosomes may not be made out as distinct units. It seems probable, however, judging from the nature of the process as seen in the fusion in the ascus, that the union of nuclei with an organization such as is found in Phyllactinia must always result in an immediate apparent reduction of the chromosome number, though an actual reduction is only effected here, as in the higher plants, by a process of synapsis, with its succeeding reduction divisions. These latter considerations, of course, have only a hypothetical value in the absence of an exact determination of the number of chromosomes in the cases involved, and it is important that the number of chromosomes appearing in the first and the succeeding divisions of the egg-nucleus should be determined. I have been unable so far to find figures of this division which permit of counting the number of chromosomes with certainty. The division figures in the young ascogonium seem especially hard to find and are very liable to show the chromosomes so closely bunched together that it is difficult to make out their number.

I have observed in a number of ascogonia, after fertilization in the early stages of their growth, a small nucleus, one-third or less the diameter of the ordinary nuclei, whose fate I have been unable to determine. It is possible that the first division in the oogonium gives rise to a supernumerary nucleus, such as Klebahn has described as being formed in the germination of the zygospore of Closterium. It is, of course, also of great importance to trace out in detail the behavior of the central bodies here, both in the sexual fusion and the divisions which immediately follow, and I hope, either in the case of Phyllactinia or other favorable material, to be able to throw further light on these questions. At present we can conclude, from the number of chromosomes in the division following synapsis in the ascus, that the somatic number is 8 , and, further, that at least 8 presumably bivalent chromosomes are present in each of the nuclei which fuse in the ascus.

If we attach the significance which I have indicated above to the triple nuclear division in the ascus, and if we further assume that the 
nuclear fusion in the ascus had at first no sexual significance, but arose in connection with a process of inhibited cell and nuclear division incident to the relatively excessive nutrition supplied to the ascus, the relations of the young ascus, teleutospore, and basidium become at once intelligible. They are all to be interpreted morphologically as spore mother cells. In the ascus the triple division of the nucleus is necessitated by the fact of the two nuclear fusions from which it has arisen. But in the teleutospore and basidium, since the process of conjugate division has worked back, as described above, from its origin at the close of the sporophyte generation to the fertilization with which it began, and one nuclear fusion has thus disappeared, we find the normal double division which occurs elsewhere in spore mother cells. The disappearance of a nuclear fusion in the egg would thus be correlated with the disappearance of a third division in the spore mother cell. The conditions in the rusts and the conditions in the mildews and Pyronema thus represent two stages in the evolution of a sporophyte in the higher fungi, of which that shown in the ascocarp is the more primitive. There is, however, as I have pointed out above, no sufficient evidence in this to lead us to infer that Ascomycetes and Basidiomycetes must be forced into the same phylogenetic series.

If it is true that the rusts have arisen from the red algæ and the fusion in the teleutospore is to be interpreted as I have suggested, we must probably assume, as noted above, that in some of their ancestral forms two nuclear fusions are present in the life cycle. In their present condition it is plain that they are much changed from the red algæ. We have nothing in the red algæ which can be directly compared to such series of carpogonia, each with its special trichogyne and forming a single row of spores, as Blackman assumes to represent a stage just preceding the present condition of the recidium. Blackman has certainly strengthened the evidence that the spermatia are sexual cells, and that they once functioned in fertilizing a trichogyne-like organ. This conclusion, however, leads us to assume some still more primitive condition than the sorus of carpogonia which he conceives. We must believe that at some period the æcidium was more like a cystocarp and that a single trichogyne sufficed for the fertilization of the entire structure, whether by ooblastema filaments, as in many of the red algæ to-day, or by the development of a common procarpic hypha from which, when fertilized, the entire spore mass of the æcidium arose in a fashion analogous to the method of origin of an apothecium of Collema. The discovery by Richards (80) of what is apparently a carpogonial branch in the young æcidium cup of Uromyces caladii and other forms 
gives us a possible connecting link between the cystocarp and the cæoma type of æcidium. It may be that in the cup-shaped æcidia branches bearing gametes arise from a true carpogonium, while in indeterminate æcidia of the cæoma type this carpogonial branch has disappeared.

If the evidence advanced by Mottier and Williams that a reduction division occurs in the development of the tetrasporange be confirmed, it is plain that the homologue of the ascus and teleutospore, and of the basidium as well, is in the tetrasporange and not in the carpospore, as many have been inclined to assume. The carpospores must be interpreted as conidia intercalated in the life cycle of the sporophyte, just as are the æcidiospores and uredospores in the sporophyte of the rust. In this case a close relationship may be assumed between the æcidium and the cystocarp, each being an asexual stage appearing early in the life history of the sporophyte and having no analogous stage in the sporophyte of the moss or fern. The ascus, on the other hand, would correspond to the tetrasporange, and there would be no stage in the Ascomycetes to correspond to the carpospores of the red algæ. We should thus be relieved of the difficulty of assuming relationship between the carpospores produced as buds or chains of cells and the ascospores formed internally by free cell formation. If the tetrasporange is the progenitor of the ascus we must assume that free cell formation, with an abundance of epiplasm, has been developed in the latter for the dissemination of the spores and as an adaptation to a terrestrial habit, and that the basidium and teleutospore may have arisen from the tetrasporange in a similar and parallel series of developmental forms.

At what stage in the evolution of the Ascomycetes from the red algæ the nuclear fusions in the ascus originated is not apparent from any facts yet available. It may be found that some of the simpler Ascomycetes, whose asci are reported as regularly producing only four spores the triple division has been replaced by the ordinary double division of spore mother cells. In that case it may be expected that the fusion of nuclei in the ascus will also be lacking. It is quite possible, however, that this stage is not represented by any forms at present known.

The conceptions thus developed form a consistent and harmonious account of the development of the ascocarp and bring the main facts as to its nature and origin into line with what has been learned in other groups as to the nature of the processes of fertilization, chromosome reduction, the permanence of the chromosomes and the central bodies as cell structures, and the nature of the alternation of generations. In these theoretical considerations I have aimed, of course, to do no more than endeavor to correlate the facts as we know them to-day, and 
thus attempt to systematize our very fragmentary knowledge of the higher thallophytes; and I am very far from believing that such speculations will be so fortunate as to achieve a confirmation in all respects. Such observations as Blackman's and Christman's on the æcidium and Mottier's on the tetrasporange are sufficient to indicate how far from complete our knowledge is, even on some of the most commonly studied structures and processes in these plants. My conceptions as to alternation of generations in the higher fungi may be briefly stated as follows:

In the rusts we have sexual reproduction by vegetative fertilization. The fusing cells are perhaps morphologically vegetative offshoots of an egg-cell. Alternation of generations is present and the sporophyte generation is modified by the development of conjugate nuclear division through its whole cycle, resulting in a failure of the sexual pronuclei to fuse at the time of fertilization. Conjugate division may have arisen here, as it is perhaps beginning in Pyronema, immediately prior to a nuclear fusion in the spore-mother cell, and have worked backward through the sporophyte, thus tending to give more and more of a functional and sexual significance to the fusion in the spore mother cell, until, finally reaching the fertilized egg, the fusion of the pronuclei disappeared.

In the Basidiomyctes by apogamy sexual cell fusion may have disappeared or we may have vegetative fertilization. The sporophyte cells arise as ordinary hyphal cells which become binucleated, and conjugate nuclear division extends through the entire sporophyte generation.

In the Ascomycetes we have sexual reproduction and alternation of generations, modified by the adaptation of the spore mother cell as an explosive organ for the dissemination of the spores and as a storage reservoir for the production of resting spores with a large supply of metaplasmic reserve products. The development of the relatively gigantic size of the ascus led, on the principle of the nucleo-cytoplasmic relation, to the increase of its nuclear content by inhibition of cell division and to the fusion of sporophyte nuclei ; and this in turn necessitated a triple instead of a double division in the reduction of the chromosome number.

Madison, Wisconsin, April, 1905. 


\section{INDEX OF LITERATURE.}

I. ALLEN, C. E. The early stages of the spindle formation in the pollen mother cells of Larix. Ann. Bot., xvir, 281, 1903.

2. - Chromosome-reduction in Lilium canadense. Bot. Gaz., xxxvir, 46́4, 1904.

3. BARKER, B. T. P. Morphology and development of the ascocarp of Monascus. Ann. Bot., xviI, 167, 1903.

4. - The development of the ascocarp in Ryparobius. Report Brit. A. A. S. Southport, p. 849, 1903. (See also Report for 1904.)

5. BAUR, E. Untersuchungen iiber die Entwicklungsgeschichte der Flechtenapothecien. I. Bot. Zeit., 1904, I, 2I-44; 2 pl.

6. BENEDEN, E. VAN. Recherches sur la maturation de l'œuf, la division cellulaire, etc. Leipzig, I883.

7. BENEDEN, E. vaN et NEYT, A. Nouvelles recherches sur la fécondation et la division mitosique chez l'Ascaride mégalocéphale. Leipzig, r887.

8. Blackman, V. H. On the fertilization, alternation of generations, and general cytology of the Uredinex. Ann. Bot., xvirr, 1904.

9. - On the fertilization, alternation of generations, and general cytology of the Uredineæ. New Phytologist, IIr, 23, I904.

10. Boveri, Th. Zellen Stud., II. Die Befruchtung u. Teilung des Eies von Ascaris megalocephala. Jena, r888.

II. - Zur Physiologie der Kern- und Zellteilung. SB. phys.-med. Gesell., Würzburg, Jahrg. I896-I897.

12. - Uber mehrpolige Mitosen als Mittel zur Analyse des Zellkernes. Verh. phys.-med. Gesell., Würzburg, 1902, 24 p.

13. - Ergebnisse über die Konstitution der chromatischen Substanz des Zellkerns. Jena, rgo4.

I4. ChMIELEWSKI, W. F. Matériaux pour servir à la morphologie et physiologie des procès sexuels chez les plantes inférieurs. I890.

15. Christman, A. H. Sexual reproduction in the rusts. Bot. Gaz., xix, p. 207, April, I905.

16. Chaussen, P. Zur Entwicklungsgeschichte der Ascomyceten. Boudiera. Bot. Zeit., Jahrg., I905, s. I.

I7. ConkLIN, E. G. Karyokinesis and cytokinesis in the maturation, fertilization, and cleavage of Crepidula and other Gasteropoda. Jour. of Acad. of Nat. Sciences of Phila., 2d series, XII, p. I-I22, pl. I-vI; I902.

I8. Dale, Miss E. Observations on the Gymnoascaceæ. Ann. Bot., XVII, 57 I, 1903.

I9. DANGEARD, P. A. La reproduction sexuelle chez les Basidiomycètes. Le Botaniste, 4e serie, p. 87. 25 Janvier, 1895.

20. —_ La sexualité dans le genre Monascus. Le Bot., ge. ser., p. 28, 1903.

21. - Recherches sur le développement du périthèce chez les Ascomycètes. Le Bot., ge. ser., p. 59, Ig04.

22. Davis, B. M. The relationships of sexual organs in plants. Bot. Gaz., XXXVIII, 24I-264, 1904.

23. DrÜNER, L. Studien über den Mechanismus der Zellteilung. Jen. Zeitschr. f. Naturw., $\operatorname{xxIx}$ (N. F. 22), p. 27I-344, 1905. Dated I904.

24. Farlow, W. G., and SEYmour, A. B. Provisional host index of the fungi of the United States. I888-1891.

25. Flemming, W. Neue Beiträge zur Kenntniss der Zelle., II. Arch. f. Mikr. Anat., xxxVII, 685, I89I.

26. Gerassimorf, J. J. Über den Einfluss des Kerns auf das Wachstum der Zelle. Bull. Soc. Nat. Imp. Mosc. I901, Nr. I-2, p. 185-220.

27. — Die Abhängigkeit der Grösse der Zelle von der Menge der Kernmasse. Zeitschr. f. allg. Physiol. I, p. 220-258. 1902. 
28. Zur Physiologie der Zelle. Bull. Soc. Imp. Nat. Mosc. No. I, p. I34, I904.

29. Über die Grösse des Zellkerns. Beih. zum Bot. Centr., Xviri, 43, I904.
30. GrEGoIrE, V. La reduction numerique des chromosomes et les cineses de maturation. La Cellule, xxi, p. 297, 1904.

3I. Guilliermond, A. Contribution à l'étude cytologique des Ascomycètes. C. R. de l'Acad. des Sci., vol. 137, p. 938-939 and 1088; 1903.

32. - Nouvelles recherches stur l'épiplasme des Ascomycetes. C. R. de l'Acad. des Sci., vol. I36, p. I487-1489; 1903.

33. — Sur la Karyokinèse de Pezize rutilans. C. R. de la Soc. de Biol., LVI, 4I2, I904.

34. - Contribution ä l'étude de l'épiplasme des Ascomycètes et recherches sur les corpuscles métachromatiques des Champignons. Annales $\mathrm{My}-$ cologici, I, p. 20I-2I5, pl. vI-vII ; I903.

35. HARPLi, R. A. Beiträge zur Kenntniss der Kernteilung und Sporenbildung im Ascus. Ber. d. Deutsch. Bot. Gesell., XIII, 67, I89s.

36. — Die Entwicklung des Peritheciums bei Sphaerotheca castagnei. Ber. d. Deutsch. Bot. Gesell., XIII, 475, I895.

37. - Uber das Verhalten der Kerne bei der Fruchtentwicklung einiger Ascomyceten. JB. f. wiss. Bot., XxIx, 656, I89ó.

38. - Kernteilung u. freie Zellbildung im Ascus. JB. f. wiss Bot., xxx, 249, 1897.

39. - Nuclear phenomena in certain stages in the development of the smuts. Trans. Wis. Acad. Sci., XIr, 475, I899.

40. - Sexual reproduction in Pyronema confluens and the morphology of the ascocarp. Ann. Bot., XIv, p. 32I-400; pl. I9-2I ; I900.

40a. - Binucleated cells in certain Hymenomycetes. Bot. Gaz., xxxIII, I, IgO2.

4I. HeIdENhAIN, M. Neue Untersuchungen über die Centralkörper. Arch. f. mikr. Anat., XLIII, 423, I894.

42. HENKING, H. Utber Spermatogenese u. deren Beziehung zur Entwicklung bei Pyrrhocoris apterus L. Zeitschr. f. wiss. Zool., LI, p. 685-74I; pl. 35-37; I89I.

43. Hermann, F. Beitrag zur Lehre von der Entstehung der karyokinetischen Spindel. Arch. f. mikr. Anat., xxxvir, 569, I89I.

44. HerTwig, R. Was veranlasst die Befruchtung bei Protozoen. SB. Gesell. Morph. u. Phys., München; x I, p. 62-69; 1899.

45. - Ueber Korrelation von Zell- und Kerngrösse und ihre Bedeutung für die geschlechtliche Differenzierung der Zelle. Biol. Cent., xxIII, 49-62, I903.

46. Hor,DEN, R. J., and HARPER, R. A. Nuclear division and nuclear fusion in Coleosporium sonchi-arvensis Lev. Trans. Wis. Acad. Sci., XIV, 63 , I903.

47. IKENo, S. Die Sporenbildung von Taphrina-Arten. Flora oder Allg. Bot. Zeit., XCII, p. I-3I ; pl. I-3; I903.

48. - Uber die Sporenbildung und systematische Stellung von Monascus purpureus Went. Ber. d. Deutsch. Bot. Gesell., xxI, 259, I903.

49. Janssens. F. A. La Spermatogénèse chez les Tritons. Ia Cellule. xIx, fasc. I, pp. 5-II6, I902.

50. JENKINSON, J. W. Observations on the maturation and fertilization of the egg of the Axolotl. Quart. Jour. Mic. Sci., XLviI, 428, I904.

5I. JUEL, H. O. Taphridium Lagerh. und Juel. Eine neue Gattung der Protomycetaceen. Bihang till $\mathrm{K}$. Svenska Vet. Akad. Handlinger, xxvir, I, I902.

52. — Uber Zellinhalt, Befruchtung und Sporenbildung bei Dipodascus. Flora. Ergänzungsbd. p. 47; 1902.

53. KosTANECKI, K. V., and WIERZYSKY, A. Über das Verhalten der sogen. achromatischen Substanzen im befruchteten Ei nach Beobachtungen an Physa fontinalis. Arch. f. mikr. Anat., XLVII, 309, I8g6.

54. Kostanecki, K. V. Über die Bedeutung der Polstrahlen während der Mitose. Arch. f. mikr. anat., XLIX, p. 65I-706; pl. 19-20; I897 
55. KuYPER, H. P. Die Perithecium Entwickelung von Monascus purpureus Went und Monascus Barkeri Dang. und die systematische Stellung dieser Pilze. Ext. du Recueil des Travaux botanique Néerlandais, I904, 2-4.

56. — De perithecium-ontwikkeling van Monascus purpureus Went en Mon. Barkeri Dang. Kon. Akad. von Weten., Amsterdam, xin, 46, May 28, 1904.

57. Lindau. Nat. Wochenschr., Nr. 27, April 3, I904, p. 425.

58. Luвоscr. Utber die Eireifung d. Metazoen. Ergeb. der Anat. und Entwick., Merkel u. Bonnet, II, 709, I90I.

59. MAIRE, R. Reoherches cytologiques sur le Galactinia succosa. C. R. de '1'Acad des Sci. Paris, vol. 137 p. 769-771; 1903.

60. La formation des asques chez les Pézizes et l'évolution nucléaire des Ascomycètes. C. R. de 1. Soc. de Biologie, LV, p. I40I, Nov., 1903.

6r. _- Sur les divisiones nuclèaires dans 1'Asque de là Morille et de quelques autres Ascomycètes. C. R. de 1. Soc. d. Biologie, LVI, p. 822, I904.

62. Recherches cytologiques et taxonomiques sur les Basidiomycètes. Lons-le-Saunier, 1902.

63. MEVEs, F. Uber die Entwicklung der männlichen Geschlechtszellen von Salamandra maculosa. Arch. f. mikr. Anat., xLVIII, r, 1897.

64. MöLLER, A. Phycomyceten u. Ascomyceten. Jena, Igor.

65. MonTgOMERY, T. H. The spermatogenesis in Pentatoma up to the formation of the spermatid. Zool., JB., xir, Abt. f. Anat., p. I-88; pl. I-5; I898.

66. A study of the chromosomes of the germ cells of Metazoa. Trans. Am. Phîl. Soc.., xx, p. I54-23ó; pl. 4-8; rgor.

67. Motriter, D. M. Nuclear and cell division in Dictyota dichotoma. Ann. Bot., XIV, IO3, 1900 .

68. Neger, F. W. Beiträge zur Biologie der Erysipheen. Flora, LxxxviIr, 333, 1901 ; and Xc, 22I, 1902.

69. - Neue Beobachtungen über das spontane Freiwerden der Erysipheenfruchtkörper. Centr. f. Bakt. Parasit. u. Infekt., 1903; 2. Abt. x, $570-573$.

70. NEMEC, B. Ueber die Einwirkung des Chloralhydrates auf die Kern- und Zellteilung. JB. für wiss. Bot., Xxxıx, 645, I904.

71. Nichols, S. P. The nature and origin of the binucleated cells in certain Basidiomycetes. Trans. Wis. Acad. Sci., xv, 1905.

72. Olive, E. W. The morphology of Monascus purpureus. Bot. Gaz., xxxix, 56,1905 .

73. OVERTON, E. Über die osmotischen Eigenschaften der Zelle in ihrer Bedeutung für die Toxikologie und Pharmakologie. Festschr. Nat. Gesell. Zurich, I896.

74. - Uber die allgemeinen osmotischen Eigenschaften der Zelle, ihre vermutlichen Ursache u. ihre Bedeutung für die Physiologie. Vierteljahrschr. Nat. Gesell. Zurich, Jahrg., XLIV, 88, I899.

75. Paulmier, F. C. The spermatogenesis of Anasa tristis. Journ. Morph., xv, I899, p. 223-269; p1. 13-I4.

76. Palta, E. Utber die Gattung Phyllactinia. Ber. d. Deutsch. Bot. Gesell., XVII, 64-72, 1899.

77. Poirault, G. and Raciborski, M. Sur les noyaux des Uredinées. Extr.

78. RABL, C. Uber Zellteilung. Morphologisches Jahrbuch, x, 1885.

79. $\longrightarrow$ Uber Zellteilung Anat. Anz., Iv, 21, 1889.

80. Richards, H. M. On some points in the development of the Aecidia. Proc. Am. Acad. Arts and Sci., xxxi, 255, 1896.

81. RosenBERG, O. Ueber die Individualität der Chromosomen im Pflanzenreich. Flora oder Allg. Bot. Zeitung, XciII, 251, 1904.

8ra. _ Zur Kenntniss der Reduktions-Teilung in Pflanzen. Bot. Not., 1905, p. 1-24.

82. Salmon, E. S. A monograph of the Erysiphacex. Mem. Torr. Bot. Club, IX, 1900.

83. — Supplementary notes on the Erysiphex. Bull. Torrey Bot. Club, XXIX, I8I. 
84. SAPpin-TroufFy. Recherches histologiques sur la famille des Uredinées. Le Bot., 5e ser., 1896, pp. 59-244.

85. Schaper, A. Beiträge zur Analyse des tierischen Wachstums I. Theil. Arch. f. Entwick.-Mech., Bd., XIv, pp. 307-400, pl. 15-25; 1902.

86. Smith, Grant. The Haustoria of the Erysipheæ. Bot. Gaz., xxix, 153, 1900.

87. STrasburger, E. Zellbildung u. Zellteilung, 3 Auf., pp. 26-27. Jena, I880.

88. - Uber Kern- und Zelltheilung im Pflanzenreich. Hist. Beitr., r, Jena, I888.

89. — U Uber die Wirkungssphäre der Kerne u. die Zellgrösse. Hist. Beitr. v, pp. 95-I24; Jena, 1893.

90. — Uber Reduktionsteilung, Spindelbildung, Centrosomen und Cilienbildner im Pflanzenreich. Hist. Beitr., vi, Jena, I900.

91. - Ueber Reduktionstheilung. SB. d. Kön. Preuss. Acad. d. Wiss., I904, I. Halbbd, pp. 587-6r4.

92. Surron, M. S. On the morphology of the chromosome group in Brachystola magna. Biol. Bull., IV, pp. 24-39; 1902 .

92a. Swingle, W. T. Zur Kenntniss der Kern- und Zellteilung bei den Sphacelariaceen. JB. f. wiss. Bot., xxx, 297, I897.

93. THAXTER, R. Contributions toward a monograph of the Laboulbeniacex. Mem. Am. Acad. Arts and Sci., XII, I87.

94. TifGhem, Ph. van. L'œuf des plantes consideré comme base de leur classification. Ann. de Sci. Nat. Bot., 8. sér., xIv, pp. 213-390; r901.

95. Trow, A. H. On fertilization in the Saprolegnieæ. Ann. Bot., xvin, $54 \mathrm{I}, 1904$.

96. VRIES, H. de. Befruchtung u. Bastardierung. Liepzig, 1903.

97. WAGER, H. The sexuality of the Fungi. Ann. Bot., XIII, pp. 29-55, 1899.

98. Williams, J. L. Studies in the Dictyotaceæ. Ann. Bot., Xvir, I4I, I904.

99. WoLFE, J. J. Cytological studies on Nemalion. Ann. Bot., xvin, 607, I904.

I00. Woycicki, Z. Einige neue Beiträge zur Entwicklungsgeschichte von Basidiobolus ranarum. Flora, xcIII, 87, 1904. 
[All figures were drawn with the Abbe camera lucida and, with the exception of fig. 30, with the Zeiss apochromatic objective, $2 \mathrm{~mm}$. n. ap. I.40; figs. I, 3-I I, 25, $44-47,55-6 \mathrm{I}, 65-78$ with compens. oc. 8 ; figs. 2 , 12-20, $22,5 \mathrm{I}$ with oc. o; figs. $21,26-29$ with oc. 4 ; figs. $23,24,50,52-54,59,62-64,79$ with oc. I2; figs. $31-42,48,49$ with oc. I8; fig. 30 obj. $8 \mathrm{~mm}$. oc. 8 .]

\section{Plate I.-Phyllactinia corylea.}

FIG. I.-Male and female branches; the gametes not yet cut off by septa.

FIG. 2.-Same, showing hyphal cell, from which the oogonium arises, most of the oogonial branch cut away.

Fig. 3.-The oogonial branch coiled around the antheridial branch; the latter septate at the level at which it is constricted by the oogonial branch.

FIG. 4.-The nucleus of the male branch has divided to form the antheridial and stalk-cell nuclei.

FIG. 5.-The antheridium has been cut off from the stalk-cell and lies above and to one side of the apex of the oogonium.

FIG. 6.-Slightly older than stage of fig. 5. Antheridium and stalk partly behind the oogonium.

FIG. 7.-Antheridium and oogonium just before conjugation, the former behind the apex of the latter.

FIG. 8.-Stage of conjugation. The section lies in the plane of contact of the antheridium and the apex of the oogonium. The conjugation-pore is present and appears as a circular opening through the walls of the gametes. The male nucleus is in contact with the larger egg nucleus.

Fig. 9.-Stage of conjugation a little later than fig. 8 . The section cuts the plane of contact of the gametes at right angles. The conjugation-pore is open, and through it the protoplasts of the gametes form a continuous mass of cytoplasm; a large vacuole in the antheridium just outside the conjugation-pore. The pronuclei are in contact; the male nucleus larger than in fig. 8 , but still smaller than the egg-nucleus.

FIG. Io.-Oogonium with single large fusion nucleus. Cytoplasm of antheridium still spongy but containing some granules.

FIG. II.-Oogonium still uninucleated. Wall of antheridium beginning to swell.

FrG. I2.-Oogonium still uninucleated. Wall of antheridium swollen and showing strong affinity for orange stain. Early stage of perithecial walls.

Fig. 13--Egg-nucleus has divided.

Fig. I4.-Ascogonium binucleated. Stalk-cell of antheridium has grown out into a hyphal branch, which curves over the antheridium and is a part of the perithecial wall.

FIG. I5 $a, b .-$ Two sections of the young ascocarp. Antheridium with thick wall and dense content.

FIG. I6.-Slightly older; perithecial wall becoming two-layered.

FIG. I7 $a, b$.- Young ascocarp in two sections; uninucleated cell cut off from the end of multinucleated ascogonium; perithecial hypha is shown arising from stalk of antheridium.

Fig. I $8 a, b$.-Somewhat older; end cell of ascogonium separated from the antheridium by crowding in of the perithecial hyphæ.

FIG. I9.-Ascogonium with three cells, the next to the last binucleated, the others uninucleated. The whole ascocarp is perhaps dwarfed in this case. 
HARPER.

PLATE I
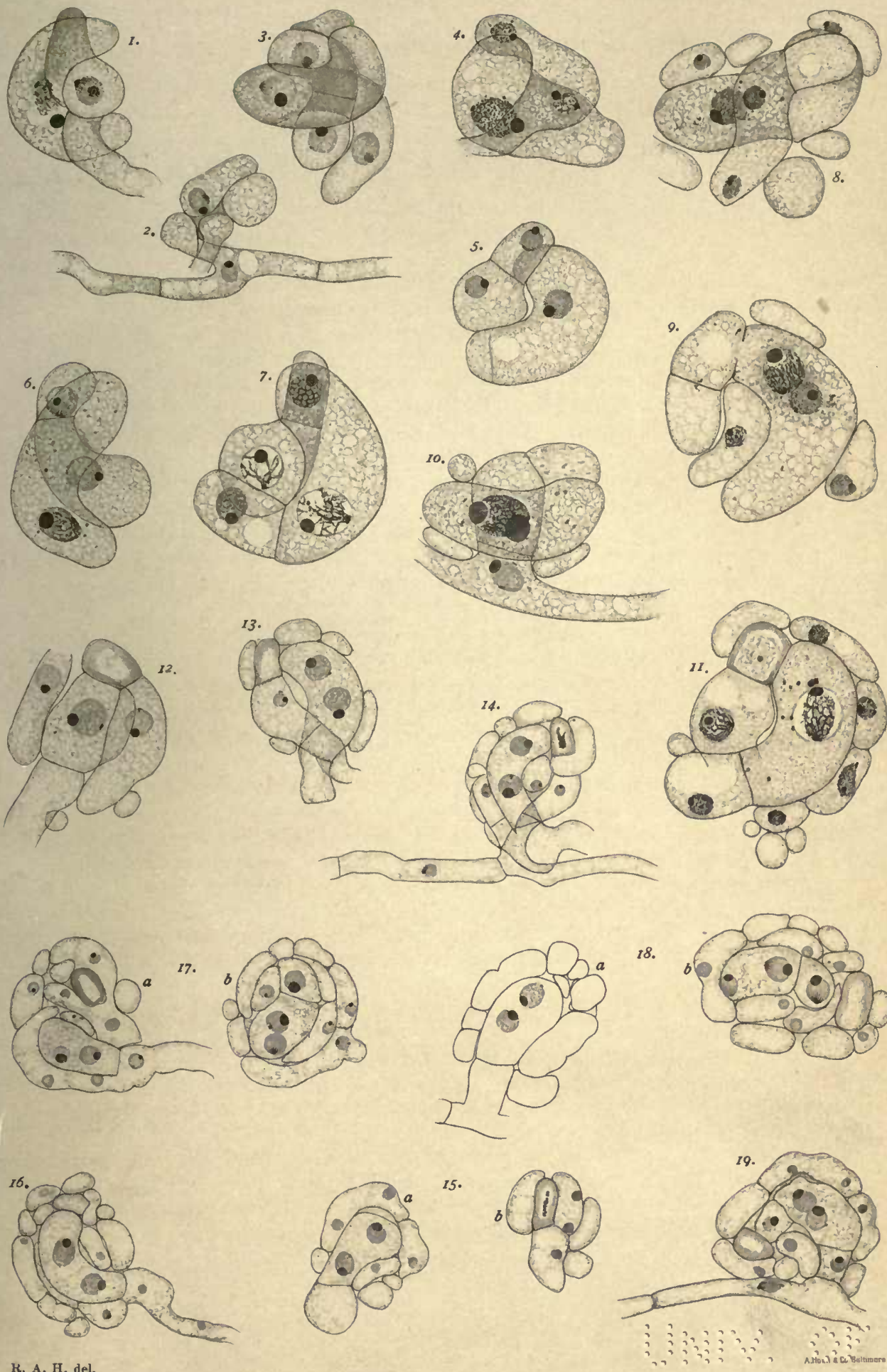

k. A. H. del. 




\section{Plate II.-PhyLLACTINIA CORYLEA.}

FIG $20 a, b$.-Ascogonium with four cells; the apical cell uninucleated and narrowed above by pressure of surrounding hyphæ. Penultimate cell binucleated, nucleus of basal cell in next section.

FIG. 2I $a, b$.-Ascogonium four-celled; basal cell with two nuclei.

FIG. 22.-Ascogonium with five cells; penultimate cell budding out in ascogenous hyphæ; nuclei of second and third cells in another section.

FIG. 23.-Perithecial cells with resting nuclei and a metaphase stage of nuclear division; nucleolus near one pole of spindle.

FIG. 24.-Resting nucleus from mycelial hypha with central body connected with chromatin.

FIG. $25 a, b$.-Ascogonium with five cells; penultimate cell budding out in ascogenous hyphæ; apical cell still connected to thick-walled antheridium.

FIG. 26.-Median section of older ascocarp, showing sections of ascogenous hyphæ, antheridium, etc.; peripheral cells swollen, in some cases in preparation for pushing out as hyphal branches.

FIG. 27.-Median section of still older ascocarp, showing portion of ascogonium and sections of multinucleated ascogenous hyphæ.

FIG. 28.-Section showing cells of ascogonium and ascogenous hyphæ at stage when latter become septate.

FIG. $29 a, b$.- Sections showing the pushing out of the cells of the ascogenous hyphæ to form the young asci.

FIG. 30.-Median section of ascocarp just after fusion of nuclei in the young asci; two or more layers of cells around the asci, with dense content and thin walls; peripheral cells on upper surface of ascocarp swelling out to form penicillate cells. 
HARPER.
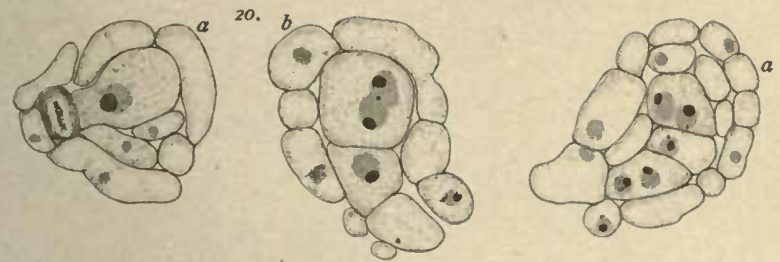

$2 x$.
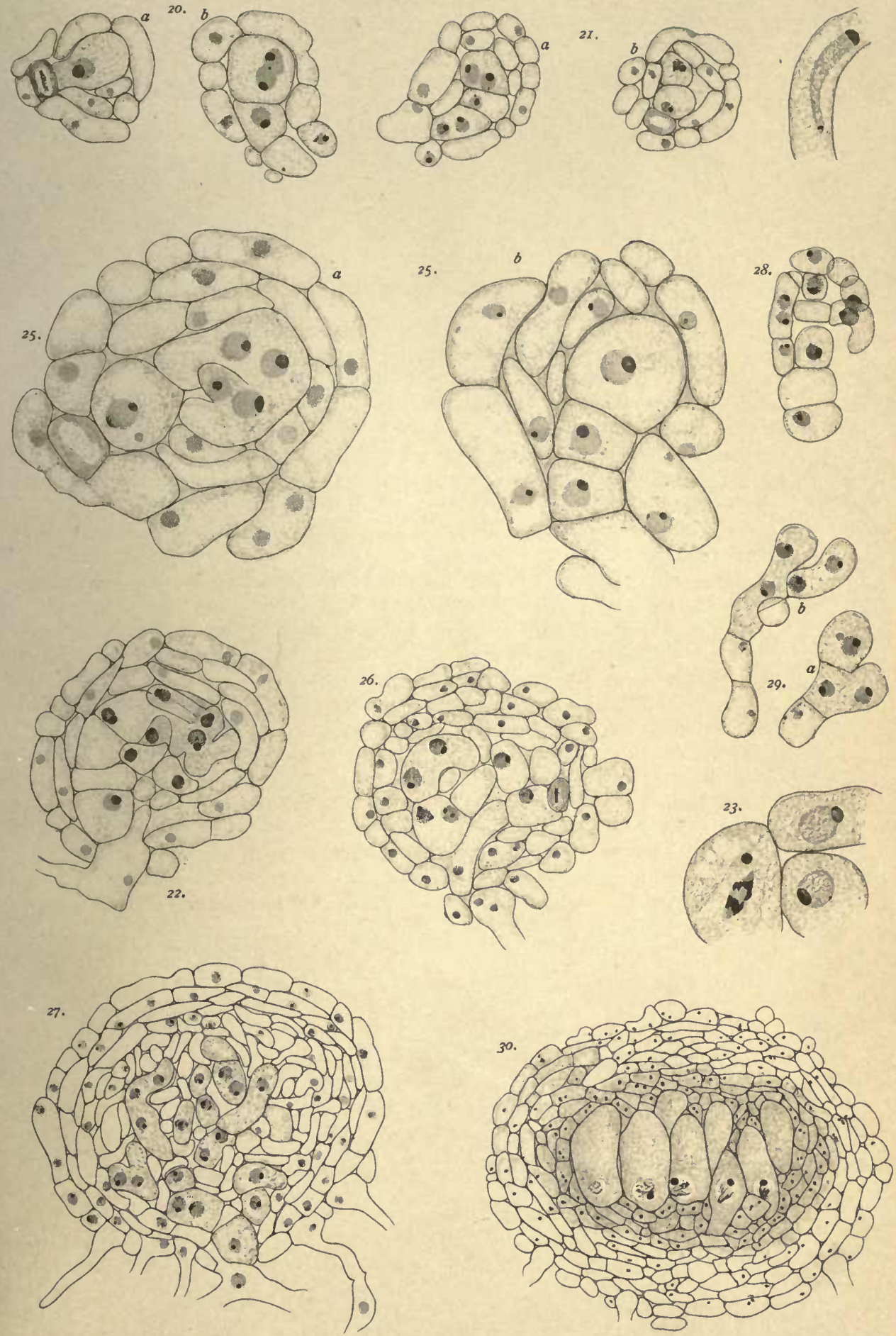

R. A. H. del. 




\section{Plate III.-Phyliactinia CORYLEA.}

FIg. 31.-Young ascus with two nuclei; central bodies facing each other.

FIG. 32.-Slightly older ascus; chromatin strands more conspicuous.

FIG. 33- -Just before nuclear fusion in ascus. Lower nucleus lies above and partially overlapping the other.

FIG. 34.-Section of ascus with slice of one nucleus showing three chromatin strands and sections of others.

Fic. 35.-Early stage in fusion of nuclei; central body of upper nucleus has pushed ahead on the membrane of the lower nucleus, its chromatin system drawn out in long cone.

FIG. 36. - Stage of fusion. Central bodies and chromatin of two nuclei side by side, but independent; nucleoli already combined in one.

FIc. 37.-Chromatin systems overlapping, but distinct. Nucleoli in contact.

FIc. 38. - Stage just before the central bodies combine; nucleoli in this case still separate.

Fig. 39. - The central bodies are joined side by side. Chromatin systems combining.

FIG. 40.-Central bodies and chromatin systems completely combined. Nucleoli still separate.

FIG. 4I.-Shows entire ascus; stage about the same as in fig. 40.

FIG. 42.-Fusion of nuclei complete. 

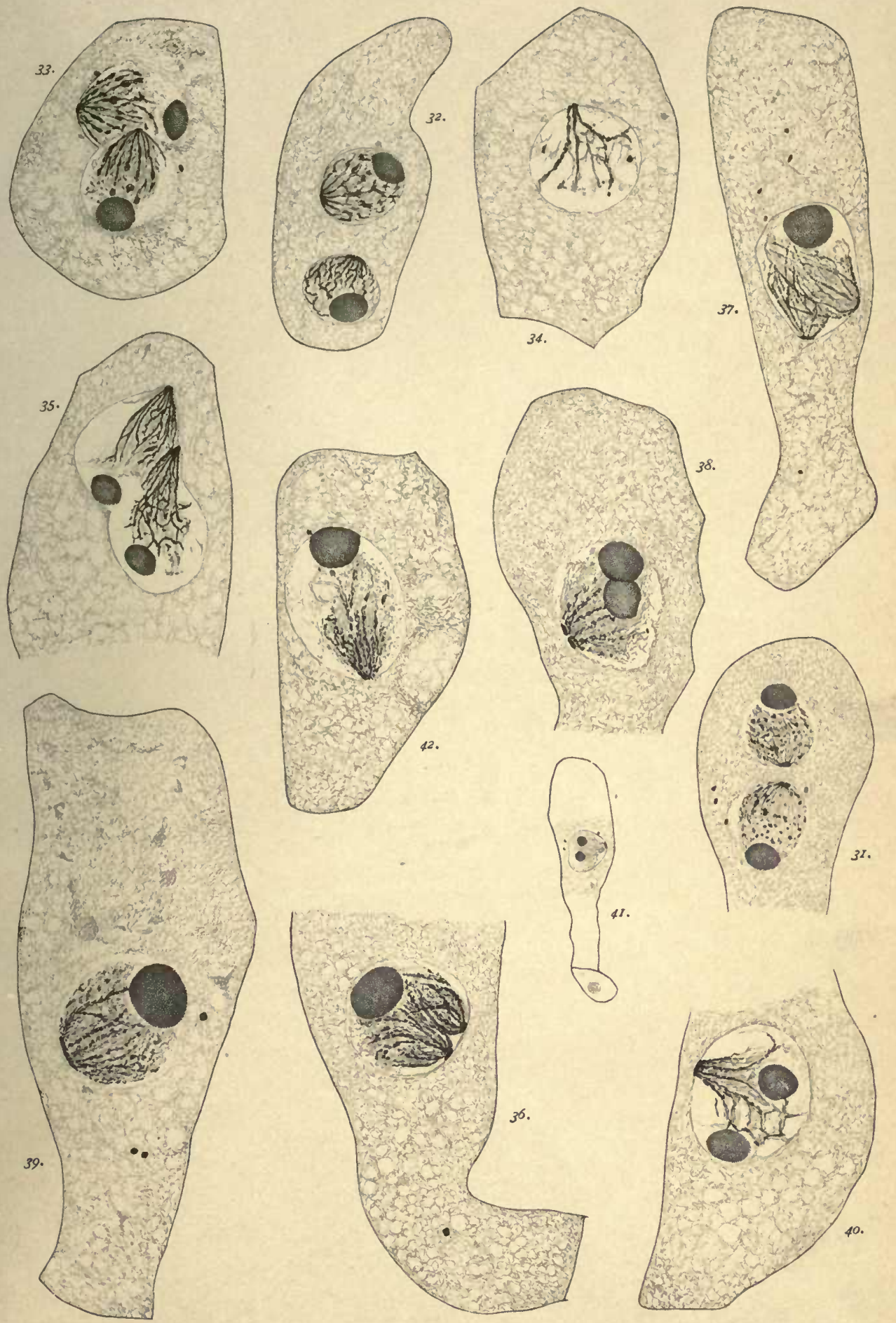




\section{Plate IV.-Phyllactinia corylea.}

Fig. 43.-Early stage in synapsis.

FIG. 44.- Synapsis; ends of chromatin strands protruding from contracted mass.

FIG. 45.-Late synapsis stage stained to specially differentiate the central body.

FIG. 46.-Loosening up of chromatin after synapsis.

Frg. 47.-Early spirem stage.

FIG. 48.-Culmination of spirem stage; eight distinct chromatin strands corresponding to eight chromosomes of later stages.

FIG. 49.-Same stage; strands spreading from center without forming cone.

FIG. 50.-Young penicillate cell. Three nuclei showing central bodies.

FIG. 51.-Full-grown penicillate cell.

FIG. 52.-Transverse section of ascus, showing prophase in formation of spindle.

FIG. 53.-Primary nucleus of ascus; equatorial-plate stage, eight chromosomes. 

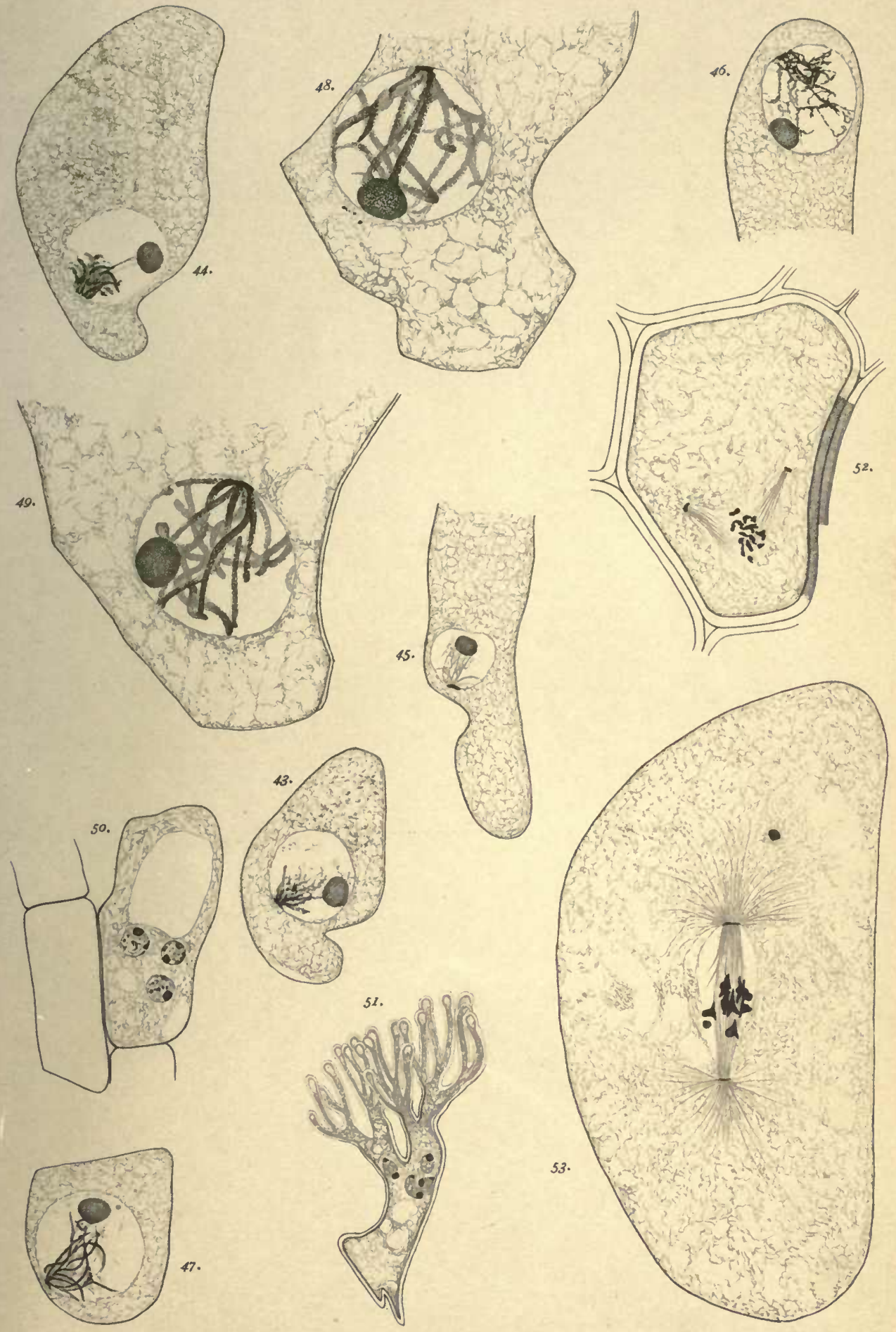

R. A. H. del. 



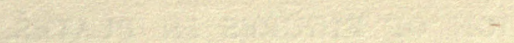

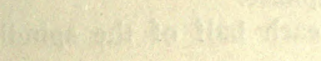

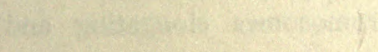

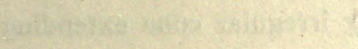


Plate V.-Phyli,actinia CORYLEA.

Fig. 54.-Primary nucleus of ascus, early metaphase.

FIG. 55.-Anaphase, eight chromosomes on each half of the spindle. Polar aster strongly developed.

Fic. 56.-Late anaphase.

FIG. 57.-Diaster; chromosomes still attached to pole by spindle fibers.

FIG. 58.-Reconstruction of daughter nuclei; chromosomes elongating and becoming irregular strands of chromatin.

FIG. 59.-Later stage; strands of chromatin forming irregular cone extending from central body into antipolar region of nucleus. 

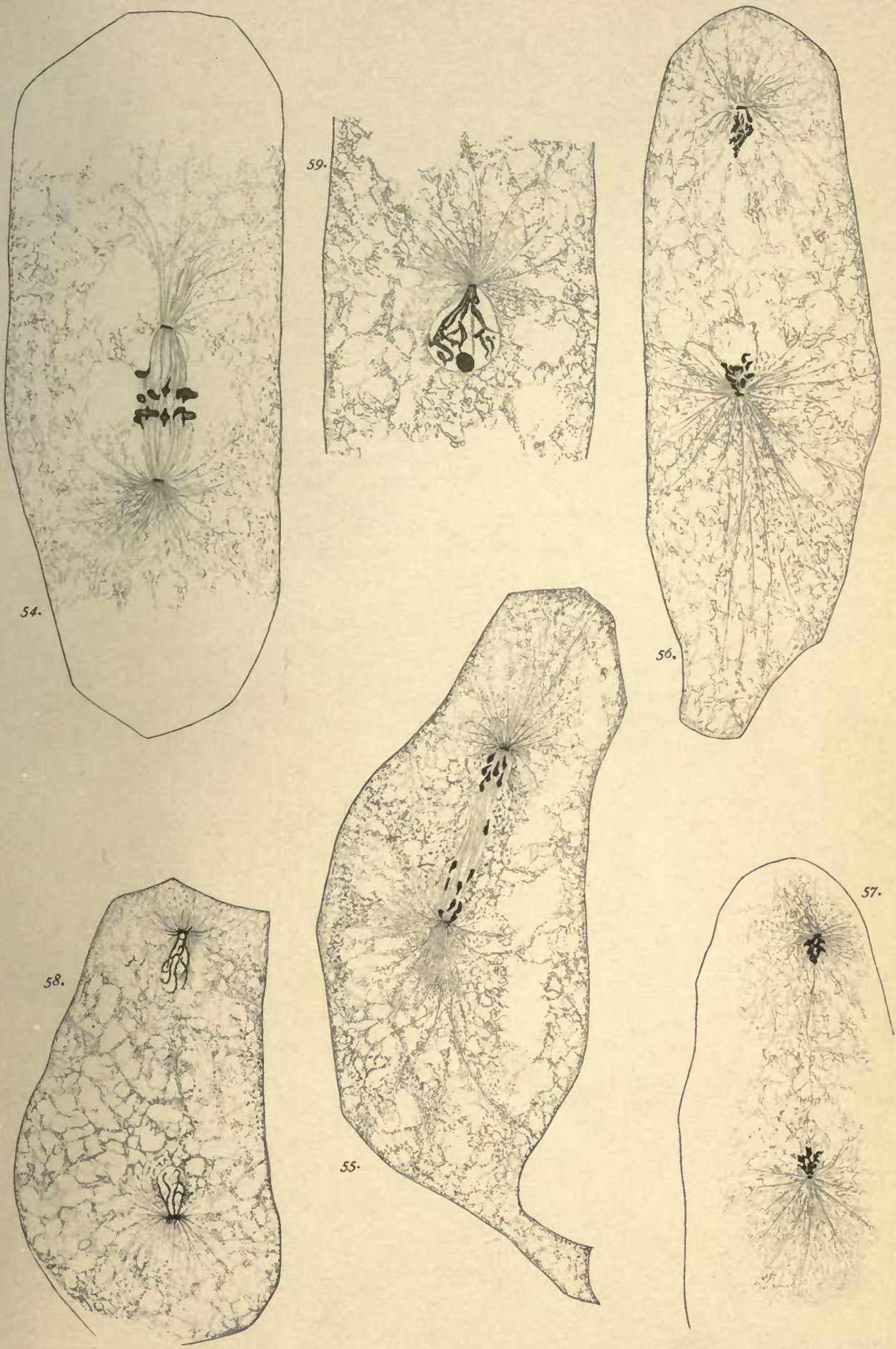

R. A. H. del. 


Plate VI.-Phyliactinia corylea.

FIG. 60.-Chromatin strands more irregular and passing over into apparent reticulum by formation of anastomoses.

FIG. 6I.-Still later, chromatin still more irregular and practically in the resting condition.

FIG. 62.-Transverse section of ascus; nucleus in spirem of second division.

FIG. $63 a, b$. - Later prophase of second division; chromosomes appearing in two sections.

Fig. 64.-Still later prophase, second division.

FIG. 65.-Equatorial-plate stage; second division; one spindle lying in plane of section, the other cut through obliquely; eight chromosomes.

Fig. 66.-Late anaphase stages, second division; eight chromosomes on each half of each spindle.

FIG. 67 a.-Equatorial-plate stages, third division; nuclei in end of ascus; one polar and one side view of the spindle figures.

FIG. $67 b$.-Larger nuclear figure from same ascus, which will form functional nuclei; nuclear membrane still intact.

FIG. 68.-Anaphase stages of third division; eight chromosomes on each spindlehalf. 

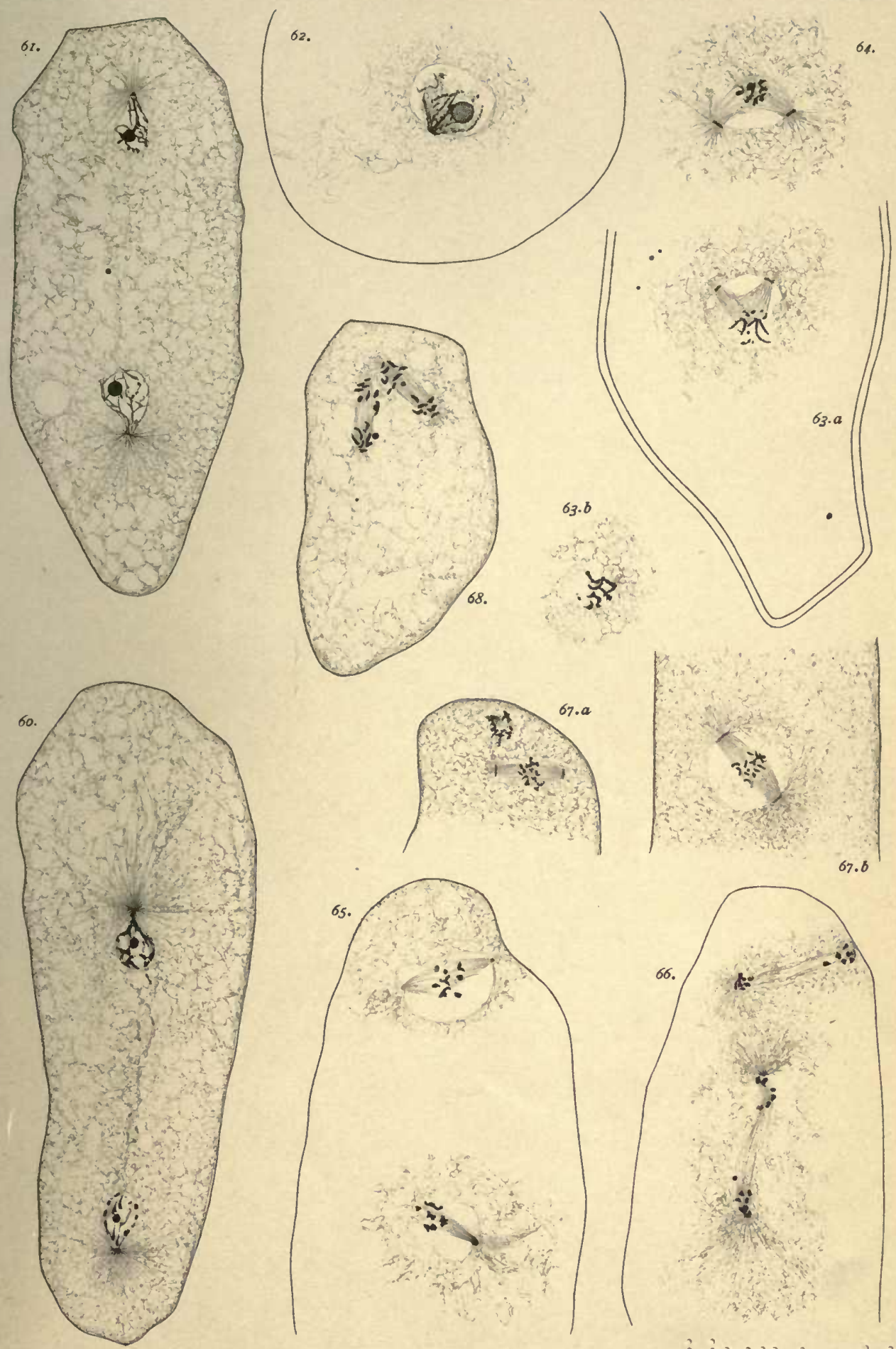

R. A. H. del 


Plate VII.-PhyLLACTINIA CORYLEA, EXCEPT WHERE OTHERWISE INDICATED.

FIG. 69.-Erysiphe cichoracearum. Dispirem stages; third division; polar asters strongly developed.

FIG. 70.-Beaked nucleus and aster in early stage of spore formation; two supernumerary nuclei at opposite end of ascus and lying with their central bodies on the plasma-membrane of the ascus.

FIg. 7I.-Beaked nucleus and aster, opposite which the plasma-membrane is drawn in forming an oval depression.

FIg. 72.-Beaked nucleus with aster strongly developed; central body broader than end of beak.

FIG. 73.-Erysiphe cichoracearum. Metamorphosis of the polar aster to form the plasma-membrane of the spore; early stage in folding over of the rays; two supernumerary nuclei present; transverse section of part of membrane of third spore shown in lower part of figure.

FIG. 74.-E. cichoracearum; the rays have formed broad, bell-shaped membranes about the nuclei; beak of nucleus lying to the right is cut off and appears in the next section.

FIG. 75.-E. cichoracearum; plasma-membrane of spore almost complete.

Frg. 76.-Spore completely inclosed; beak of nucleus still attached to plasmamembrane; astral rays have disappeared entirely.

FIg. 77.-Stage in drawing in of nuclear beak; central body conspicuous at the tip of beak.

Fig. 78.-Later stage, same process.

Fig. 79.-Ascus with two spores; nucleus in resting condition; chromatin conspicuously oriented on central body.

FIg. 80.-E. communis; late stage in spore formation; central body and system of astral rays divided; beak scarcely visible.

FIg. 8I.-E. communis; ascus with view of stage in spore formation looking somewhat obliquely down upon the end of the spore; two supernumerary nuclei in opposite end of ascus. 

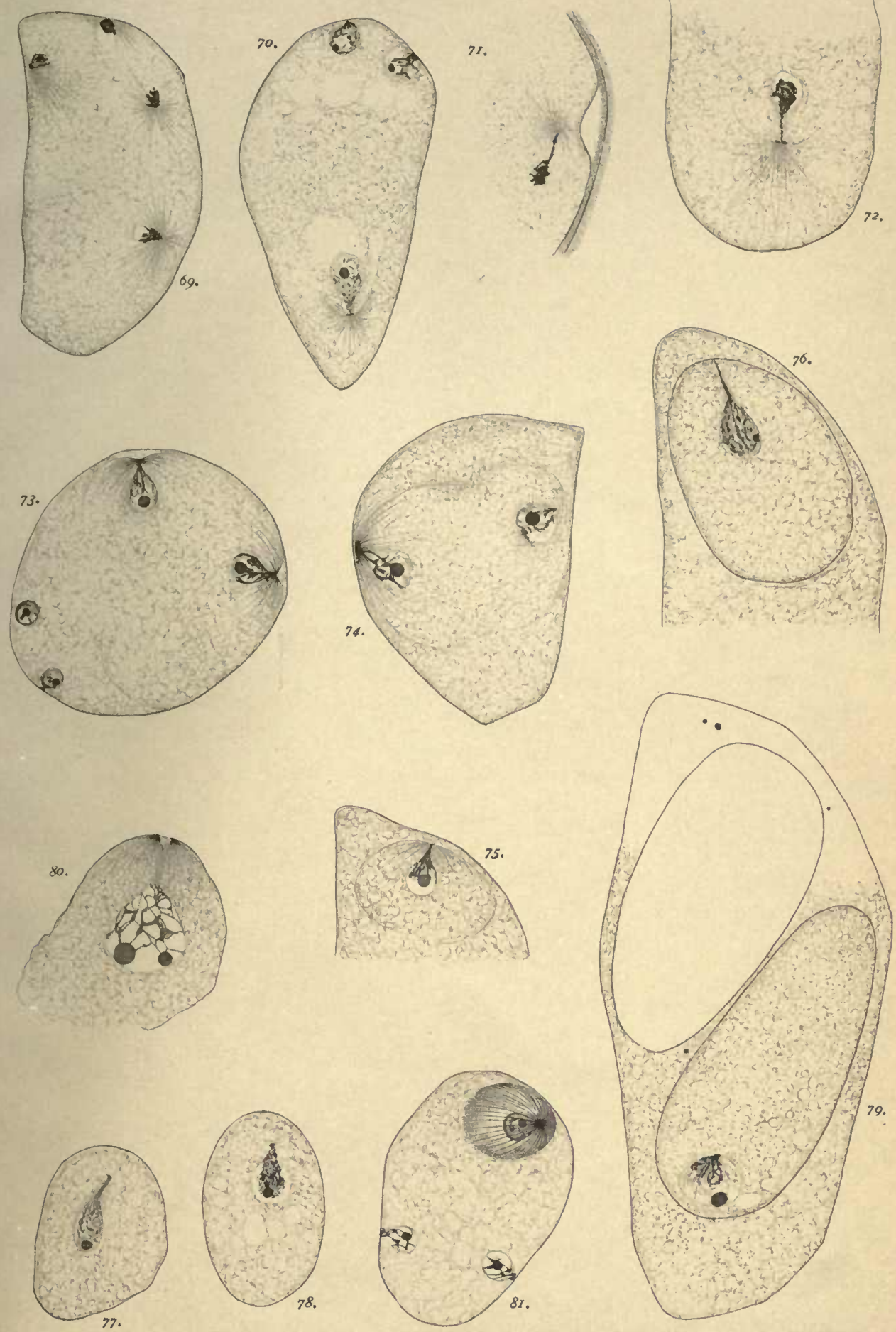

R. A. H. del, 





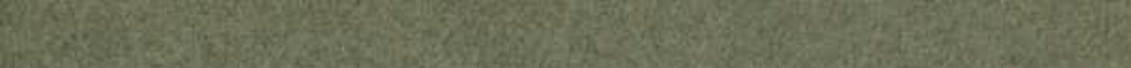

(1)

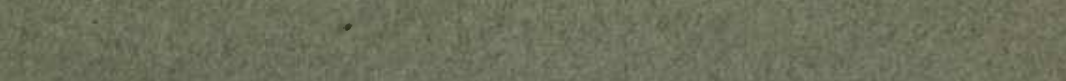

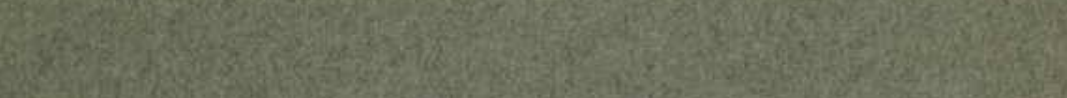
(1)

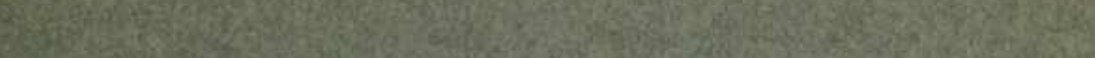

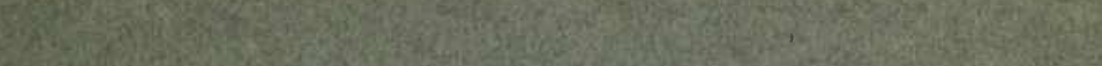

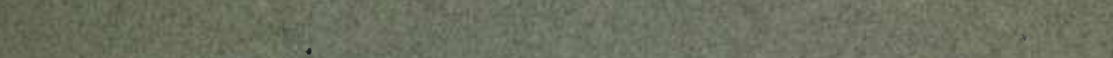

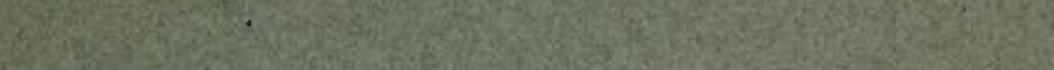
Wh

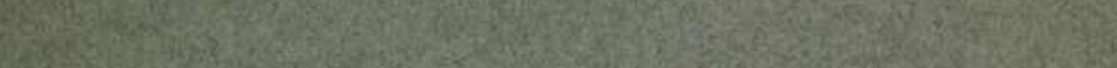
A.

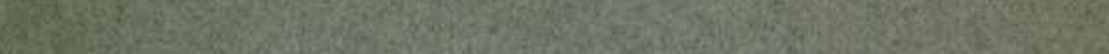
How H.

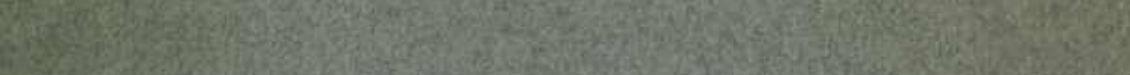
2.

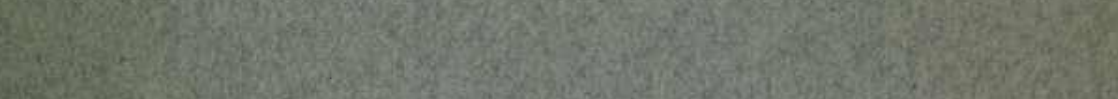
Phe

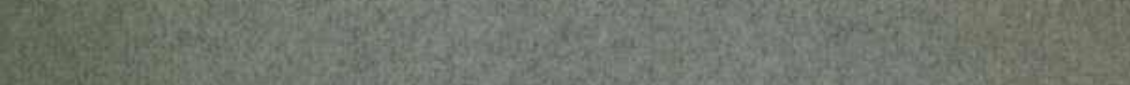

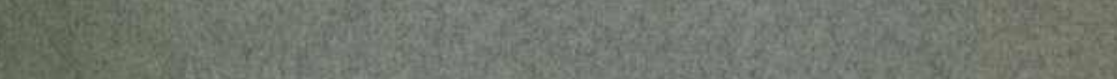

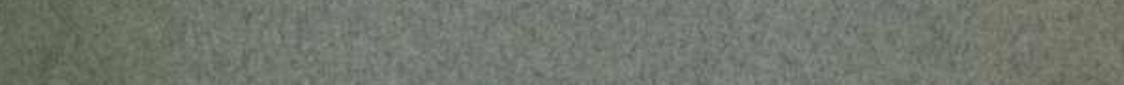

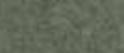
15. 13. Sis.

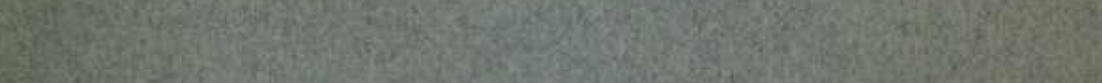

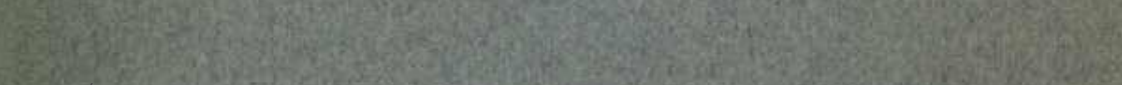

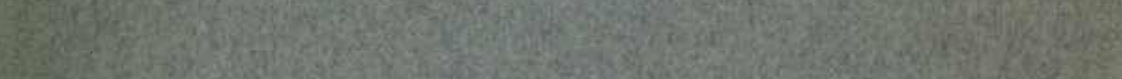
19.

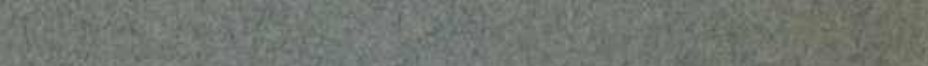

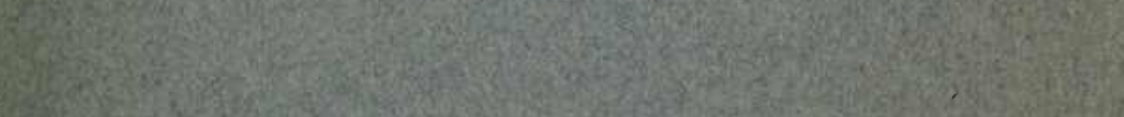

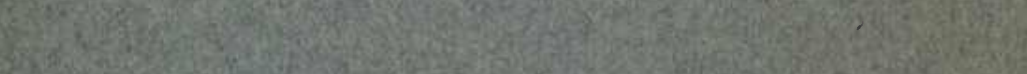

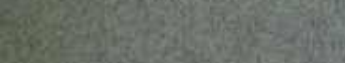

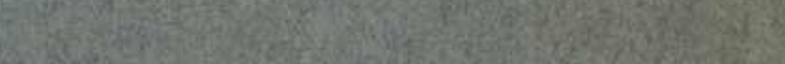
2. S. w.

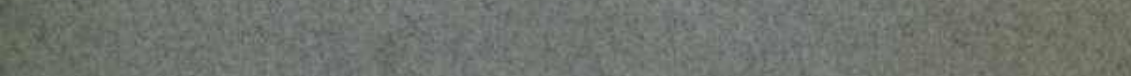

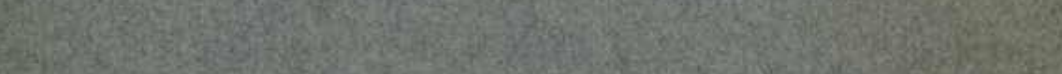

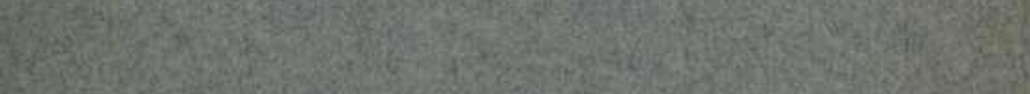
Wha E. 




U.C. BERKELEY LIBRARIES

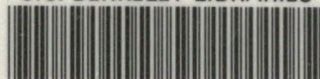

CO26301926

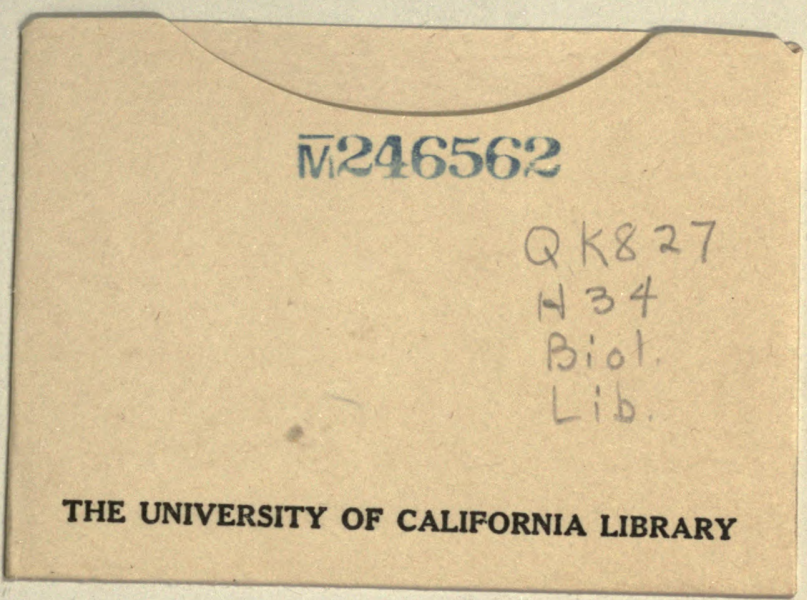


